\title{
اتجاهات الصفوة الاكاديمية نحو البراهج الحوارية في الفضائيات المصرية ودورها في الاستقطاب السياسي للمستبعدين اجتماعياً
}

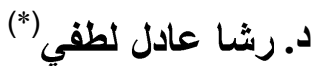

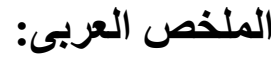

تتحدد مشكلة الدراسة في "محاولة التعرف علي اتجاهات الصفوة الأكاديمية

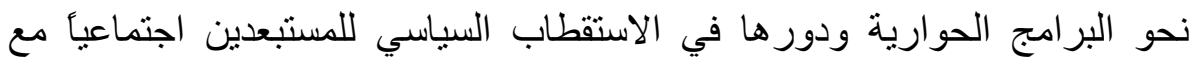

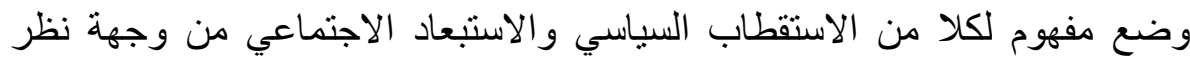
الصفوة الأكاديمية"، في ضوء نظرية تأثثر الثخص الثالث، حيث تعد من الدراسات

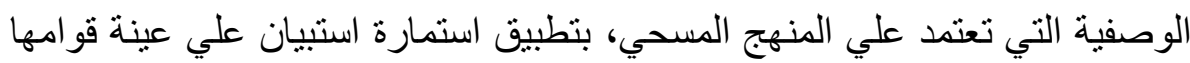

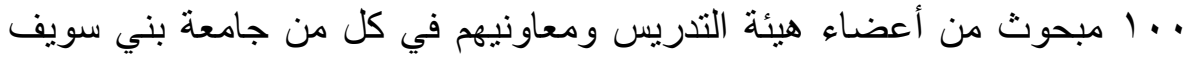

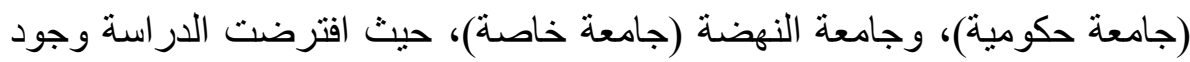

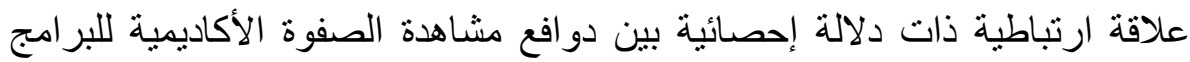

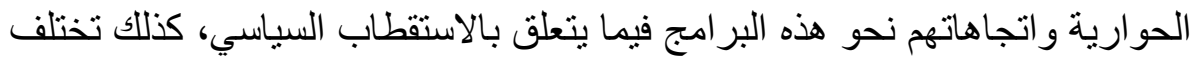

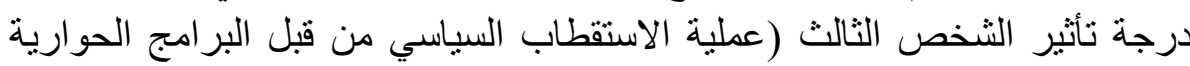

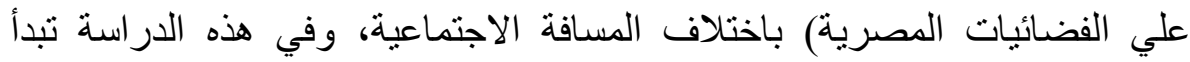

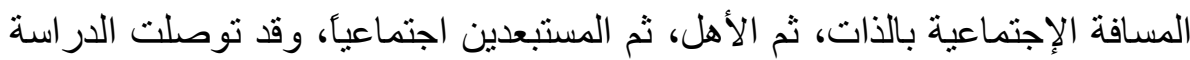

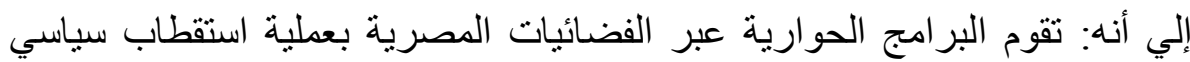

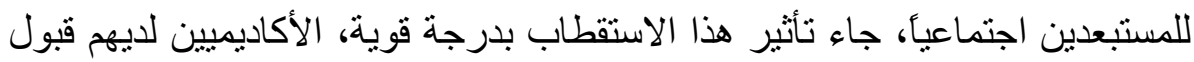

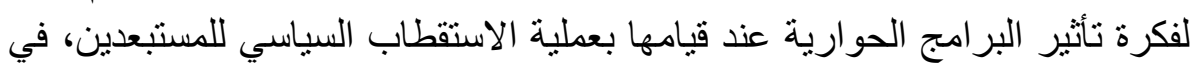

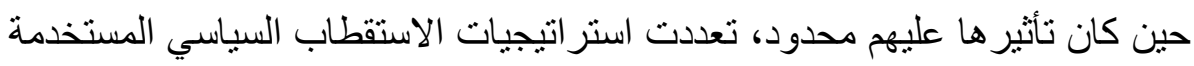

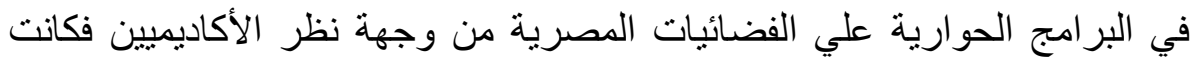

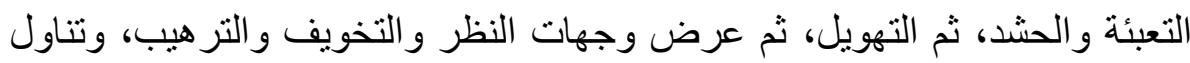

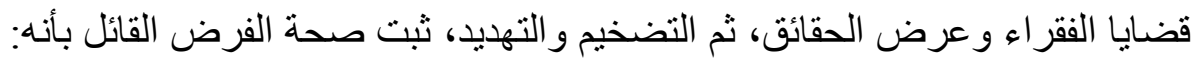

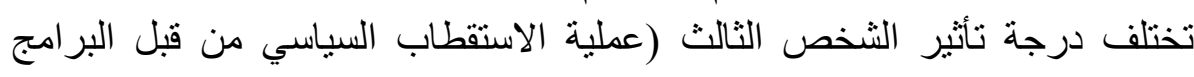
الحو ارية علي الفضائيات المصرية) باختلاف المسافة الاجتماعية .

* تم ترقية سيادتها بهذا البحث لدرجة أستاذ مساعد بقسم الإذاعة و التلفزيون - كلية الإعلام

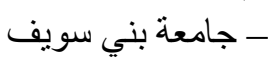

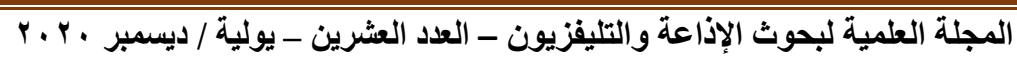




\section{Academic elite trends towards dialogue programmes in Egyptian satellite channels and their role in the political polarization of socially excluded}

The problem of study is determined in "trying to identify academic elite trends towards talk shows and their role in the political polarization of social exclusion with a concept of both political polarization and social exclusion from the viewpoint of the academic elite," in the light of the theory of the influence of the third person, It is a descriptive study that relies on the survey method, applying a questionnaire form on a sample of 100 respondents from teaching staff and their associates are at Beni Souef University (State University) and Al-Nahda University (private university), where the study assumed a statistically significant correlation between Motives for viewing the academic elite of talk shows and their orientation towards these programmes in terms of political polarization, the third person's degree of influence varies. The process of political polarization by the talk shows on the Egyptian satellite TV (depending on the social distance, and in this study begins The very social distance, then the parents, and then the socially excluded, the study found that: the dialogue programs via Egyptian satellite channels are making a political polarization for the socially excluded, the effect of this polarization has been strong, academics have accepted the idea of software impact In the process of political polarization of the excluded, while their impact on them was limited, there were many political polarization strategies used in the programmes the talk on the Egyptian channels from the point of view of the academics was the mobilization and the crowd, then the dramatize, then the view of the views and the intimidation and bullying, addressing the issues of the poor and presenting the facts, then amplification and threat, confirmed the validity of the imposition that: the degree of influence of the third person (the process of political polarization by the talk shows on the Egyptian satellite TV) varies with the social distance.

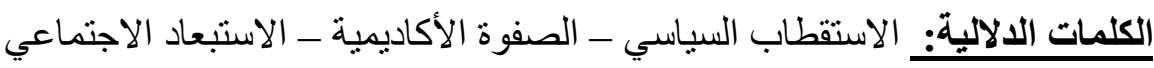




\section{مقدمة:}

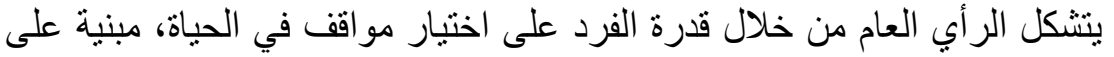

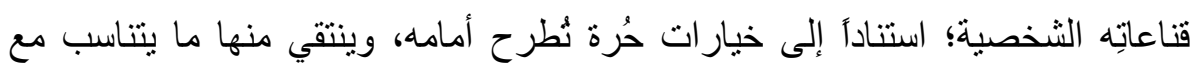

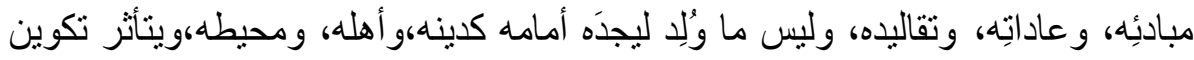

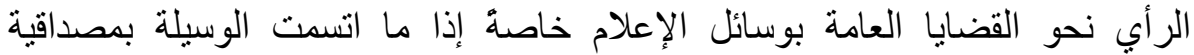

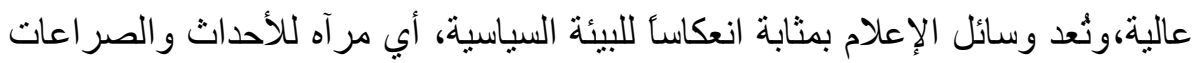

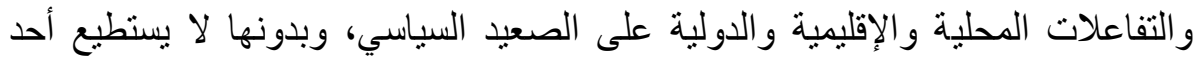
خارج الحلقة السياسية الإطلاع على الأحداث السياسية، ولكن وسائل الإعلام أثناء تأديتها

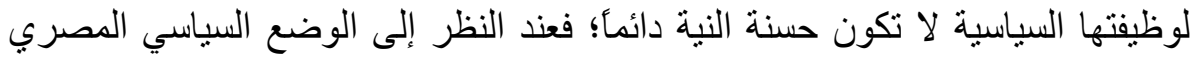

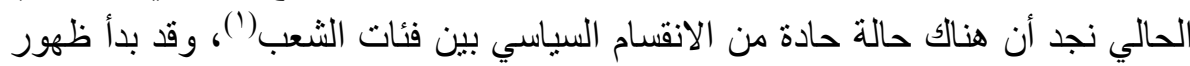

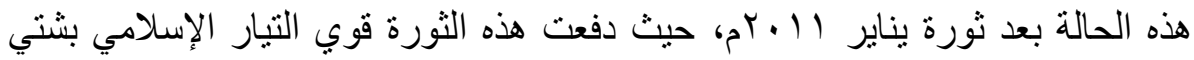

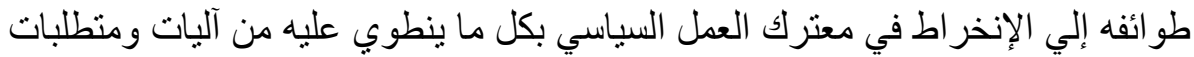
يأتي في مقدمتها قبول فكرة الديمقر اطية و التداول السلمي للسلطة، ثم كان قبول الفيول الإسلاميين بتشكيل أحزاب أو تنظيمات سياسية لا تهدف إلي خوض الإنتخابات في هذه المرحلة، و إبرام تحالفات إنتخابية مع قوي وشخصيات سياسية غير إسلامية مثل اليساريين

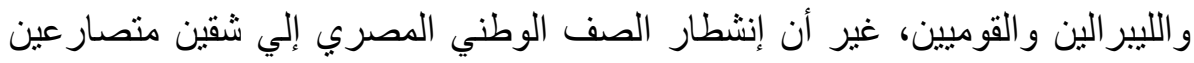

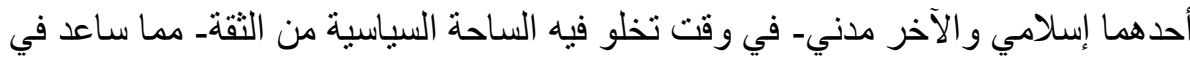

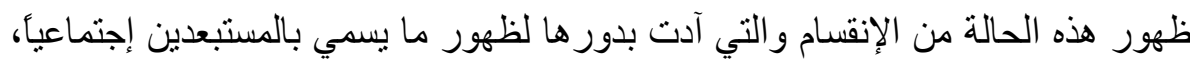
حيث تحولت العملية السياسية إلي مبارة صفرية يُشكل أي مكسب لألفي لأحد أطر افها خسارة

$$
\text { ضرورية للطرف الآخر. }
$$

$$
\text { و من المعروف أن ظاهرة الاستبعاد الاجتماعي تتنج من عدة أسباب منها: }
$$

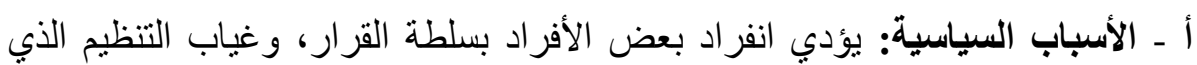

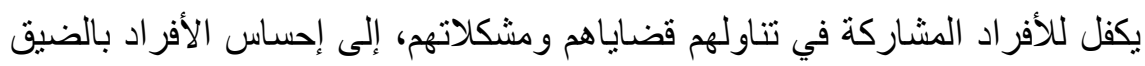

$$
\text { الذي يظهر على هيئة توتر واستعداد كبير للانفجار. }
$$

ب - الأسباب الاقتصادية: يعتبر العامل الاقتصادي أهم العوامل التي تؤدي إلى بروز

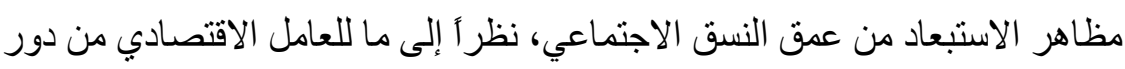

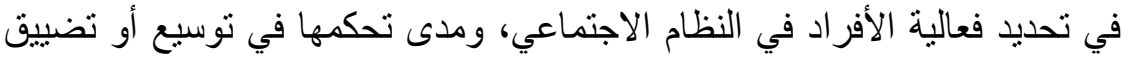

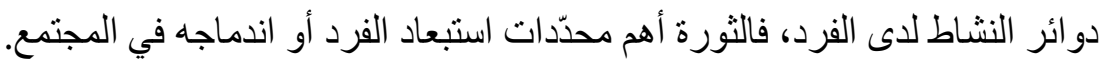
ج- الأسباب النوعية: يحدّد جنس الفرد في المجتمع دوره ومكانته، وحتى منطلق التربية،

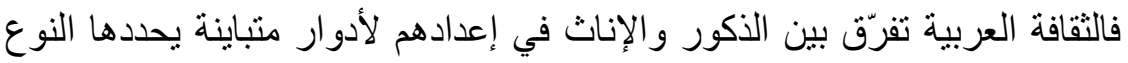


الأي ينتمون إليه، و هو ما جعل العديد من الحركات الداعية إلى رفع القيود و أشكال

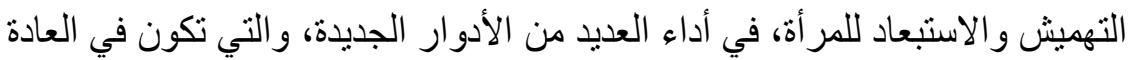

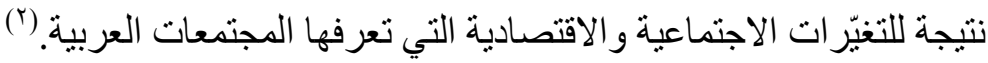

في حين نجد أن للاستبعاد الاجتماعي عدة سمات : تتحدد السمة الأولى بشكل الاتصال

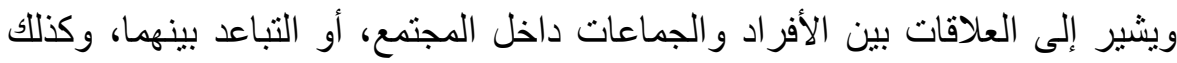

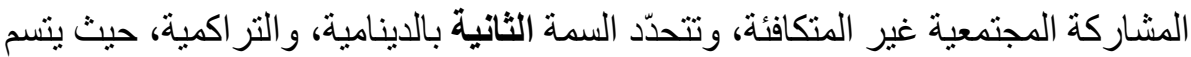

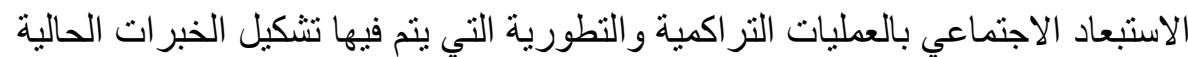

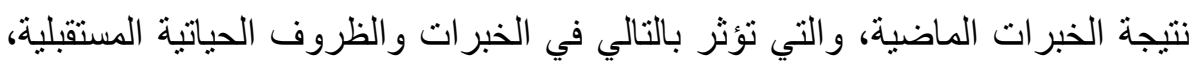

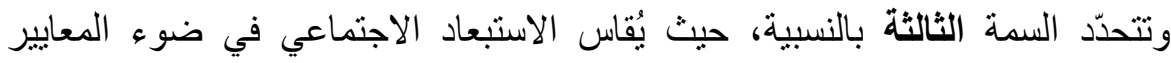

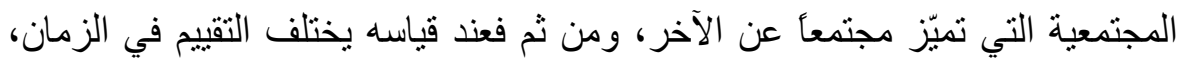

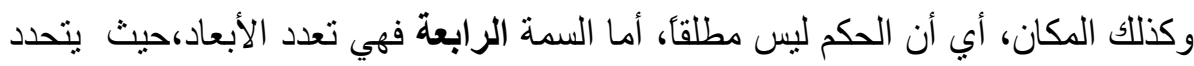

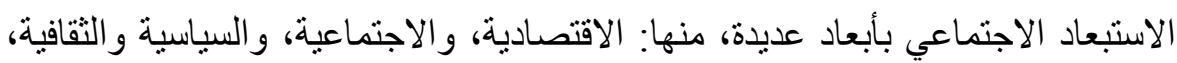

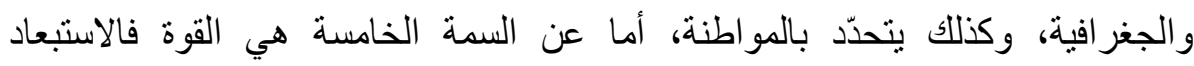
الاجتماعي يعبّر عن إرادة أصحاب القوة القادرين على السيطرة، وعلى التحاذ التهاذ القرار

ونتفيذه. (r) (1)

و علي ما سبق ترتبت العديد من التداعيات و المواقف المختلفة، والتي لعبت فيها وسائل

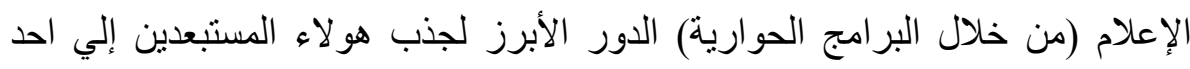

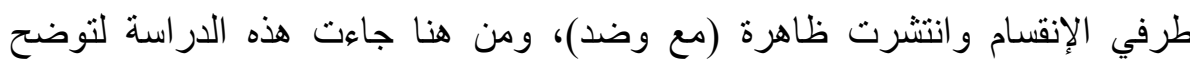

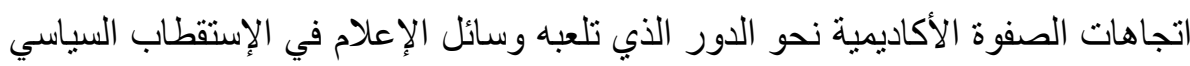

للمستبعدين اجتماعياً.

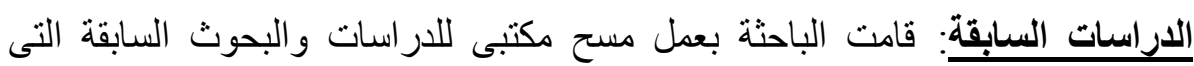

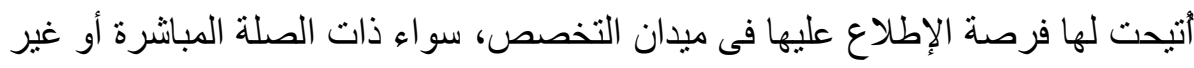

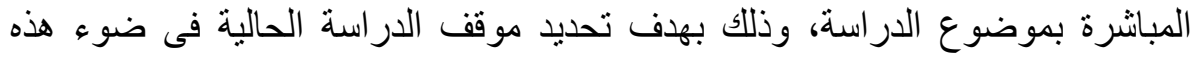

الدر اسات و البحوث. بموض.

\section{وقد تم تصنيف هذه الدراسات والبحوث العربية والأجنبية كالتالى: \\ أولاً: دراسات تتعلق بالصفوة الأكاديمية وعلاقتها بوسائل الإعلام}

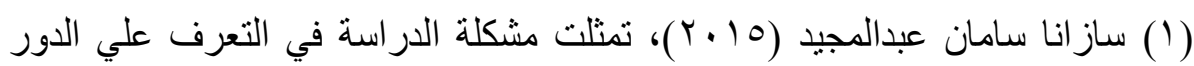

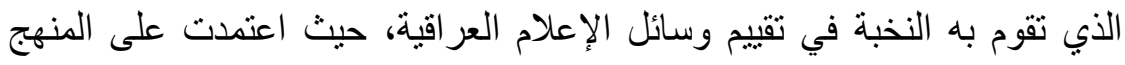

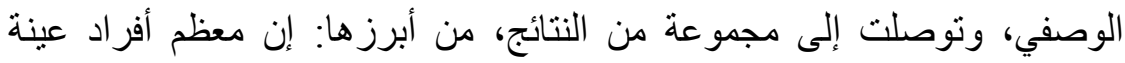

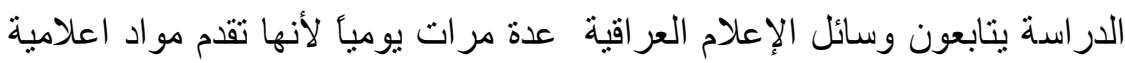


تمس مظاهر الحياة المختلفة لا سيما السياسية والأمنية، تنشر وسائل الإعلام العر اقية

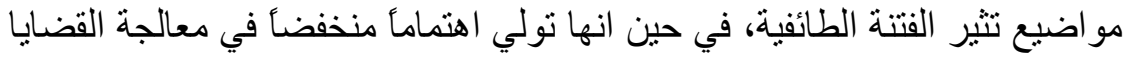

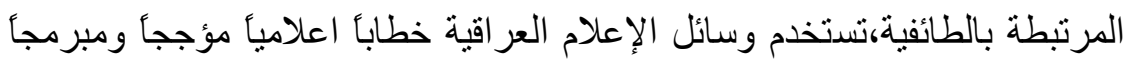

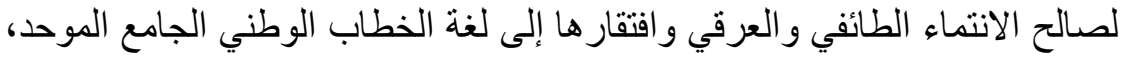

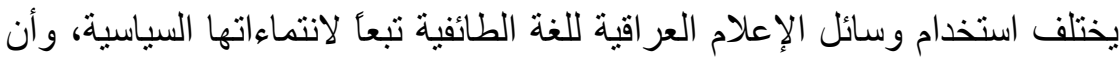
هناك تحيز من قبل السياسيين في درجة حساسيتهم للخطاب السياسي الطائفي وطريقة

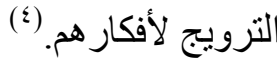

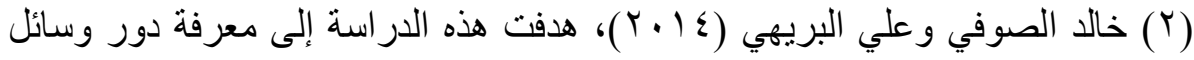

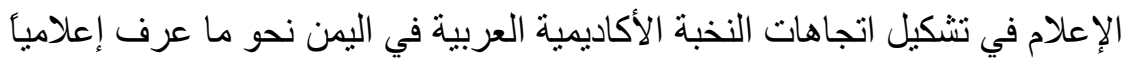
بثورات "الربيع العربي" من خلال المحاور التالية: قياس اتجاهات هذه النخبة نحو وطنية الثورات، و اتجاهاتها نحو أسباب قيام الثورات، واتجاهاتها نحو محركات

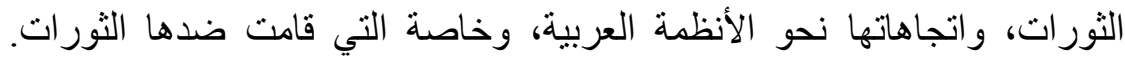

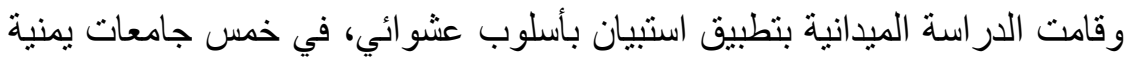
حكومية، وعلى عينة حجمها • با مبحوثأ من الأكاديميين العرب العاملين في هذه

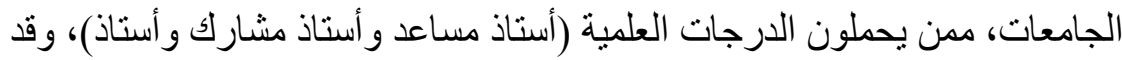
خرجت الدراسة بنتائج عدة، أهمها: جاءت القنون التات الفية الفضائية الإخبارية كأهم مصدر

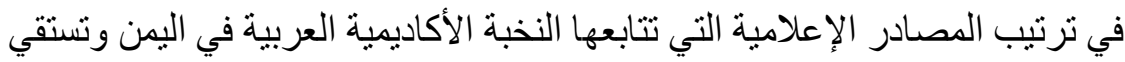

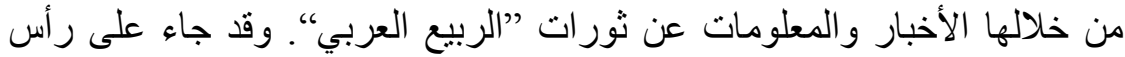
هذه القنوات تفضيلا لاى المبحوثين القنوات الفضائية الإخبارية (الجزيرة، العبات العربية،

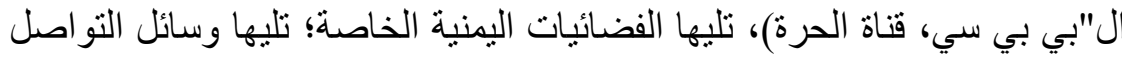

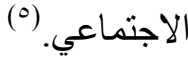

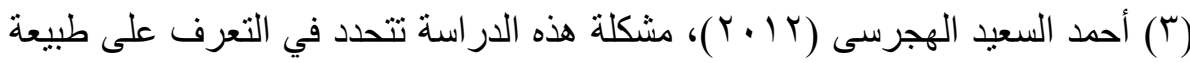

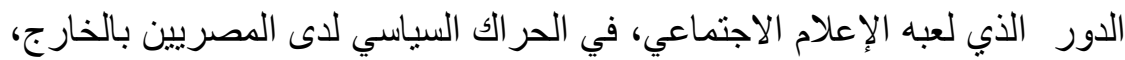

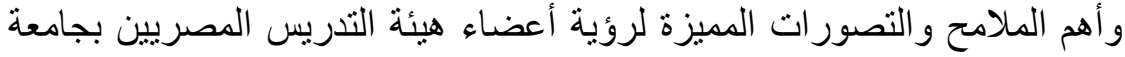

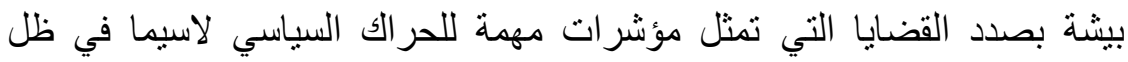

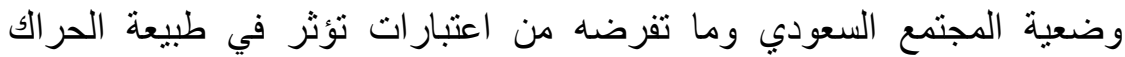

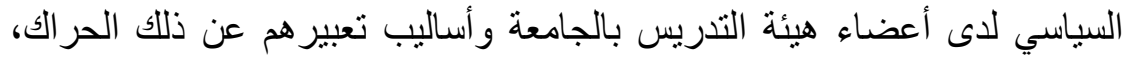

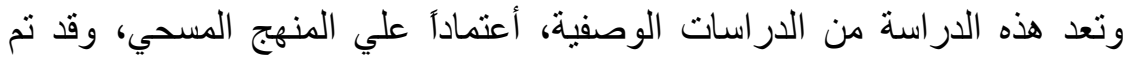

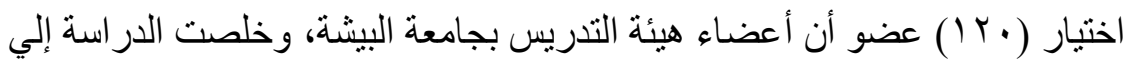

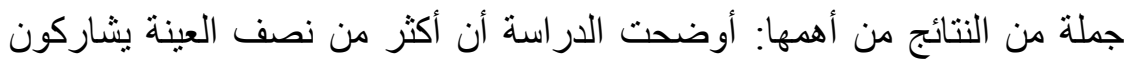
بصورة منتظمة أو غير منتظمة في مناقثة الموضو عات السياسية من خلال وسائل 
الإعلام الاجتماعي، وكان أحد أسباب عدم مشاركتهم في النقاش السياسي عبر وسائل

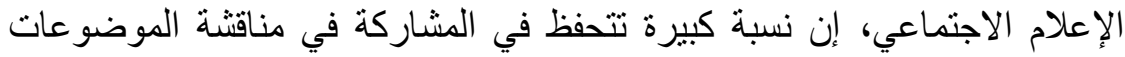

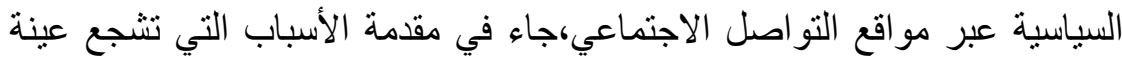
الدر اسة علي المشاركة في الحر الك السياسي عبر وسائل الإعلام الاجتماعي كون هذه

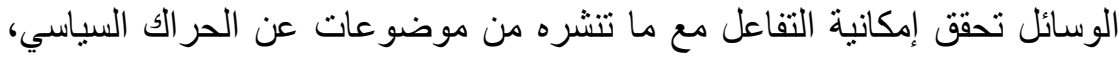

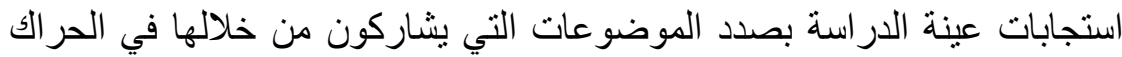

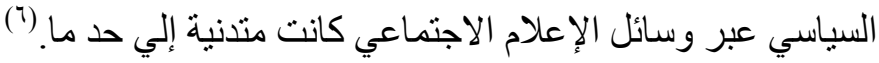
ثنانياً : دراسات تتعلق بالبرامج الحوارية في الفضائيات.

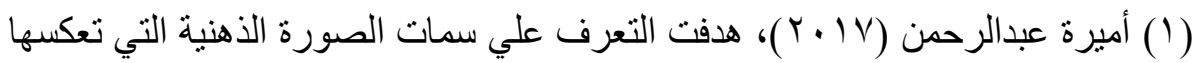

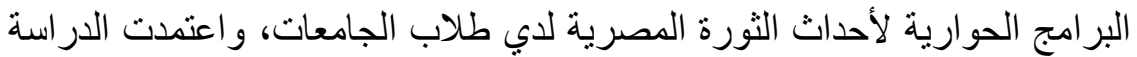

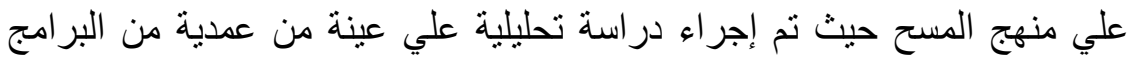

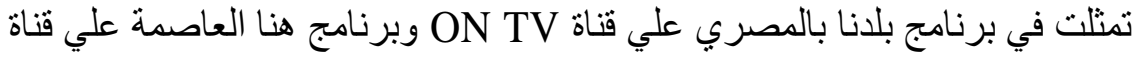
cbc

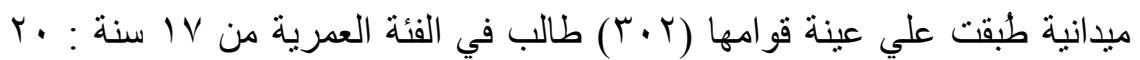
سنة من طلاب جامعات (عين شمس - جنوب الو ادي ـ فاروس)، خلال الفترة ما بين

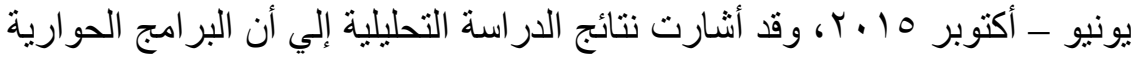

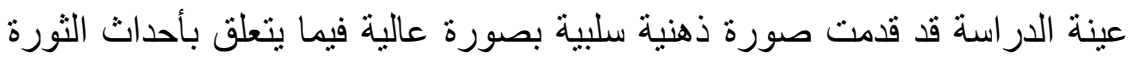

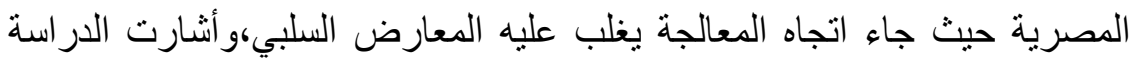

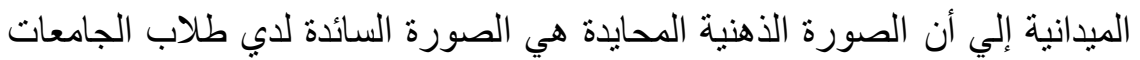

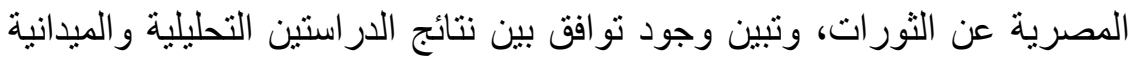

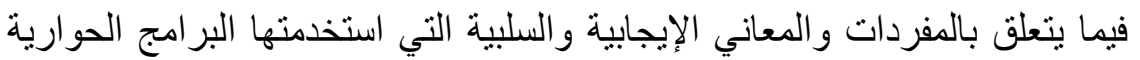

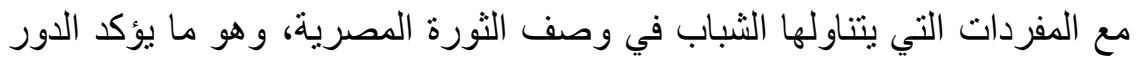
الذي تقوم به البرامج الحوارية في تشكيل اتجاهات المبحوثين بشأن أحداث الثورة

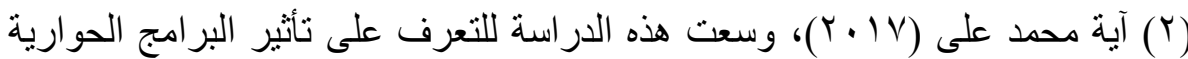

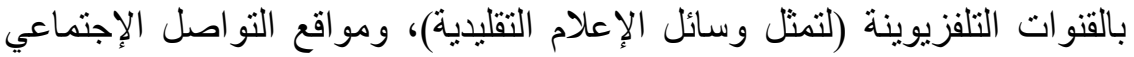

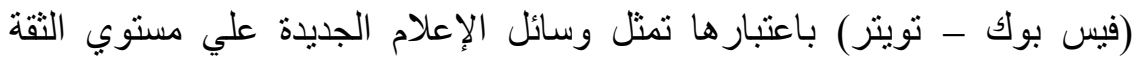

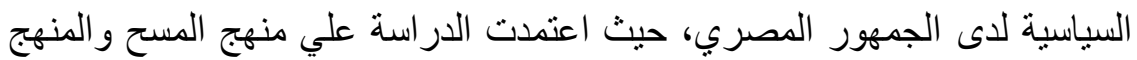

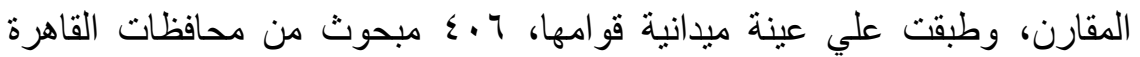

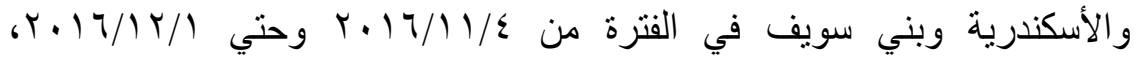


وتوصلت نتائجها إلي: هناك علاقة ارتباط طردية بين التعرض للبرامج الحوارية

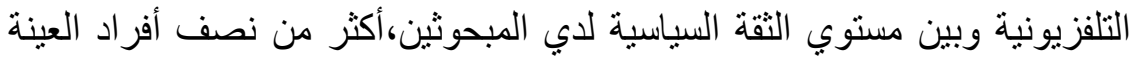

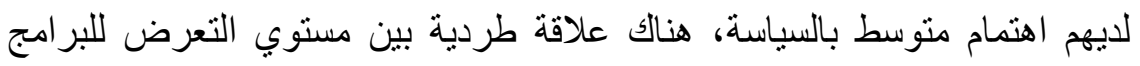
الحوارية والاتجاه الإيجابي نحو القضايا المسيطرة علي الساحة ومنها (تعويم (الجنيه). (الجوال)

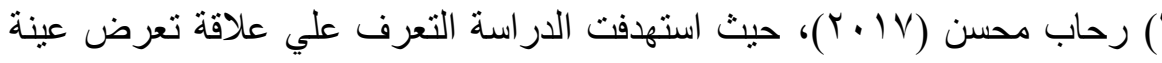

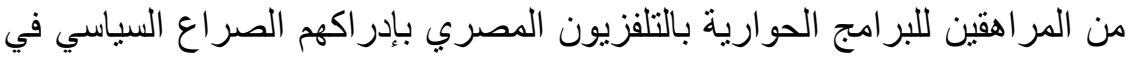

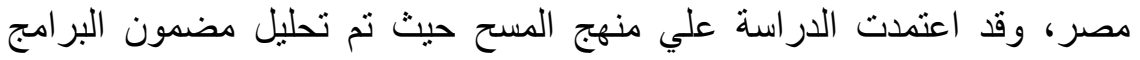

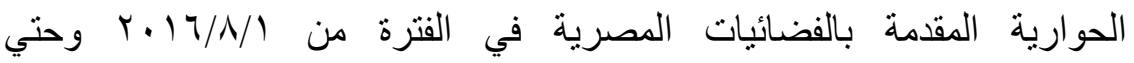

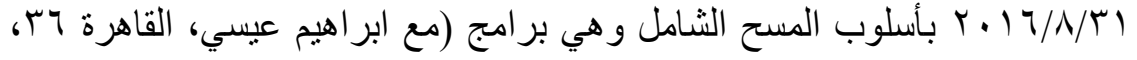

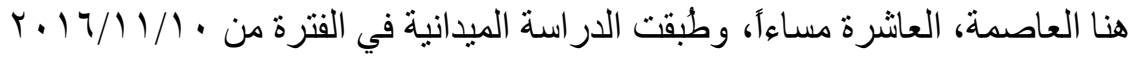

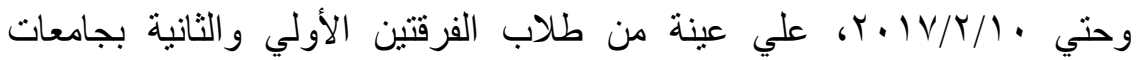

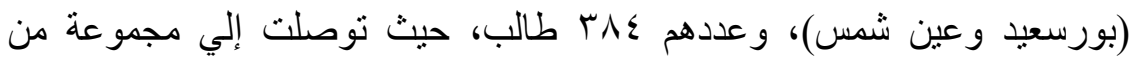

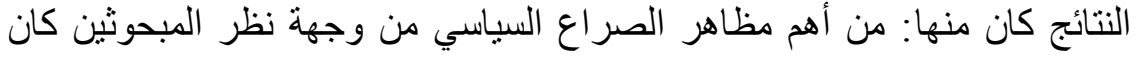

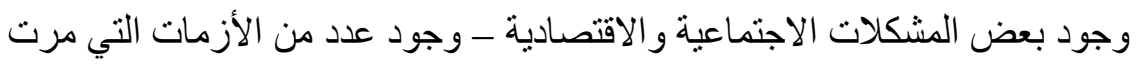

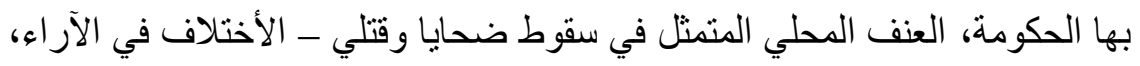

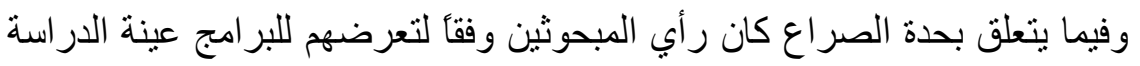

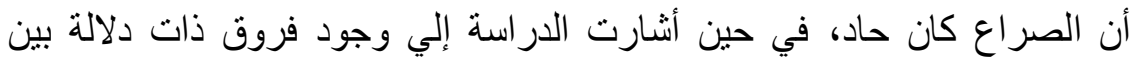

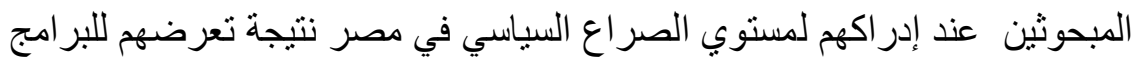

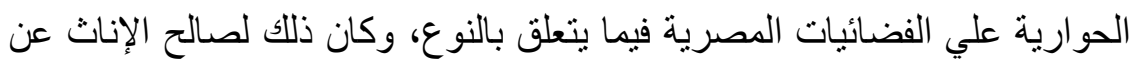
الذكور. (9)

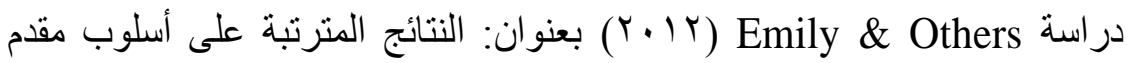

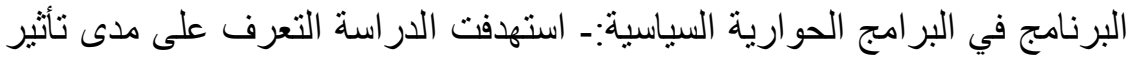

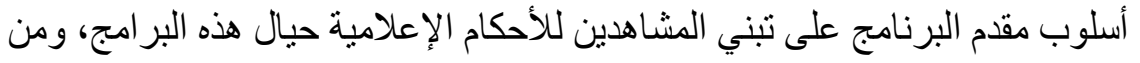

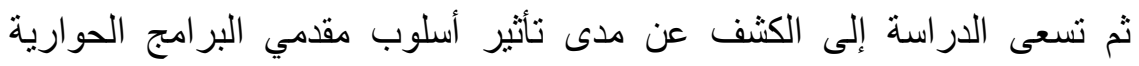

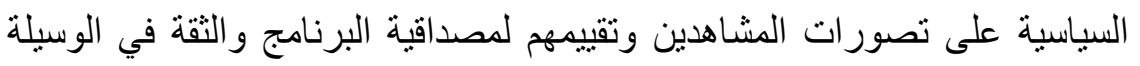

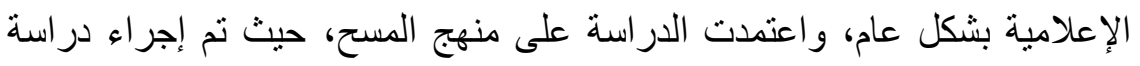

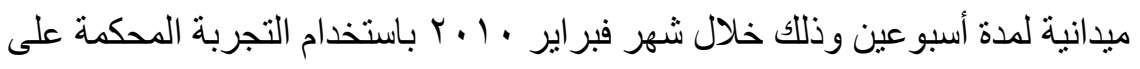

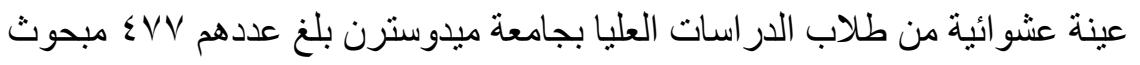

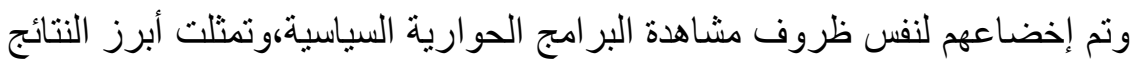
في: أسلوب مقدم البرنامج يؤثر بدرجة كبيرة على مصداقية البرنامج بالوسيلة 
الإعلامية، حيث يزيد مقدم البرنامج المحايد من تطورات القيمة المعلوماتية للبرنامج

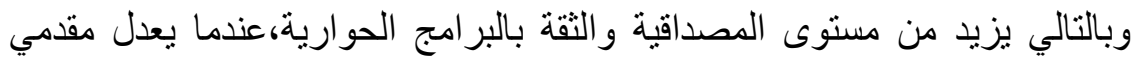

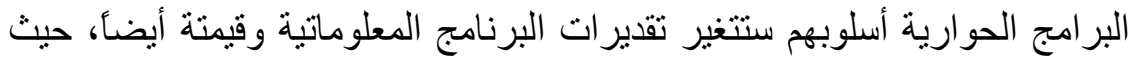

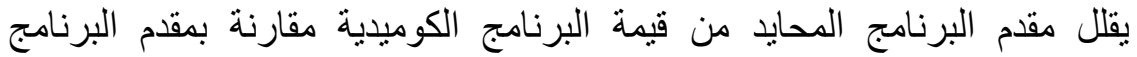
الكوميدي. (1.)

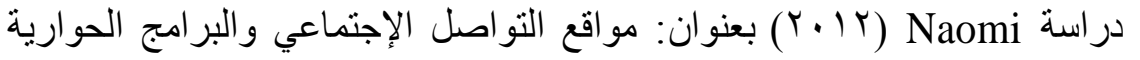

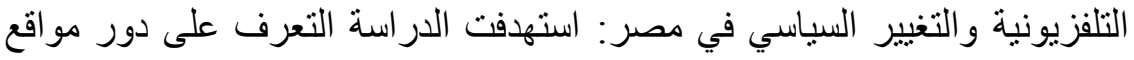

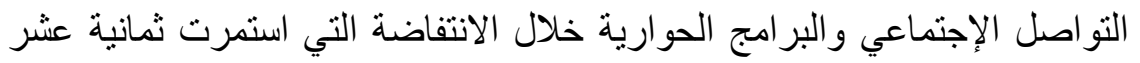

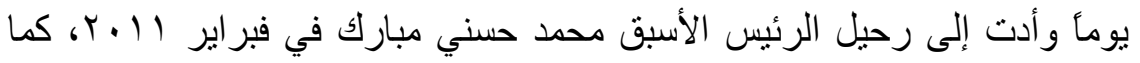

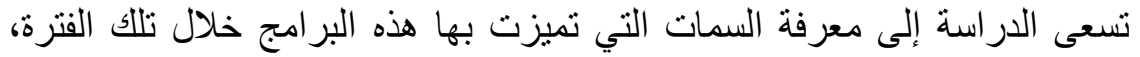
وكذلك معرفة القيود التي فرضت عترهي على وسائل الإعلام فدفعت بها إلى الإنى الإنصال

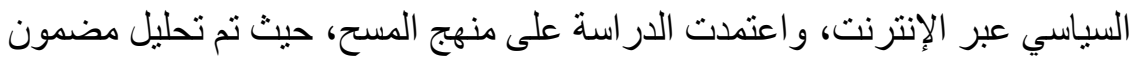

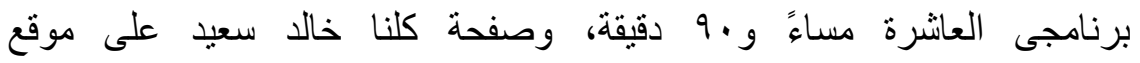
الفيسبوك.وكان من أهم النتائج :تميز بر امج الفضائيات المصرية الخاصة خلهاءة خلال فترة

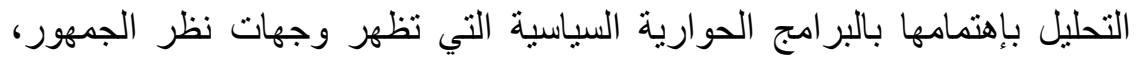

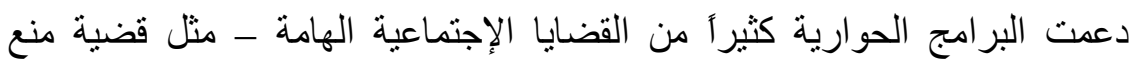
التحرش الجنسي - والتي كان لها صدى بمعالجتها بعد ذللك عبر وسائل الإعلام

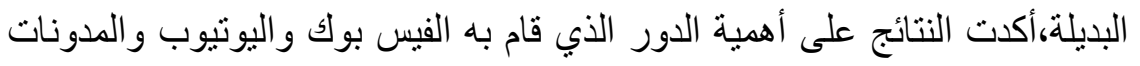

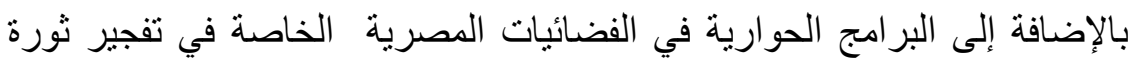

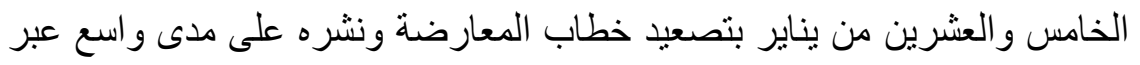

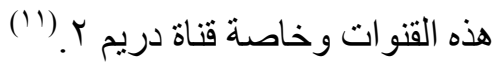

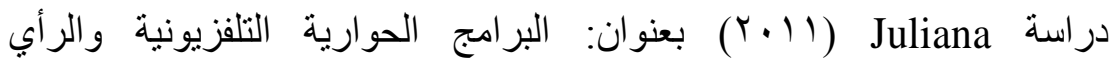
العام،استهدفت الدراسة التعرف على النمط العام للبرامج الحوارية المتاحة حالياً

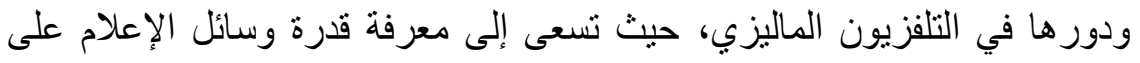

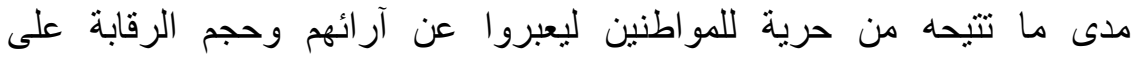

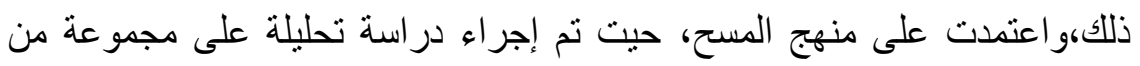

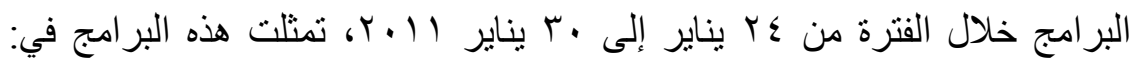

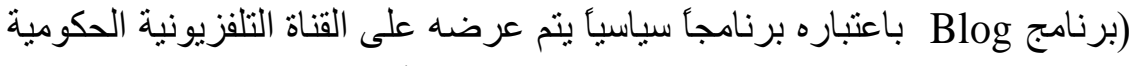

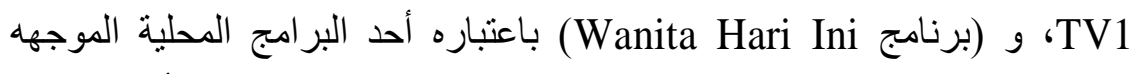

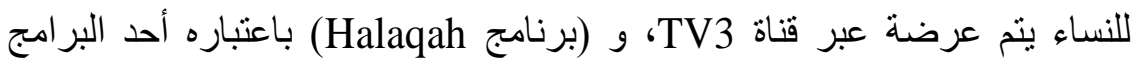
الدينية التي تذاع عبر قناة TV9، وكان من أهم النتائج :استطاعت البر امج الحوارية 
الثلاثة محل الدراسة أن تشكل وجهة نظر الجمهور حول النظام الإجنماعي الحالي،

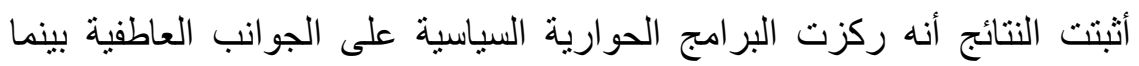

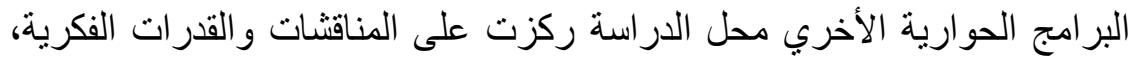

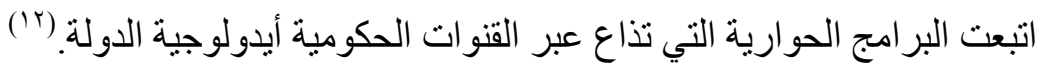

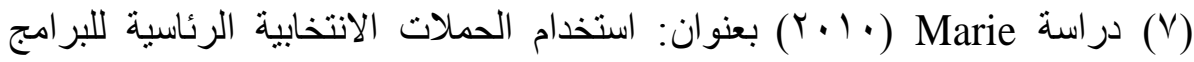

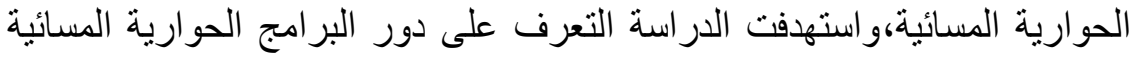

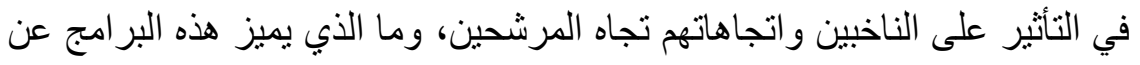

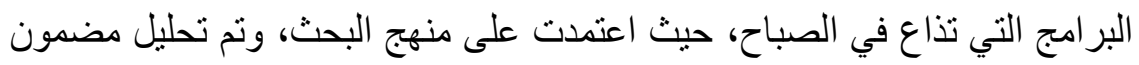

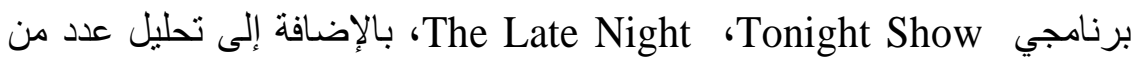

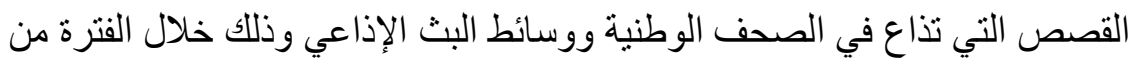

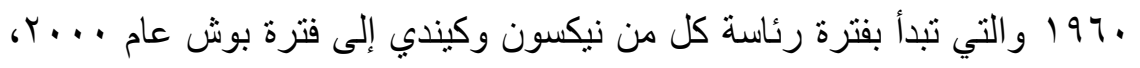

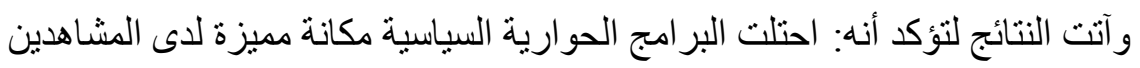

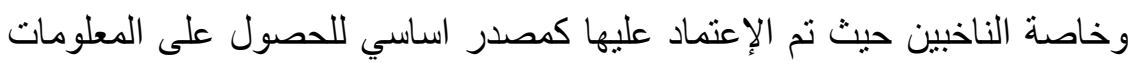
السياسية،استطاعت البرامج الحوارية التي تذاع في فترة متأخرة من الليل أن تؤثر الترادئ

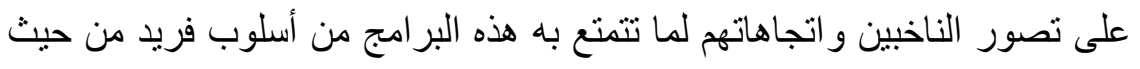

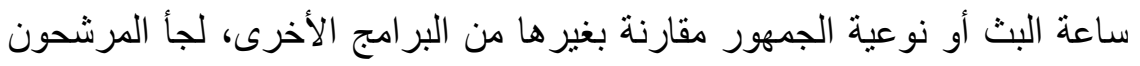

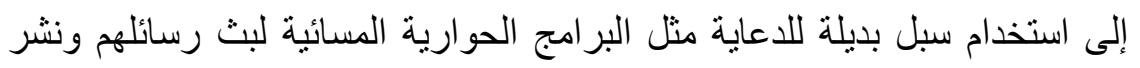

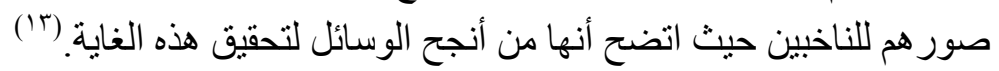
ثالثاً: دراسات تتعلق بالاستقطاب السياسي.

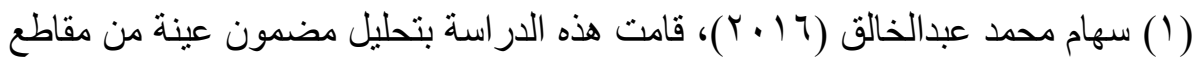
اليوتيوب المنتجة من قبل المواطن للتعرف على الأطر المستخدمة بهذه المقاطع

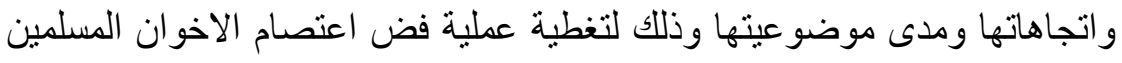

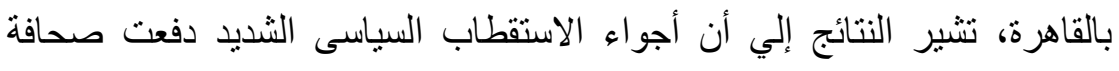

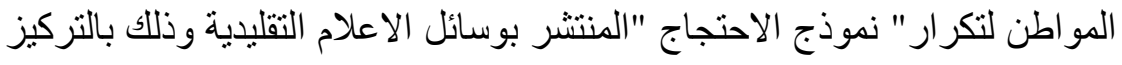

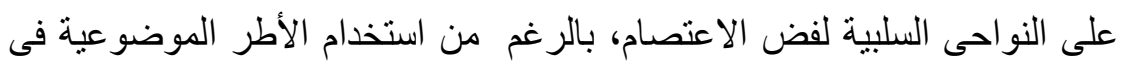

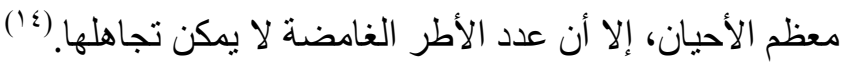

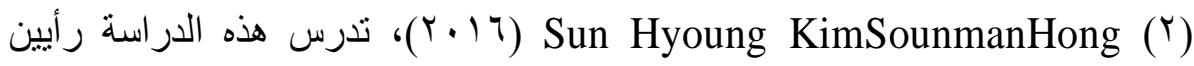
متنافسين عن دور منصات التواصل الاجتماعي في الاستقطاب الحزبي، ويركز

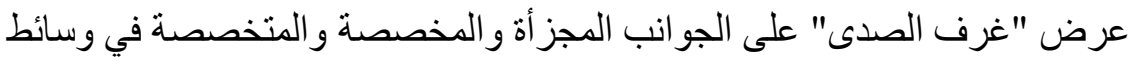
التو اصل الاجتماعي، ويقتر ح أن تعزز هذه الأماكن استقطابا سياسيا أكبر للر أبي العام. 
أما البديل الذي نطلق عليه "التفاعلات الثاملة"، فيركز على انفتاح الإنترنت ووسائل

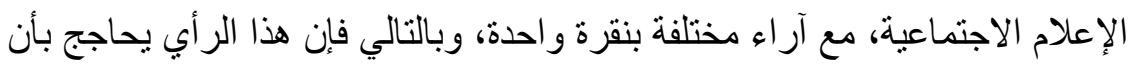

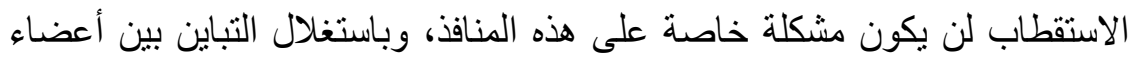

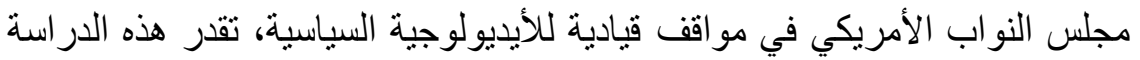

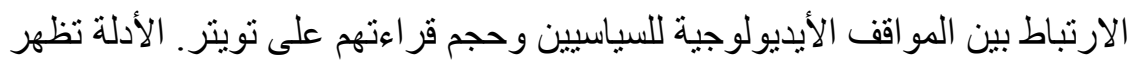

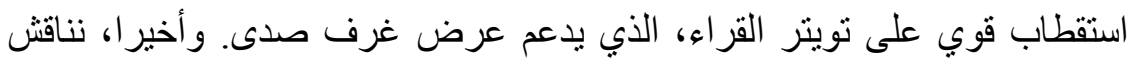

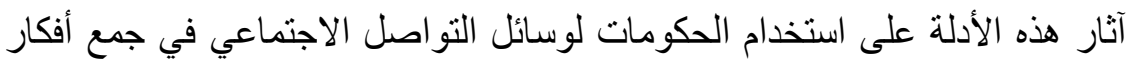

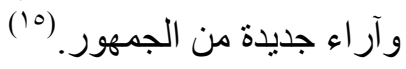

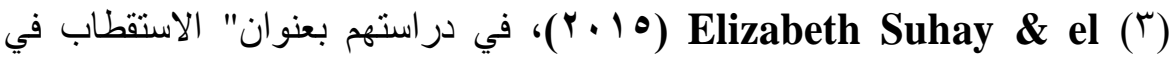
مناقثات المدونات حول اعتصام وول ستريت جورنال "بشكل آخر من أشكال

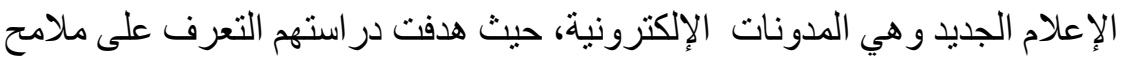

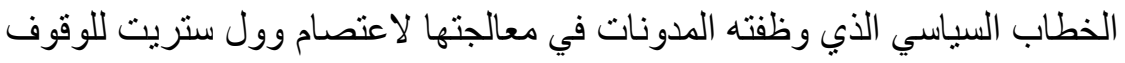
على ملامح الاستقطاب السياسي الذي تمارسه المدونات باعتبار ها شكلا من أنتكال

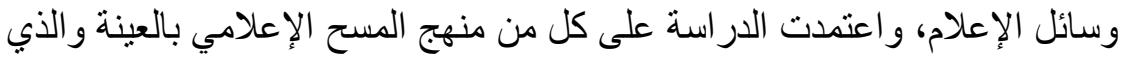

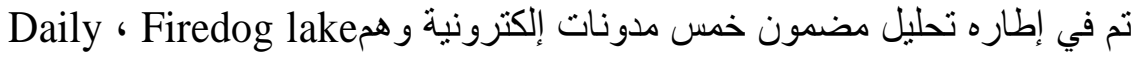

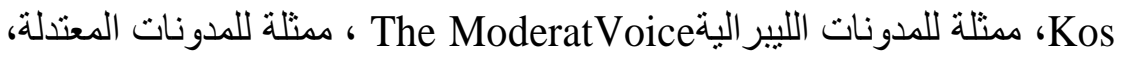
Townhall, Michelle Malkin

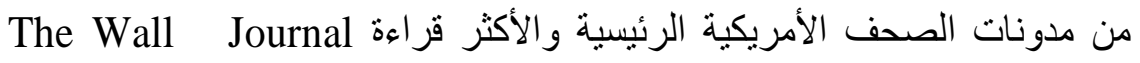
The New York Times Street على أوجه الثبه والاختلاف فيما بين المدونات عينة الدراسة كلا حسب توجها

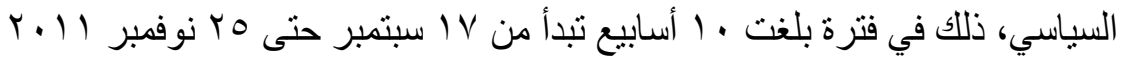

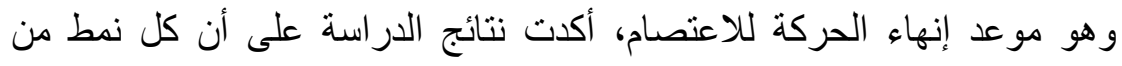
المدونات يعبر عن اتجاه و احد فقط دون الآخر ، ومارست تللك المدونات استقطاباً حاداً

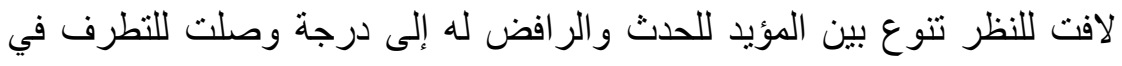

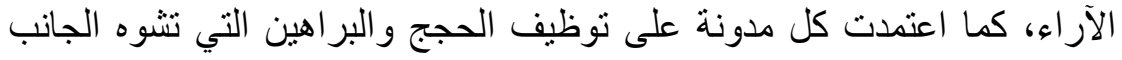

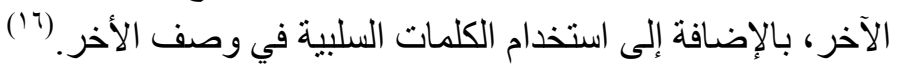

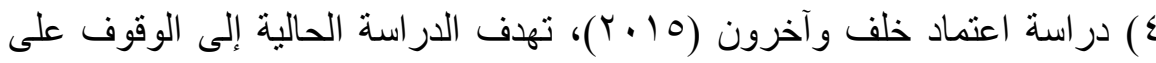

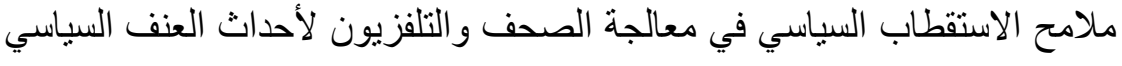

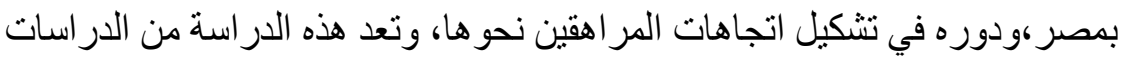

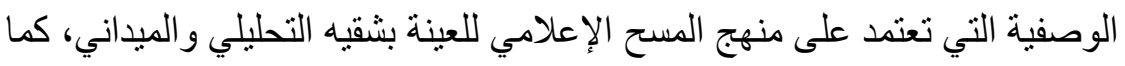
استخدمت الباحثة في هذه الدر اسة صحيفة تحليل المضمون لتحليل الثنكل و المضمون المئي 
للصحف الإليكترونية والبرامج الحوارية عينة الدراسة من أجل رصد ملامح

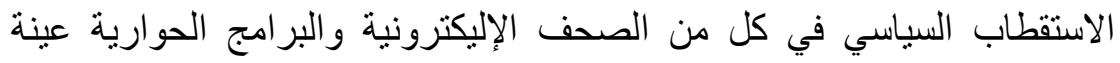

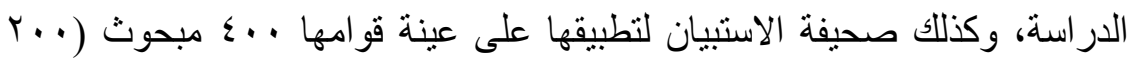

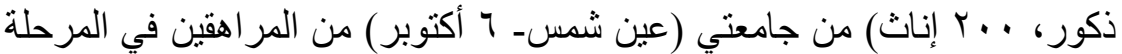

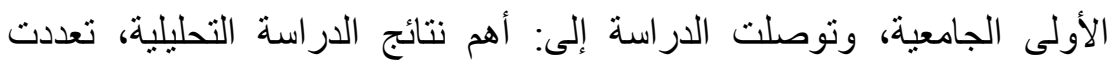

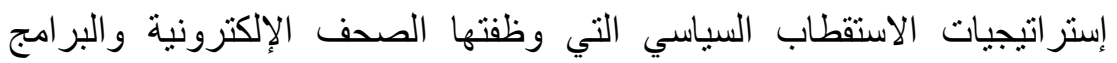

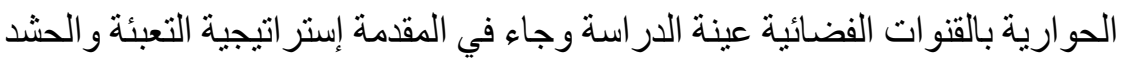
ثم إستر اتيجية الخوف من الآخر، تنوعت آليات الاستقطاب السياسي التي وظفتها

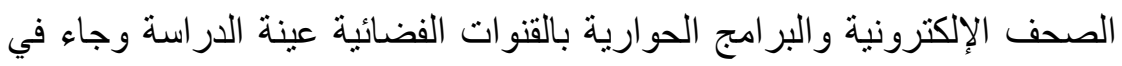
مقدمتها آلية التنميط من خلال وصف الطرف الآخر بالصفات سلبية مثل خائن، يتآمر

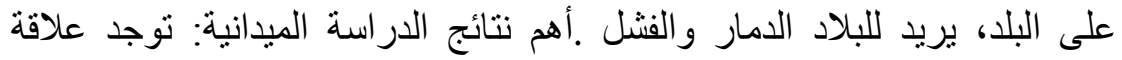

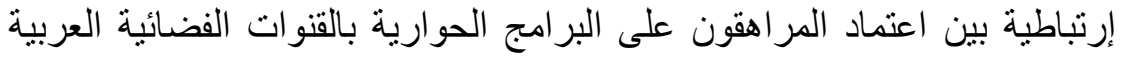

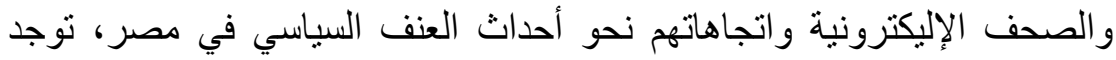

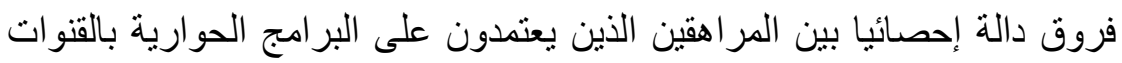

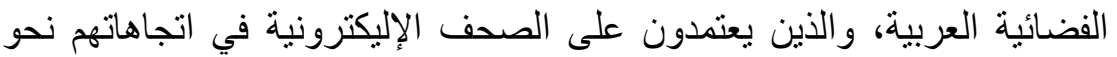
أحداث العنف السياسي، كان للاستقطاب السياسي الذي مارسته الصحف الإلئه الإليكترونية

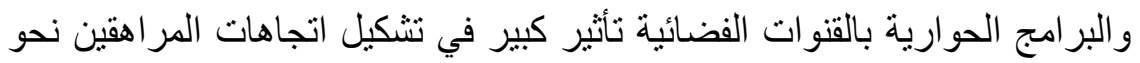

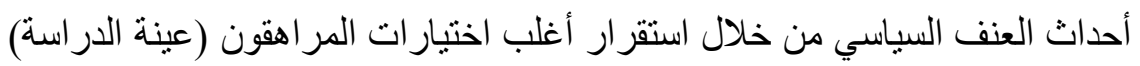

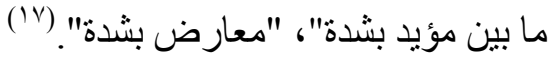

رضو ان بوجمعة (10 (1))، حيث سعت هذه الدراسة إلي التعرف علي مستويات

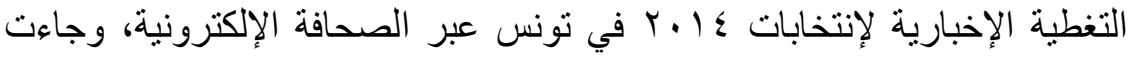

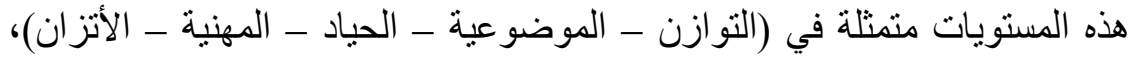

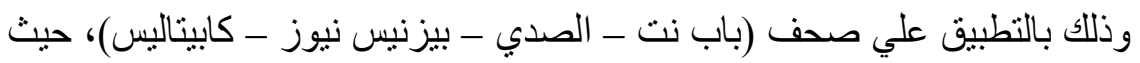

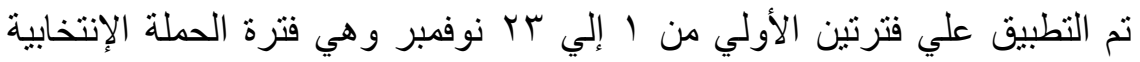

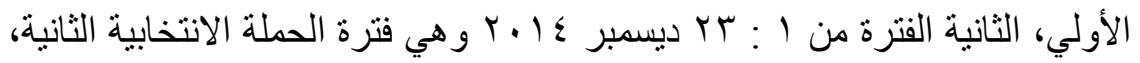

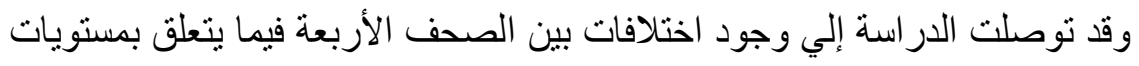

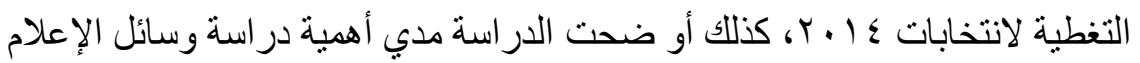

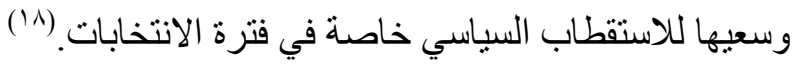

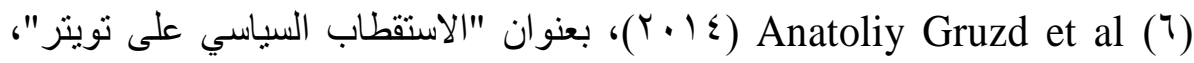
و واستهدفت التعرف على ملامح الاستقطاب السياسي الذي ينت ممارسته عبر شبكات

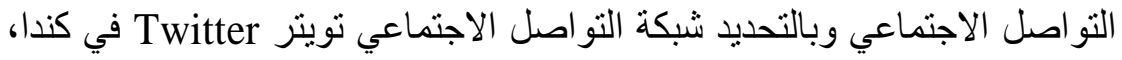




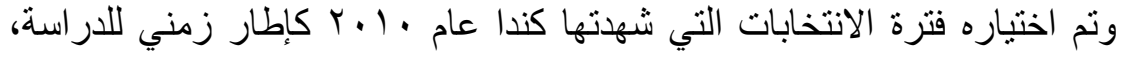

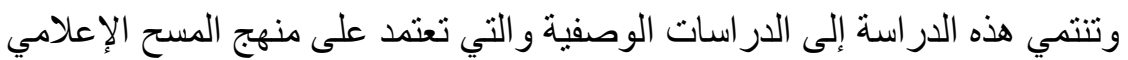

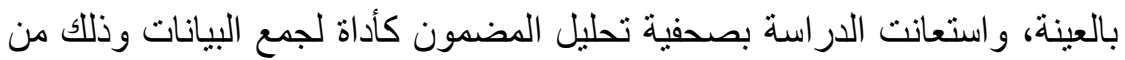

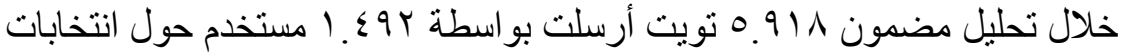

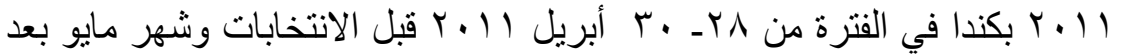
الانتخابات، أكدت الدر اسة أن:مستخدمي تويتر لا يميلون إلى تقاسم الآر اء السياسية

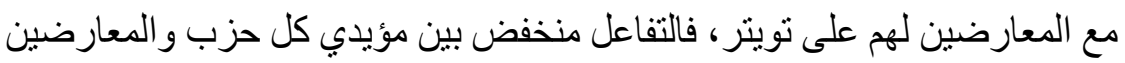

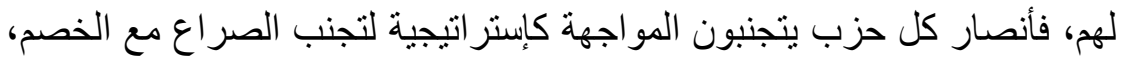

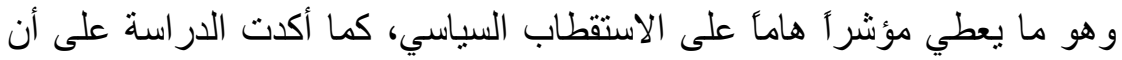

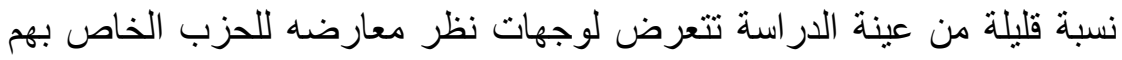
ولكن دون مشاركة، ولهذا التعرض دور هام في تقليل الاستقطاب السياسي. (19) Hannah Nam et al.(V) بناء مسجد جراوند زيرو "و التي اهتمت بالوقوف على ملامح الاستقطاب السياسي

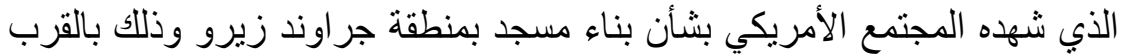

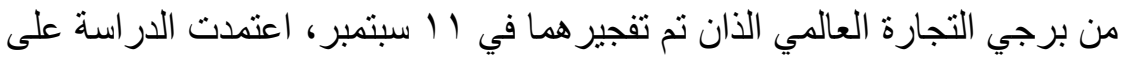

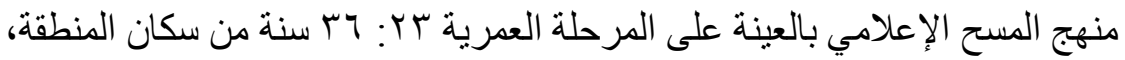

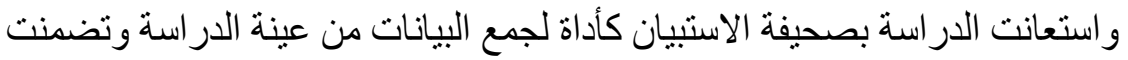
مجمو عة من العبار ات حول مدى المو افقة على المشروع تتر اوح ما بين مو افق بشدة ـ

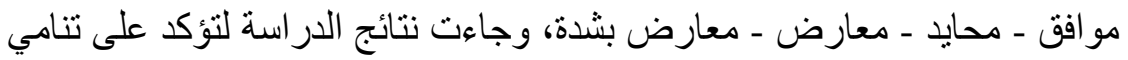

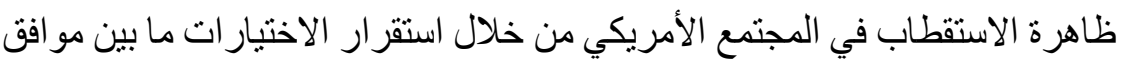

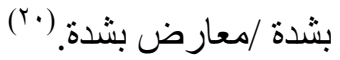

رابعاً : دراسات تتعلق بالاستبعاد الاجتماعي.

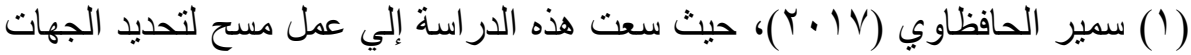
و الفئات التي تمر بوضع خاص في البلاد لتتبت السياسات الإجتماعية الاقتصادية

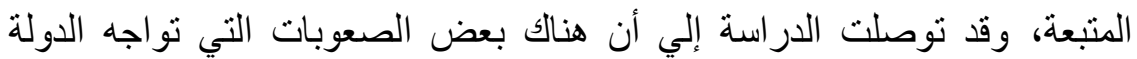
التونسية عند تحديد الفئات المقصودة كان من هذه المشكلات ظهور الجمعيات

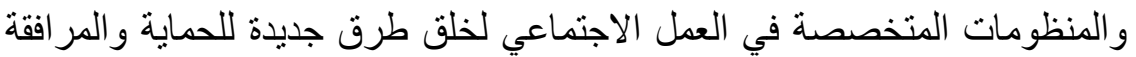
و المساندة لهذه الفئة وهو مايزيد من صعوبة إيجاد دور واضح للأولة لحل لحل مشكلاتهم. (r) (ب) 


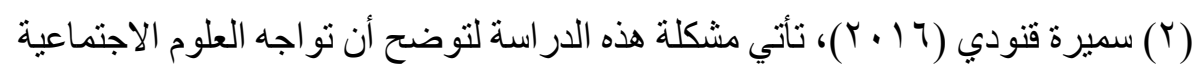

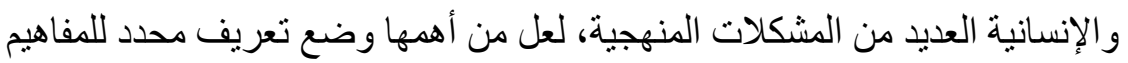

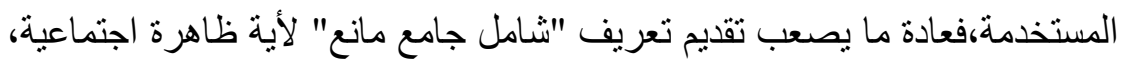

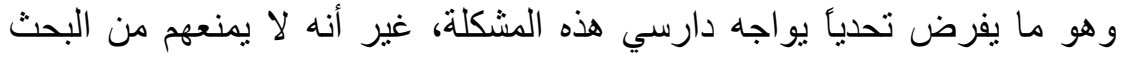

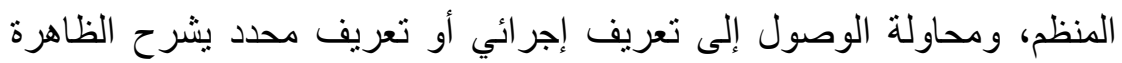

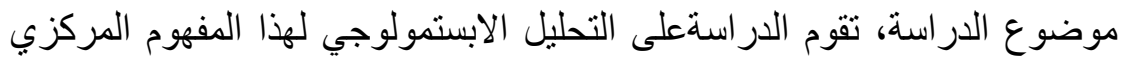

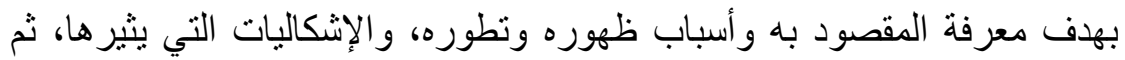
أخير أ أثره على المستو ئنسين العلمي و العملي. (rr)

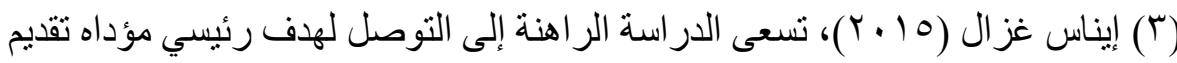

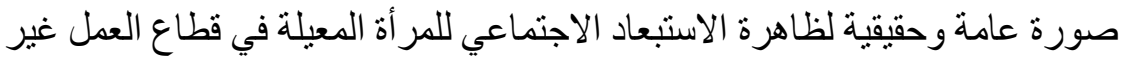
الرسمي في مجتمعنا المصري من خلال تشخيص الأوضاع الاجتماعية و الاقتصادية لهذه الثريحة والمشكلات التي تواجهها، وكذلك التعرف على على الملامح المستقبلية المتوقعة لهذه الظاهرة،وهي من الدراسات الوصفية التي تسعى إلى إعطاء صورة

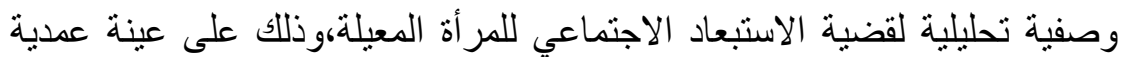
حجمها ( • () مبحوثة من نساء معيلات في منطقة سوق باكوس في مدينة الإسكندرية

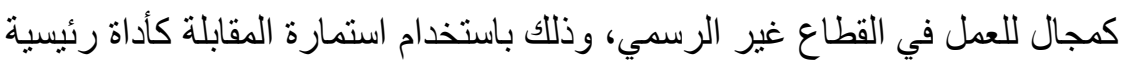
لجمع البيانات، وقد نوصلت الدر اسة إلى عدة نتائج من بينها تدني أوضاع الماع المر أة التي

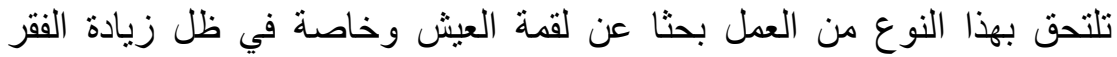

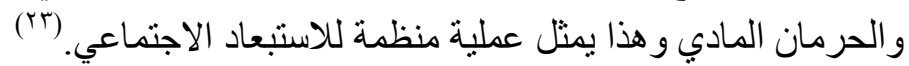

ع) روبين بيس (10 (10)، سعت هذه الدراسة للتعرف علي مفهوم محدد للاستبعاد

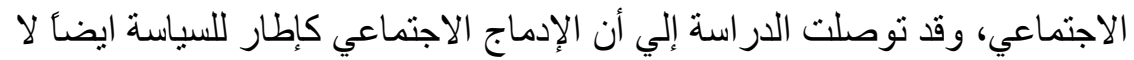

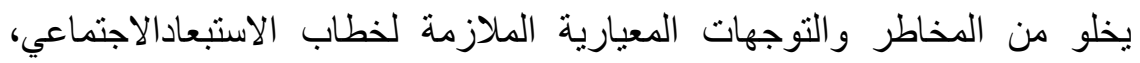
ويمكن تفسير الرغبة في الإدماج الاجتماعي في سياق السياسة كأجندة لتسهيل

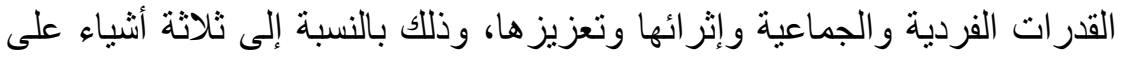

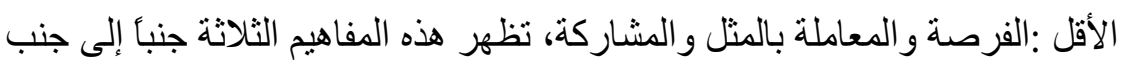
مع مفهوم الاستبعاد في كثثر من النقانشات بشأن السياسة الدولية، ويتطلب الاستثمار

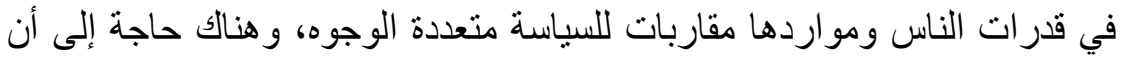
تكون تللك سياسات نوفر الوصول إلى إفادة أساسية في الصحة وانهات والتعليم و الإسكان

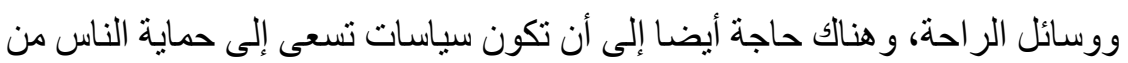

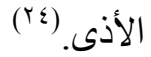


التعليق على الار اسات السابقة: من خلال استعر اض الدر اسات السابقة نجد أنه: هتتابه أهداف الدراسة الحالية مع أهداف الدراسات السابقة فيما يتعلق بتقييم النخبة

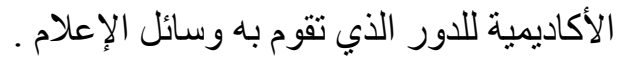

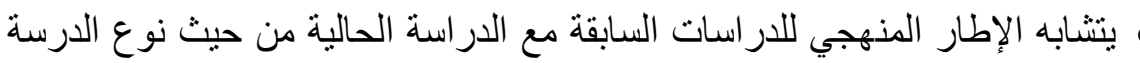
ومنهجها، و وآداة جمع البيانات المنمثلة في الاستبيان. • ثُشير نتائج الدر اسات السابقة إلي مدي تأثنير وسائل الإعلام علي الر أي العام. • تفضل النخبة الأكاديمية الاشتراك في الحراك السياسي عبر وسائل التواصل الإجتماعي عن الوسائل التقليدية نظر أ لفاعليتها.

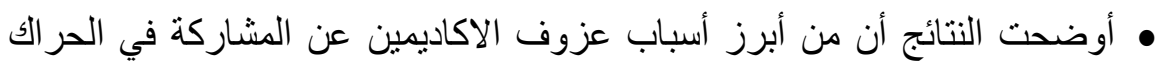

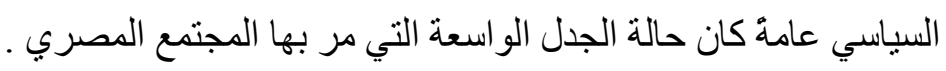

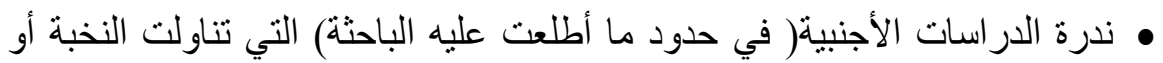
الصفوة الأكاديمية، وجاء أغلب التركيز علي الصفوة السياسية أو الفنية أو الرياضية. • أثنارت نتائج الدراسات السابقة إلي قدرة البرامج الحواريةعلي تشكيل اتجاهات الجمهور تجاه القضايا و الموضو عات المُتّارة.

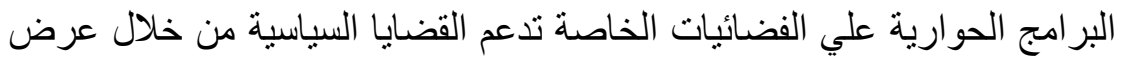

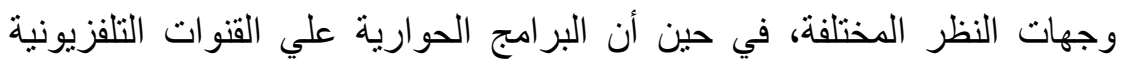
الحكومية تتبني وجهات نظر الدولة • تركز البرامج الحوارية علي القدرات الفكرية للأفر اد. • البر امج الحوارية هي مصدر المعلومات السياسية الأول للجمهور المصري. • تتشابه الدراسات العربية و الأجنبية المتعلقة بالبرامج الحوارية في نتائجها المتعلقة بتأثثر نمط الملكية للقناة الباثة، وكذللك الخصائص البه لأبر امجية. • ركزت الدراسات الأجنبية عند تناولها الأستقطاب السياسي علي وسائل الإعلام

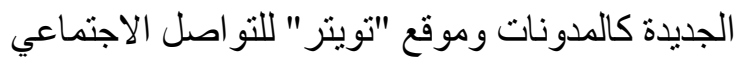
• تشابهت دراسة عربية مع الدراسة الحالية في فكرة در اسة الأستقطاب السياسي من

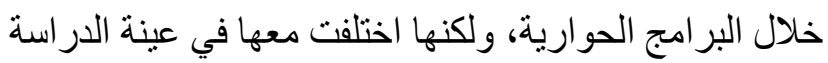
• ركزت الدراسات المتعلقة بالاستبعاد الاجتماعي علي آثر العنف علي الأفراد ودروه في عملية الاستبعاد و التهميش. 


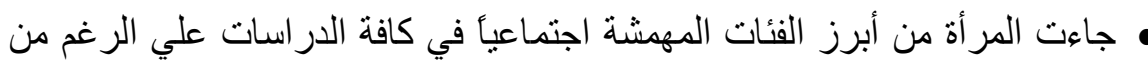

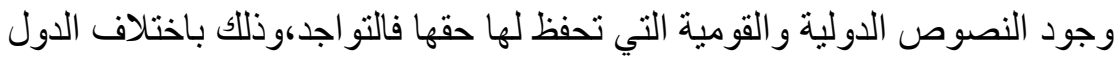
التي اجريت بها الدر اسات. • أصبح مفهوم الإقصاء والحرمان والتهميش من المفاهيم المستخدمة في الاتصال، وهو ما يُتبت أن مصطلح الاستبعاد الاجتماعي هو مصطلح غير ساكن. • لم تآتي در اسة لنوضح علاقة المستبعدين بوسائل الإعلام، أو در اسة تأثثر ها عليهم. وقد استفادت الباحثة من الاراسات السابقة فى تحديد النقاط التالية: • تحديد وبلورة مشكلة البحث و أهم متغير اتها تحديداً دقيقً. . • تحديد المفاهيم الخاصة بالبحث. • تحديد المناهج والأدوات البحثية الأكثر مُلائمة للبحث. • تؤكد نتائج الدر اسات السابقة إلي أن من بين أعضاء هيئات التنريس أصبحو ا بشكل

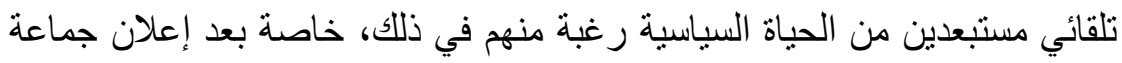

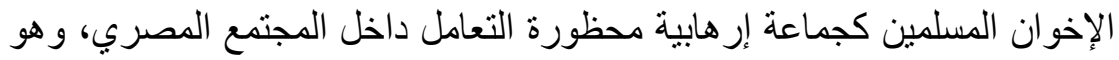
ما جعل الباحثة تعتمد علي نظرية الثخص الثالث كإطار نظري للار اسة. مشكلة الاراسة: اتفق كثير من الباحثين و الأكاديميين، بناء على عديد من نتائج البحوث و الدراسات

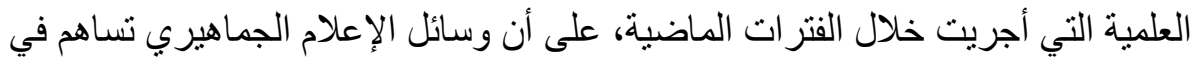

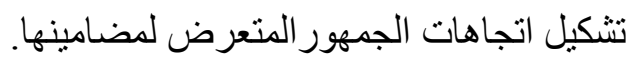
وعلى الرغم من أن الجدل ماز ال قائمأ حول الآثار السلبية والإيجابية لوسائل

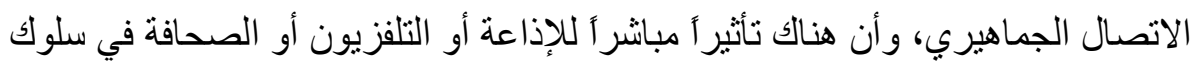

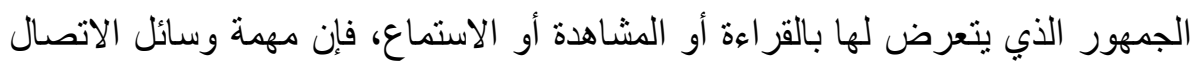
الجماهيري تتمثل في تدعيم المواقف بأكثر من تغيير ها، ما يعني أنه يجب أساسأ التخلي

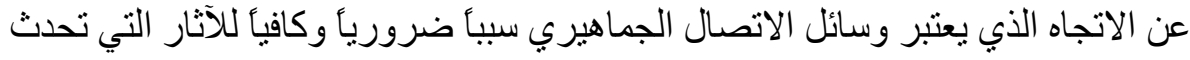

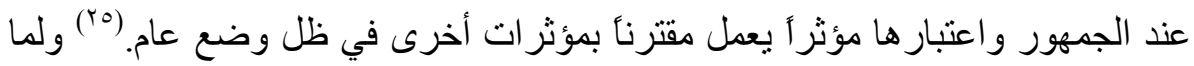

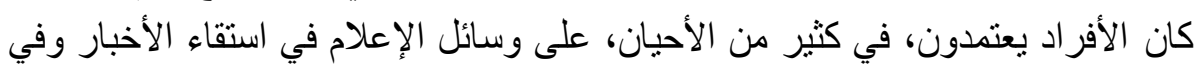

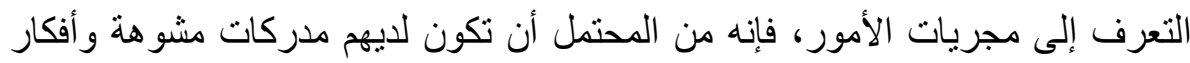

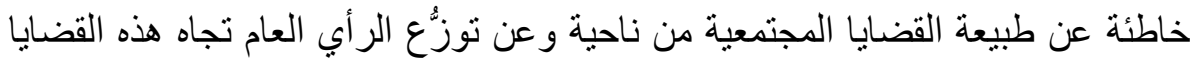

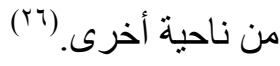


مما سبق تتحدد مشكلة الدراسة في "محاولة التعرف علي اتجاهات الصفوة

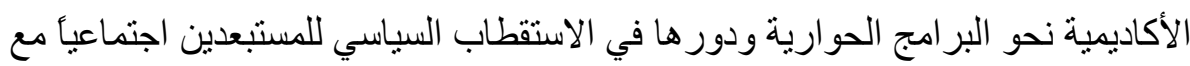

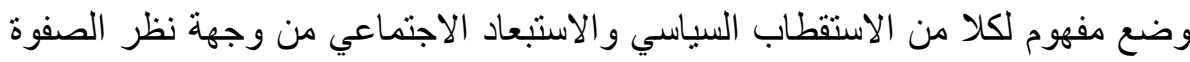

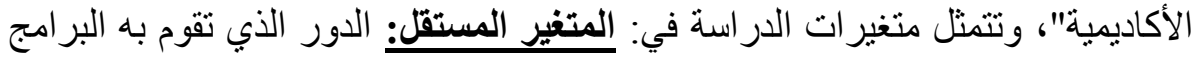

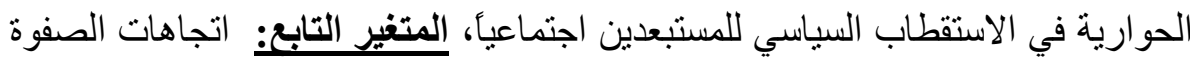

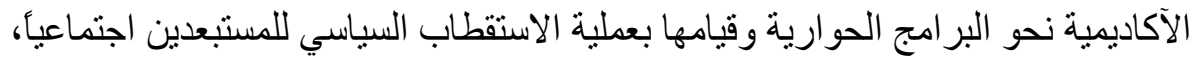

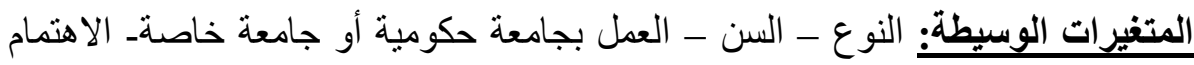

وتأتى أهمية هذه الاراسة من:-

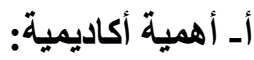

1 ـ ـتز امن تللك الدر اسة مع ما تشهده الساحة السياسية المصرية للعديد من الأحداث. r- تسعي نتائج هذه الدراسة إلي الوقوف علي نقطة كيفية التعامل الإعلامي مع الأحداث

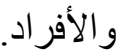
بـ يُعد نوقيت إجر اء الدراسة هو الأنسب والموصى به علمياً، لقياس تأثنير ات وسائل

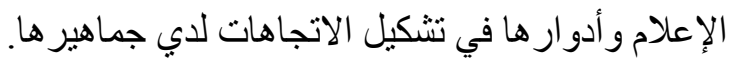

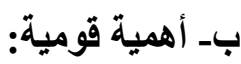
ا ـ أهمية الدور الذي تلعبه وسائل الإعلام على الساحة السياسية باعتبار ها مر آه للواقع

r- الدور الذي تسعي إلبه وسائل الإعلام من خلال إضفاء الثرعية أو القبول الاجتماعي

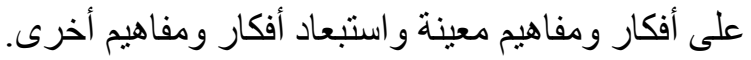

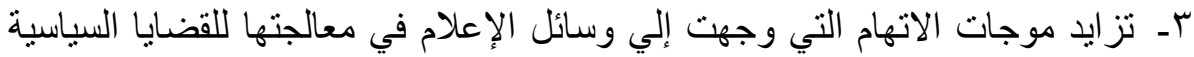
في مصر.

أهداف الاراسة: 1- إدر الك خصائص مشاهدة الصفوة الأكاديمية للبر امج الحوارية في الفضائيات المصرية

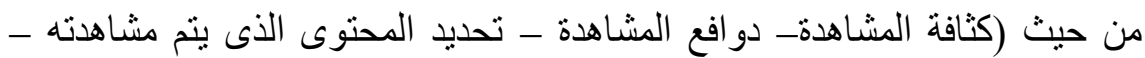

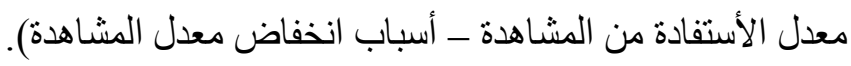
r- معرفة أهم البر امج الحوارية التي ينعرض لهاد الها الصفوة الأكاديمية. ب- التعرف علي الدور الذى تلعبه البرامج الحوارية فى الاستقطاب السياسي للمستبعدين اجتماعياً من وجهة نظر الاكاديميين.

ـ - وضع مفهوم للاستقطاب السياسي من وجهة نظر الصفوة الأكاديمية. 
ه- تحديد مفهوم الاستبعاد الاجتماعي من وجهة نظر الصفوة الأكاديمية.

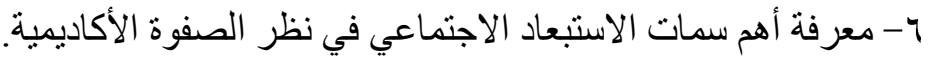

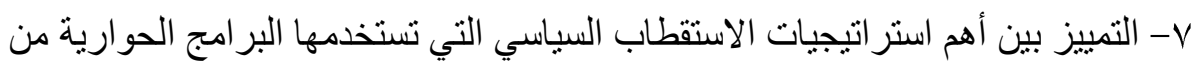

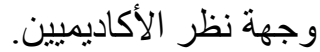

^- إدراك اتجاهات الأكاديميين نحو الاستقطاب السياسي من خلال البرامج الحوارية للمستبعدين اجتماعياً.

\section{الإطار النظرى: نظرية الثخص الثالث}

تعتمد الدر اسة الحالية في أساسها النظري وبناء فروضها على نظرية تأثثر الثخص الثالث

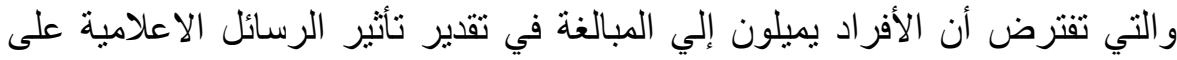

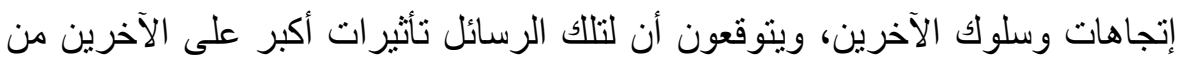

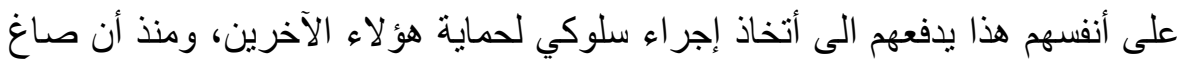
دافيسون Davison فروض نظرية تأثير الثخص الثالث قدمت مجموعة من الدراسات الثراء الثربن

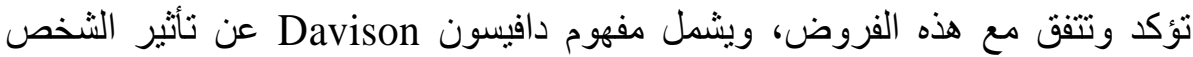

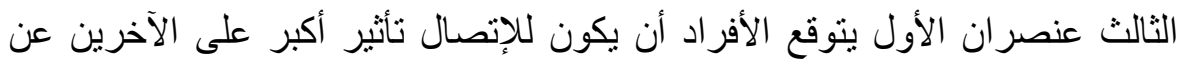

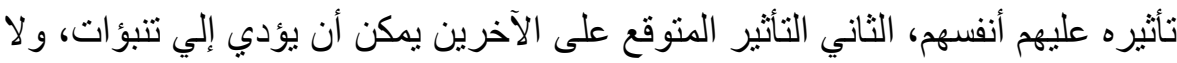
ترجع هذه التوقعات لتأثير ات الرسالة الإتصالية على الإتجاهات و السلوكيات إلي الرئي الرسائل

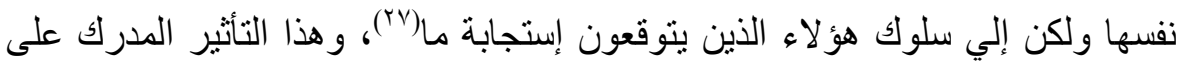

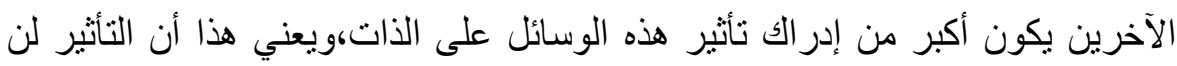

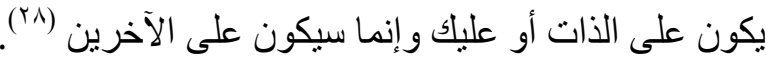

وأيدت الدر اسات فروض هذه النظرية وأن طبيعة مقارنة تأثر الذات بالآخرين ربما تكون هامة لحجم واتجاه إدر اك مدى نأثر الآخرين وخصوصا فئر فيما يتعلق بالمسافة الاجتماعية Distance Social

Perloff بيرلوف

\section{الأبعاد الاجنماعية في نظرية تأثر الثخص الثالث:}

وجد الباحثون أن لنظرية تأثير الثخص الثالث بعض الأبعاد الاجتماعية تتمثل فيما

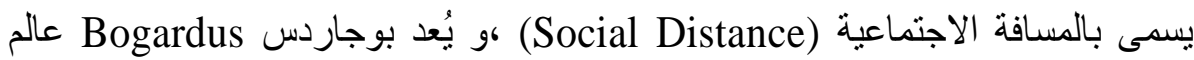
النفس أول من قدم فكرة المسافة الاجتماعية ب0 1901، والذي أكد علي أن الناس درجات

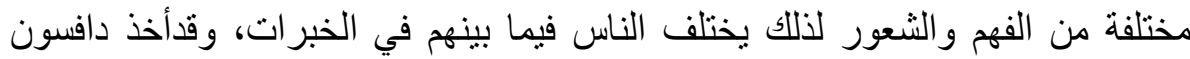

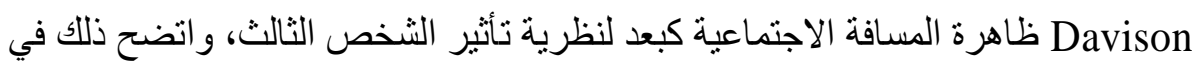

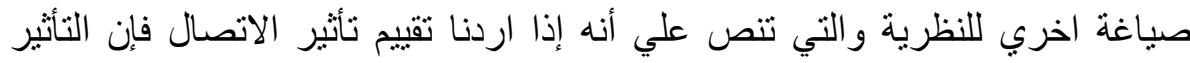


الأكبر لوسائل الإعلام لا يكون علي أنا، First Person not on me و لا عليك أنت" Second person not on you

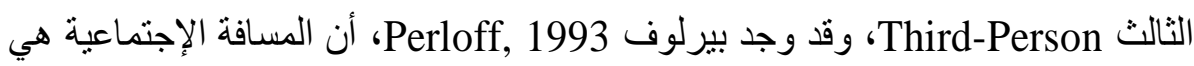

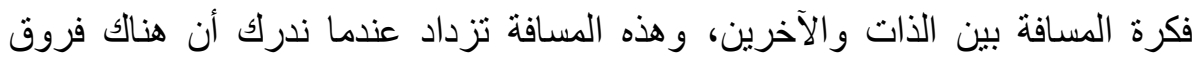

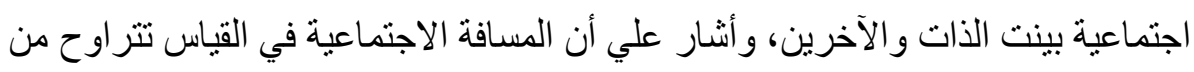
قول المبحوث Just Like me (بالضبط مثلي) إلي عبارة not at all (أبداً علي

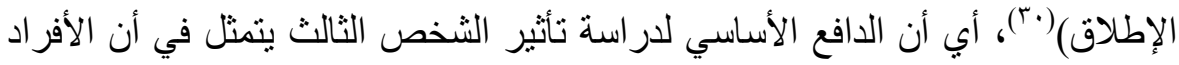

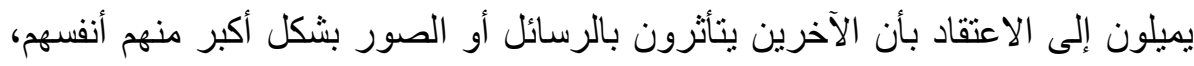

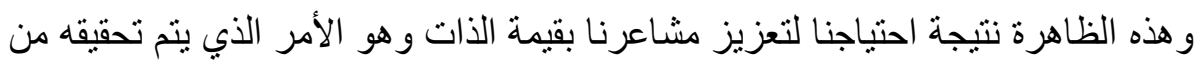

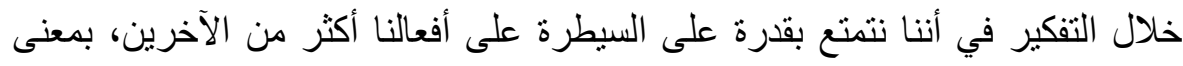

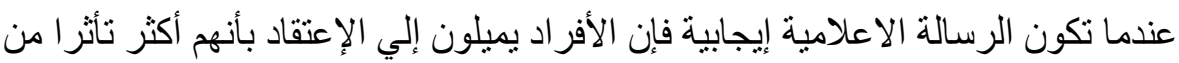

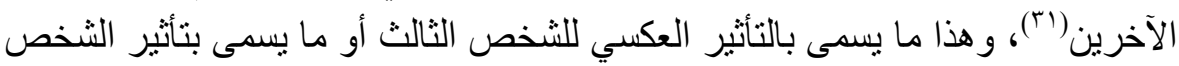

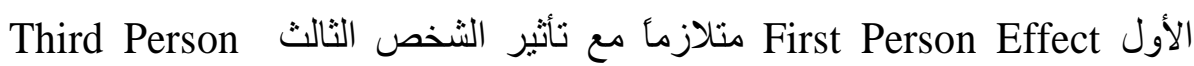
Effect

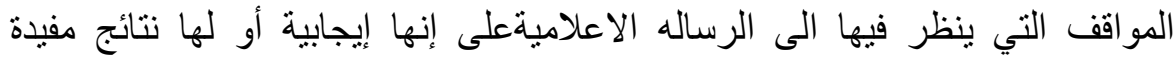

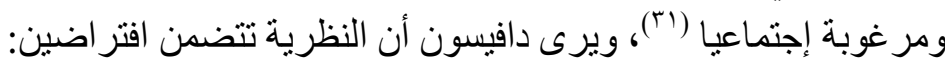

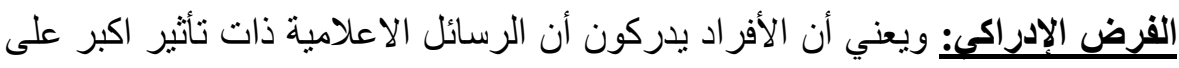

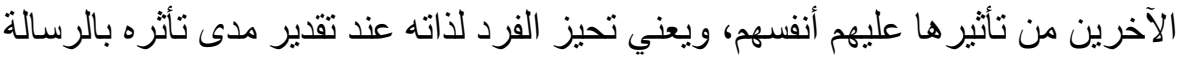

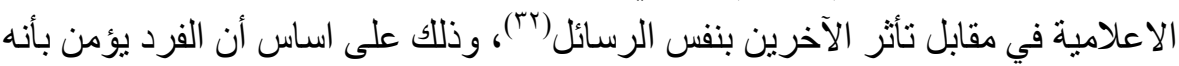

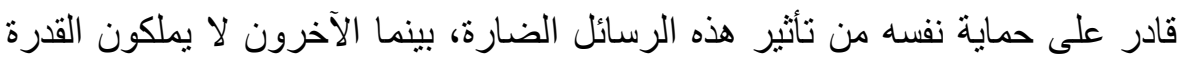

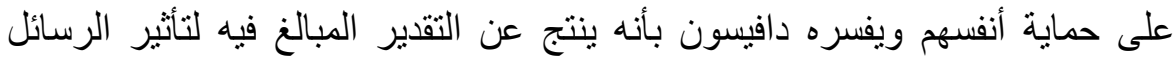

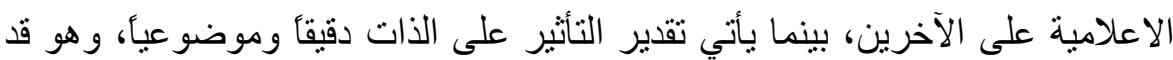

$$
\text { يحدث نتيجة لأحد هذه العو امل: }
$$

ـ ـ أما المبالغة في تقدير الرسالة على مدركات الآخرين. Overestimated

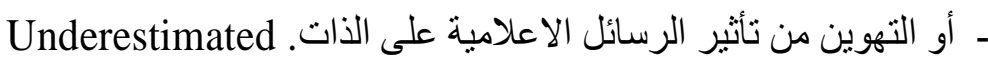

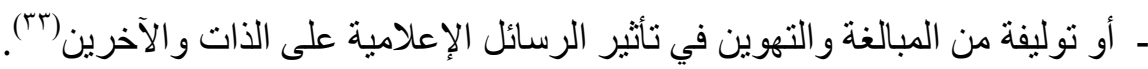

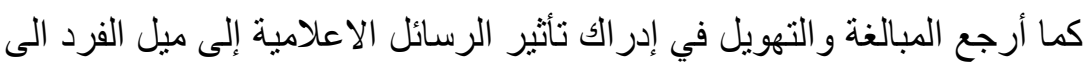

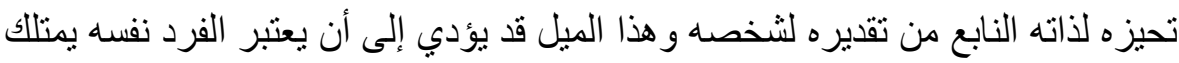

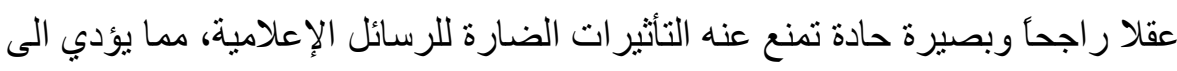

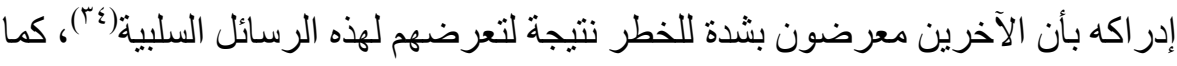


أنه يمكن تفسير الاستهانة بتأثير الرسائل الاعلامية على الذات أن الأفراد بصفة عامة

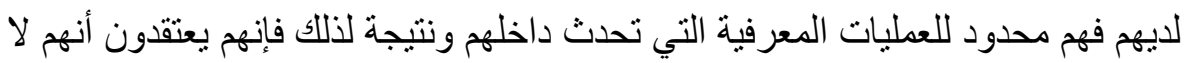
يتأثرون أبداً بالرسائل الإعلامية حتى و إن كانو ا يتأثرون بها في واقع الأمر (ب0)

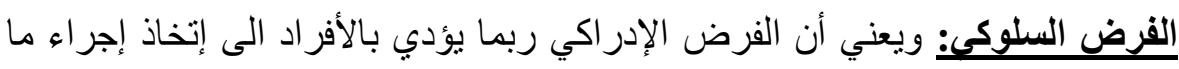

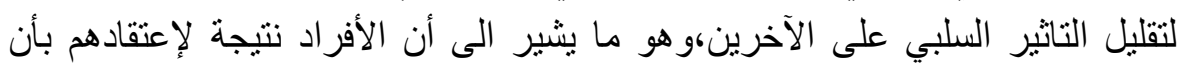

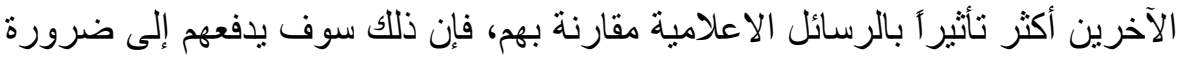

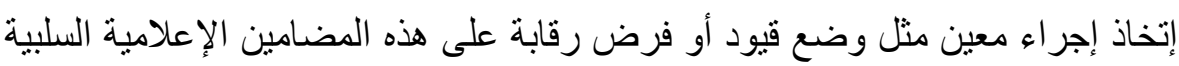

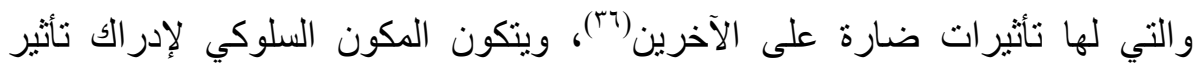

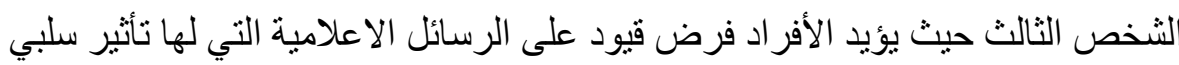
أو ضار، و إن تأييد فرض الرقابة يعتبر صورة و اضحة للتندل الاجتماعي الأبوي، لأنها

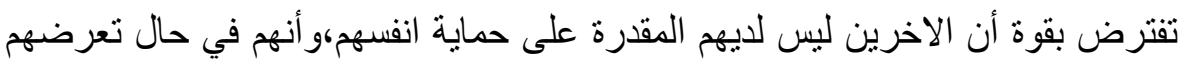

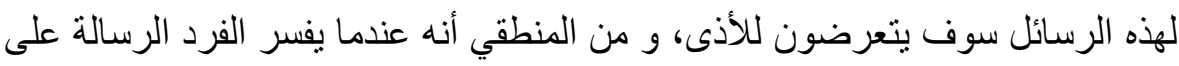

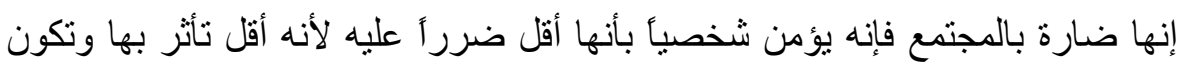

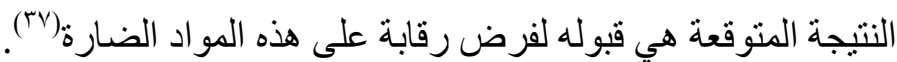

$$
\text { ويوجد تفسيرات لهذا الجانب السلوكي: }
$$

ـ ـ التفسير الأبوي أو ما أطلق عليه Paternalism explanation و الذي يصور الرقيب

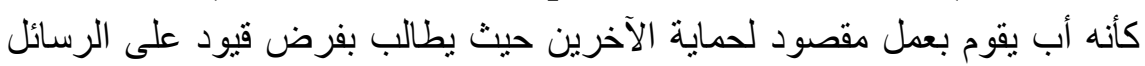

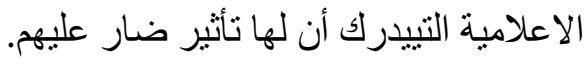

- التفسير القائم على الدافعية الوقائية Protection Motivated Theory - والتي تثير

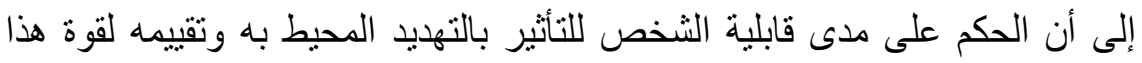

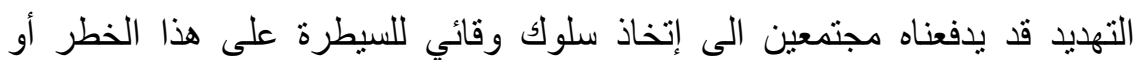

التهديد(^) مراحل حدوث تأثير الثخص الثالث: - يميل الأفراد إلى الاعتقاد بأن لايهم معلومات غير منو افرة لاى الآخرين، اعتقادآ منهم

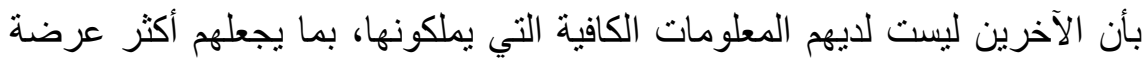
لتأثير الرسائلالاعلامية.

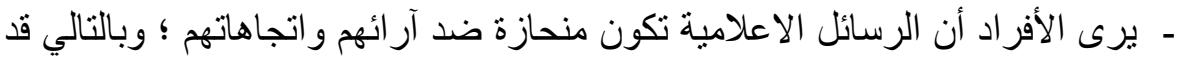

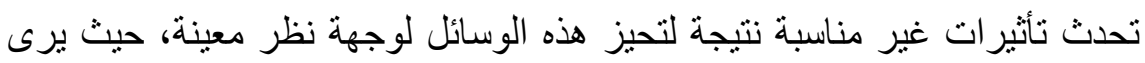


هؤلاء الأفر اد أنه من أجل تغطية منو ازنة يجب أن تعرض وسائل الإعلام وجهة النظر

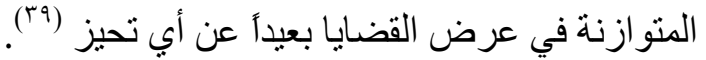

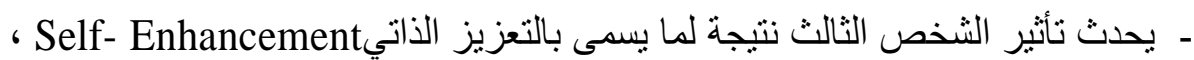

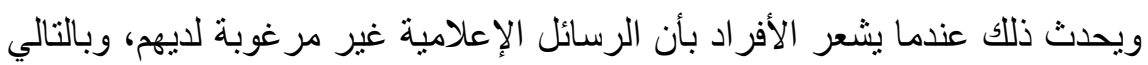

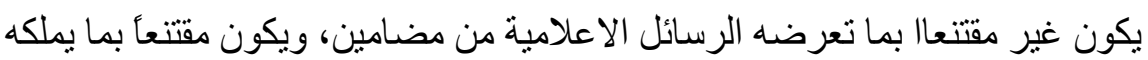

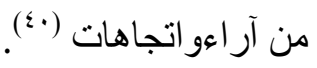

- يمتلك الآخرون فهما محدودآ من الأفكار و العمليات الإدر اكية، ومن ثم فهم أقل تأثر آل

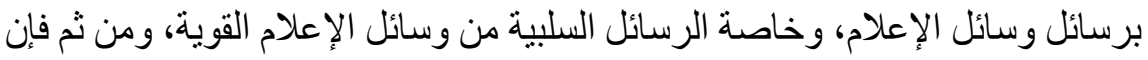

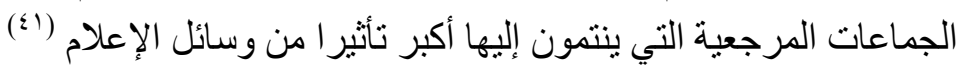
و هنالك مجموعة من العو امل والمتغيرات الوسيطة التي من شأنها أن تؤثر على فروض إنى نأثير الثخص الثالث ومن أهمها:

- إدراك الجمهور لتحبز مصدر الرسالة الإعلامية Perceived Source Bias بشكل سلبي أو غير أهل للتقة به

- موضوع الرسالة Massage Topic ويتز ايد تأثثرات الثخص الثالث حينما تتناول

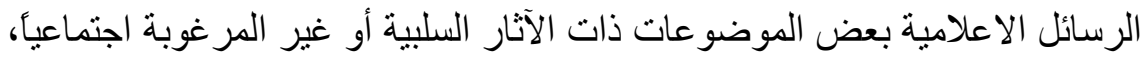

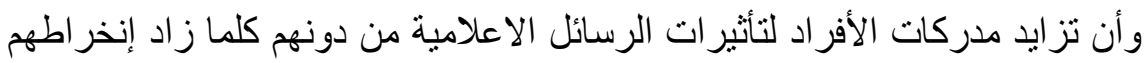
بموضوع الرسالة الاعلامية وز ادت أهميتها الذاتية بالنسبة لهم. - عو امل متعلقة بالمستقبل و هي مستوى الإستغر اق في القضية Involvement و العو امل الديموجر افية للجمهور Demographic Correlates و المسافة الاجتماعية Social

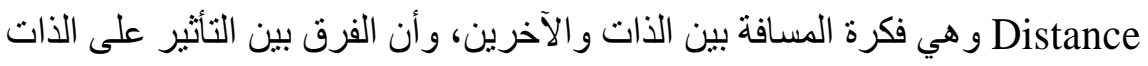

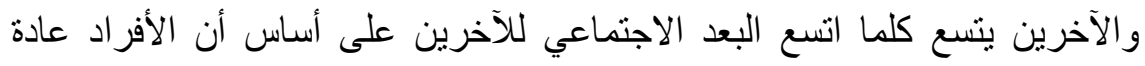

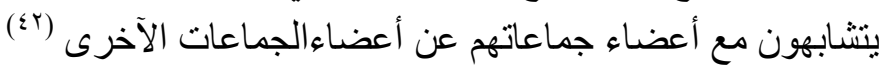

\section{الانتقادات الموجهه للنظرية :}

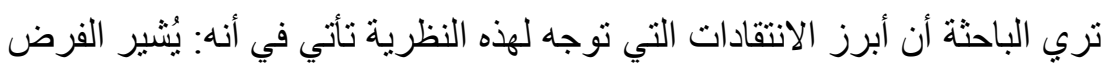

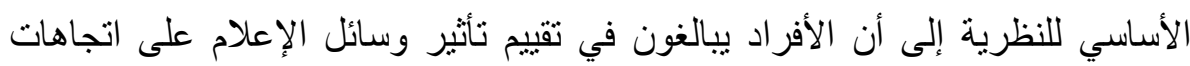

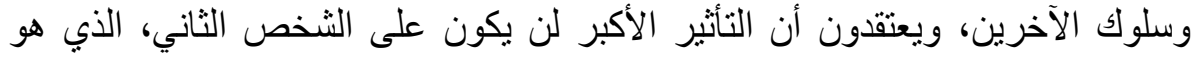

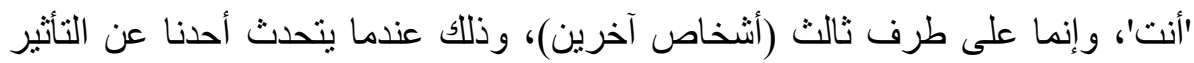

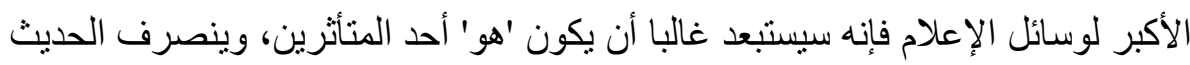

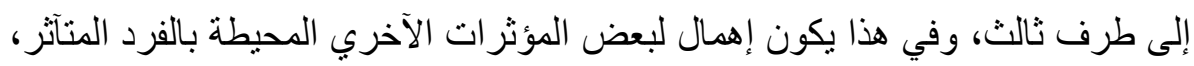


كذللك فهناك تعظيم للذات المفارقة ستكون مضاعفة عندما يتعلق التقييم بالصحافيين

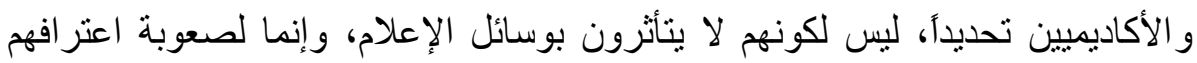
بذلك التأثر.

إن نظرية تأثثير الثخص الثالث لا تعتمد على القبول الاجتماعي، و إنما تعتمد على

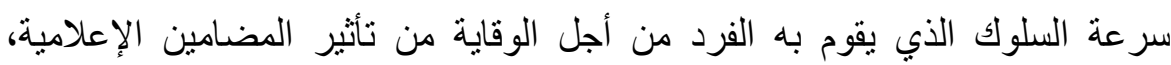

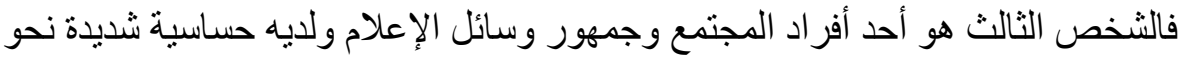

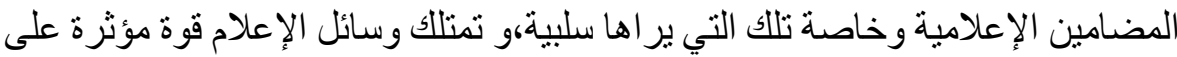

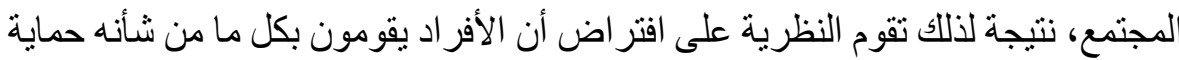
المجتمع من التأثثر ات الإعلامية السلبية كما ير اهنا.

وقد استفادت الاراسة من هذه النظرية في بناء الفروض الخاصة بها، ومحاولة

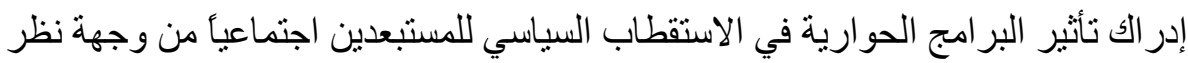

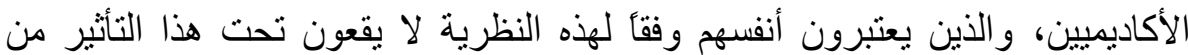

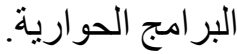
فروض الار اسة: الفرض الأول: نوجد علاقة ارتباطية ذات دلالة إحصائية بين اختبار الصفوة الأكاديمية

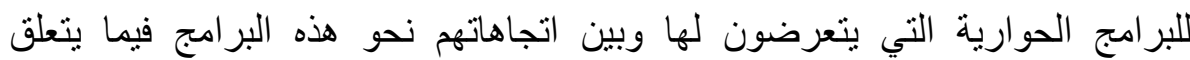
بالاستقطاب السياسي الفرض الثاني: توجد علاقة ارتباطية ذات دلالة إحصائية بين دوافع مشاهدة الصفوة

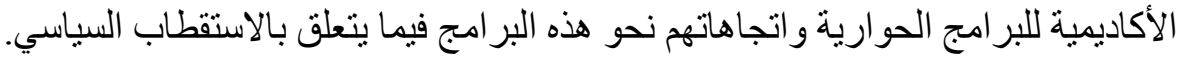
الفرض الثالث: توجد فروق ذات دلالة إحصائية بين مستوي ادراك الصفوة الأكاديمية

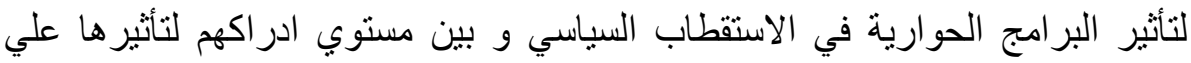
المستبعدين اجنماعياً. الفرض الرابع: توجد فروق ذات دلالة إحصائية بين مستوي ادراك الصفوة الأكاديمية

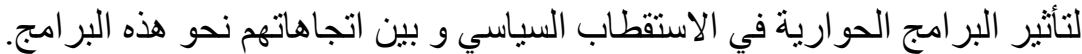
الفرض الخامس: توجد فروق ذات دلالة احصائية بين أفر اد عينة الدر اسة من الأكاديميين

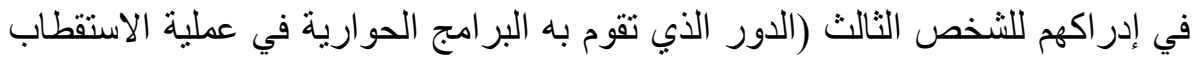
السياسي) باختلاف خصائصهم الديموجر افية (السن - النوع - الجامعة ـ الاهنهم الهام العام 


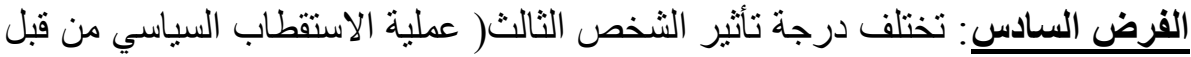

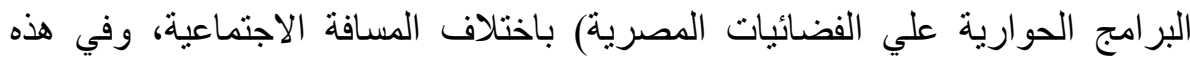
الدر اسة تبدأ المسافة الإجتماعية بالذات، ثم الأهل،ثم المستبعدين اجنماعياً

تساؤلات الاراسة:

1 ـ ماهى خصائص مشاهدة الصفوة الأكاديمية للبر امج الحوارية في الفضائيات المصرية

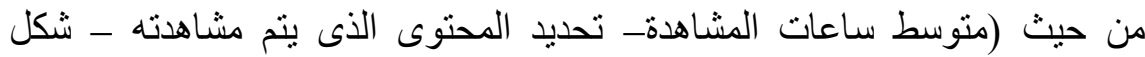

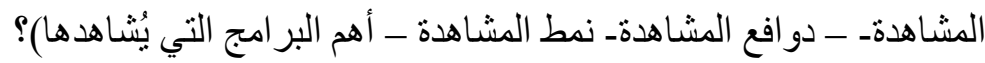

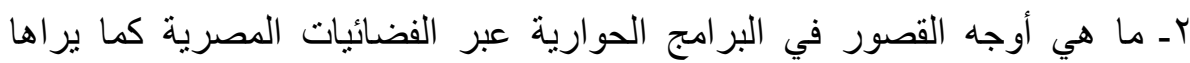

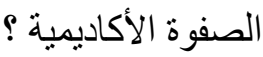

rـ ــ مفهوم الاستقطاب السياسي من وجهة نظر الصفوة الأكاديمية؟

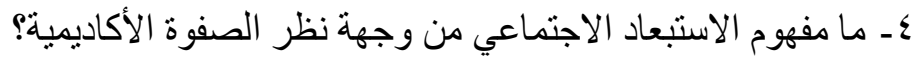

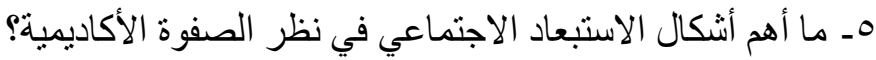
7- هل تقوم البرامج الحوارية فى الفضائيات المصرية بعملية الاستقطاب السياسي

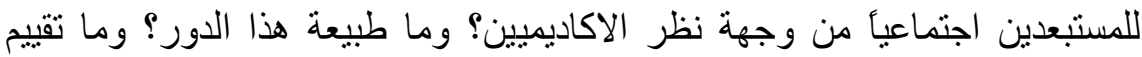

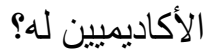

V- ما أهم استراتيجيات الاستقطاب السياسي التي تستخدمها بر امج الحوارية من وجهة نظر الأكاديمبين؟ ᄉـ ما اتجاهات الأكاديميين نحو الاستقطاب السياسي من خلال البرامج الحوارية

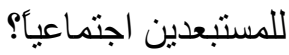

الإطار المنهجي:

نوع الدراسة: تعد هذه الدراسة من الدراسات الوصفية التى تهدف لوصف طبيعة وسمات

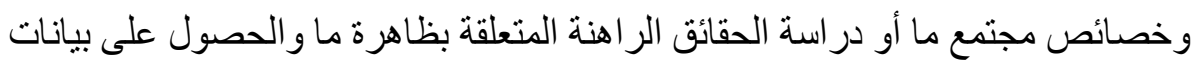

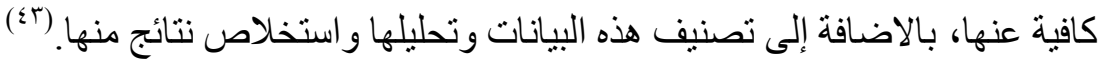
منهج الدراسة: اعتمدت هذه الدر اسة على منهج الدر اسات المسحية، وهي محاولة منظمة

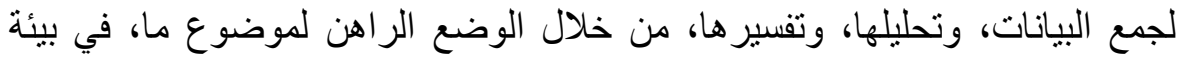

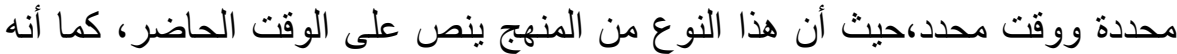
يهدف إلى الوصول للمعلومات، وتصنيفها، وتفسير ها، وتعميمها، حتى يمكن الاستفادة منا

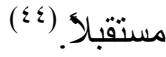
وسيتم ذلك من خلال:- مسح عينة من الصفوة الأكاديمية المصرية .

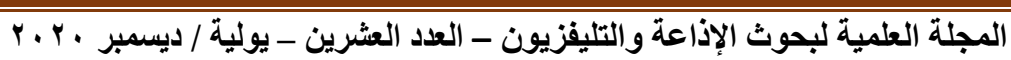


اعتمدت الدر اسة علي استمارة استبيان طبقت علي عينة من الصفوة الأكاديمية في جامعة حكو مية و اخري خاصة، وقد رُعي فيها الصدق و الثبات،يقصد بصدق الاستبيان أنه

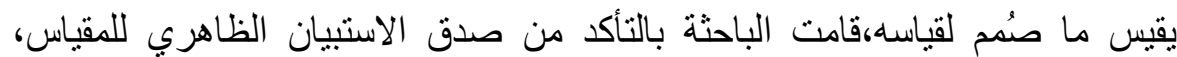

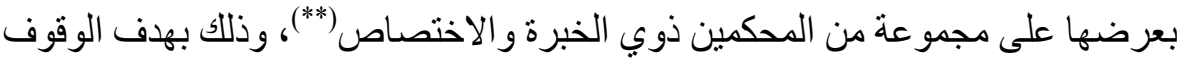

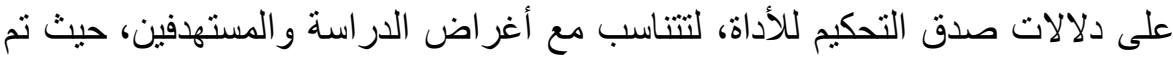

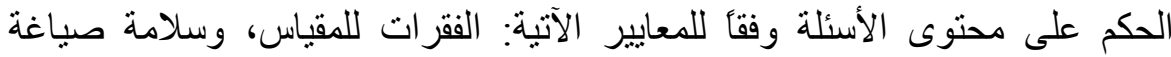
الفقزات، ومدى وضوح المعنى من الناحية اللغوية. المعالجة الإحصائية للبيانات:

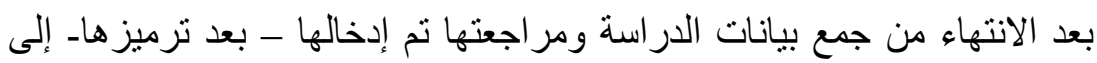

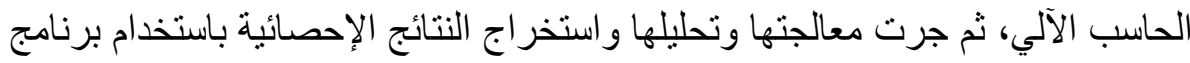

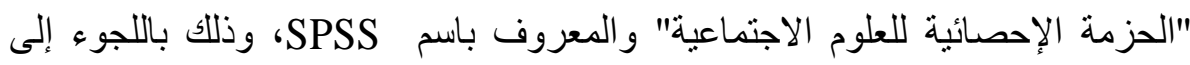
المعاملات و الاختبار ات و المعالجات الإحصائية التالية: ا ـ التكر ار ات البسيطة و النسب المئوية.

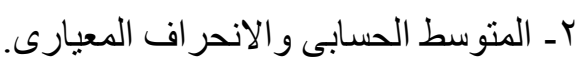

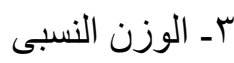
ع - اختبار كا' لجداول الاقتران (Cross Tables Chi Square Test) لدر اسة الدلالة

$$
\text { الإحصائية للعلاقة بين متغيرين. }
$$

هـ معامل التو افق (Contingency Coefficient) الذى يقيس شدة العلاقة بين متغيرين

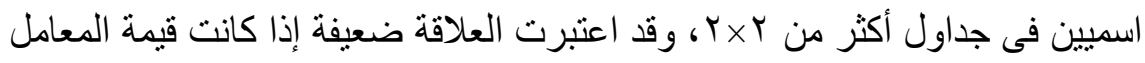

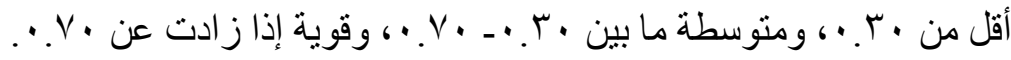

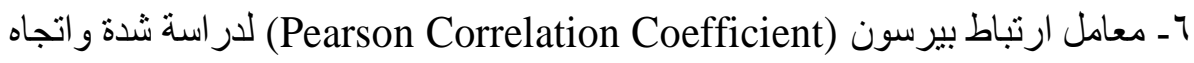
العلاقة الارتباطية بين متغيرين من مستوى المسافة أو النسبة، وقد اعتبرت العلاقة

$$
\begin{aligned}
& \text { ** أ.د حسن علي أستاذ الإذاعة و التلفزيون بجامعة السويس }
\end{aligned}
$$

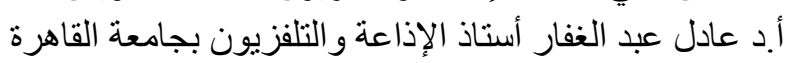

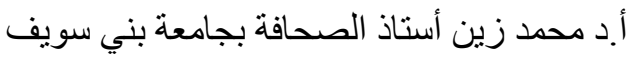

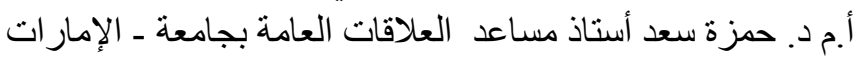

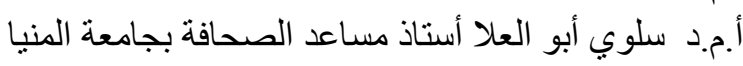

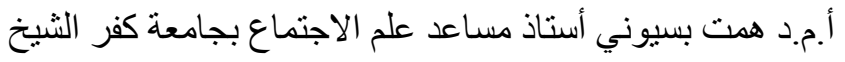




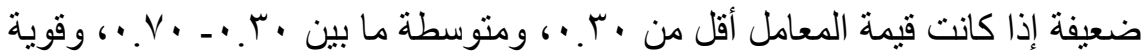

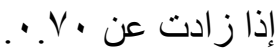

Vـ اختبار "T.test" للمجموعات المستقلة لقياس الدلالة الإحصائية للفروق بين متوسطين حسابيين لمجمو عتين من أفر اد العينة فى أحد المتغيرات.

وقد تم قبول نتائج الاختبارات الإحصائية عند درجة ثقة 90\% فأكثر ، أى عند مستوى

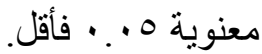

مجتمع الاراسة: الصفوة الأكاديمية المصرية . عينة الاراسة: تتمثل في عينة من الصفوة الأكاديمية بلغ قو امها ( . . ( ) عضو من أعضاء

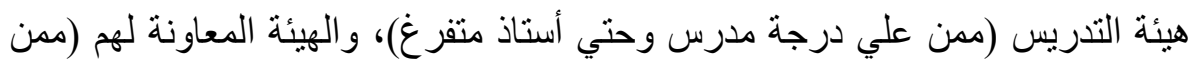

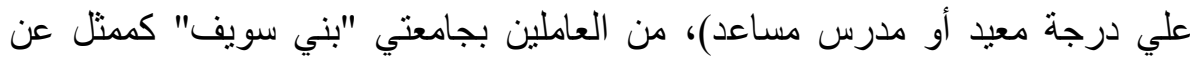
الجامعات الحكومية، وجامعة "النهضة" كممثل عن الجامعات الخاصة، وقد جاء نوزيع دريع

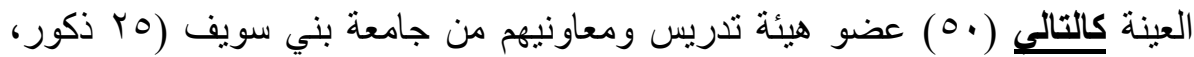

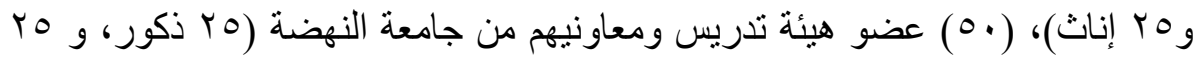

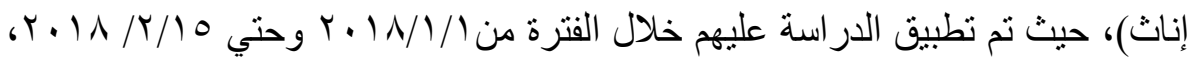
وكانت خصائص العينة كالتالي:

\section{1 - من حيث الفئة العمرية:}

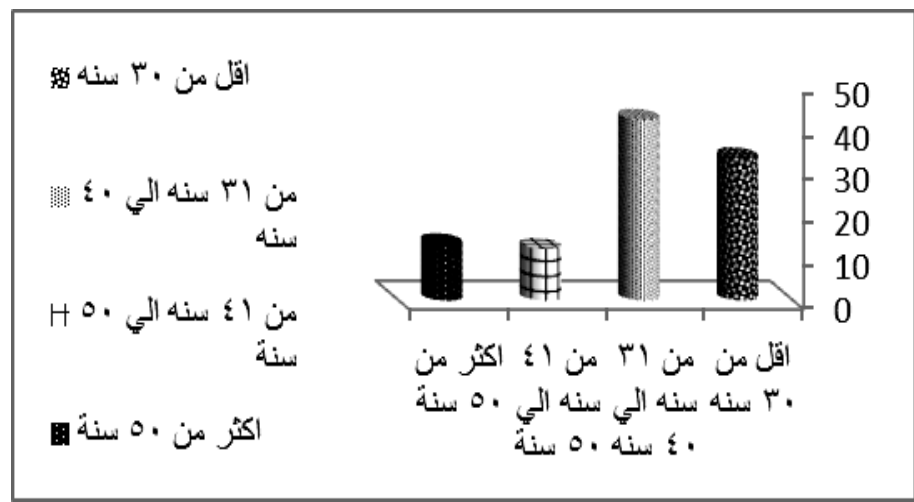

\section{شكل رقم (1) يوضح توزيع العينة من حيث الفئة العمرية}

يوضح الثكل السابق أن توزيع العينة من حيث الفئة العمرية جاء كالتالي : الفئة

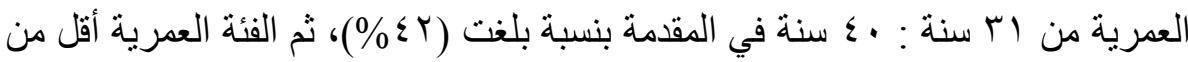

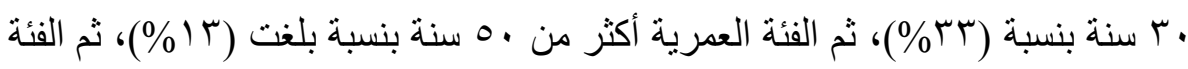

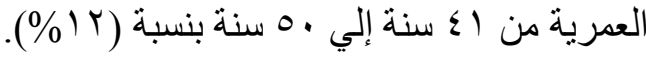




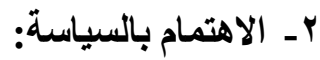

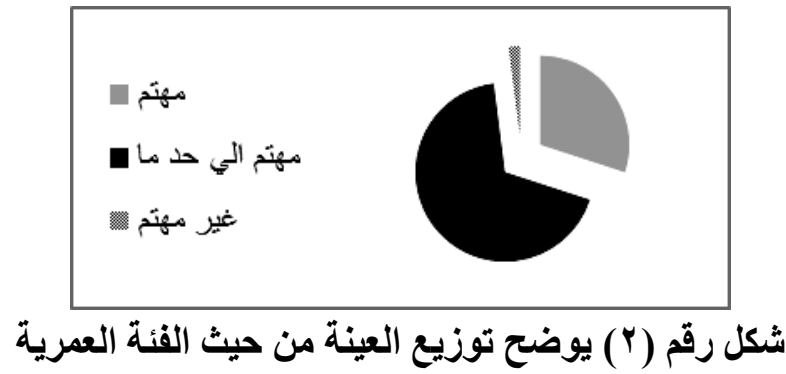

يشير الثكل السابق إلي أن توزيع العينة من حيث الاهتمام بالسياسة جاء كالتالي:

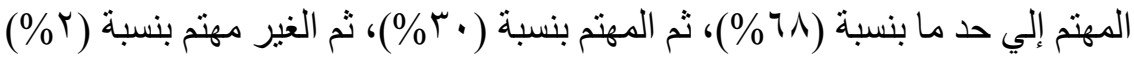
• تمثل كلا الجامعتين محل اختيار عينة الدراسة نوعان مختلفان من الملكية فيما بين

$$
\text { أسباب اختيار العينة: }
$$$$
\text { الخاص و الحكومي. }
$$

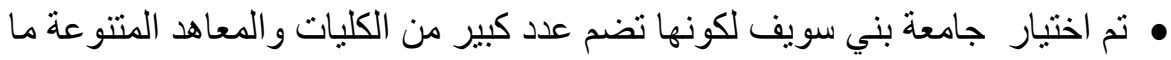

بين النظرية والعملية، كذلك وجودها في موقع وسطي بين الوجه البحري و الوجها

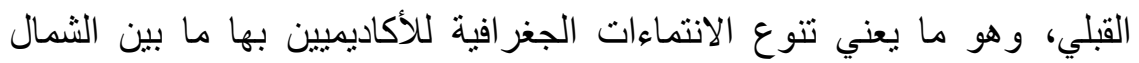

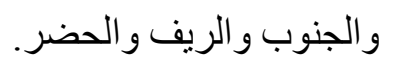

• جاء اختيار جامعة النهضة كممثل للجامعات الخاصة،وهي أول جامعة خاصة بمنطقة

$$
\text { الصعيد. }
$$

• تم تنويع العينة ما بين الذكور و الإناث لقياس فروق الاختلاف إن وجدت فيما بينهر

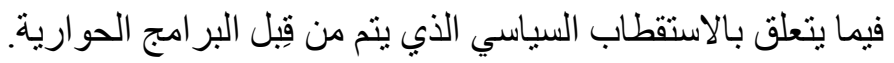

مفاهيم الاراسة:

الصفوة هي: جماعة من الأشخاص يشغلون مر اكز النفوذ والسيطرة فى مجتمع معين

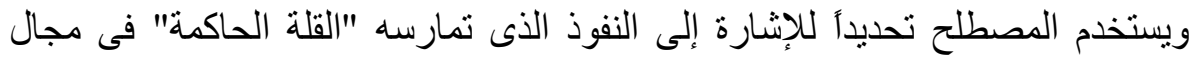

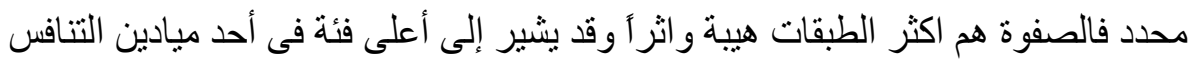
وتتألف الصفوة غالباً من أبرز المتفوقين بالقياس لغير هم ومن ثم يعتبرون قادة في ميدان فيدان

البرامج الحوارية: هي برامج تقوم علي قدرة الكلمات والأفكار المثارة علي اجتذاب المشاهد عبر الصورة التلفزيونية، والتي ليس لها أهمية بقدر الكلمات والأفكار المثارة

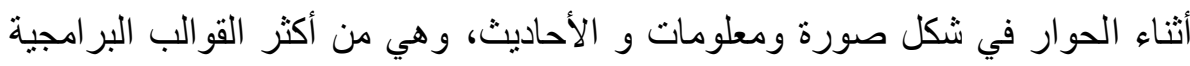

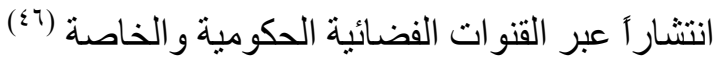




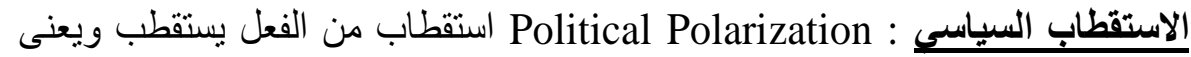

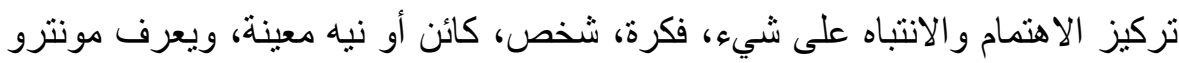
Montero (2003)

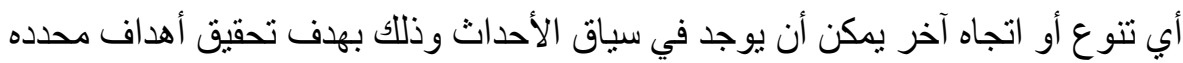

ويقصد بالاستقطاب إجرائياً: الطريقة التي تنتاول من خلالها البرامج الحوارية المقدمة عبر الفضائيات المصرية أحداث الإرهاب والقابثة القتل والاعتداءات والتدمير التي تشهدها الساحة السياسية المصرية، ومدى قيامها بتأصيل ثقافة الانقسام و الكر اهية بين فئات الشعب في معالجتها

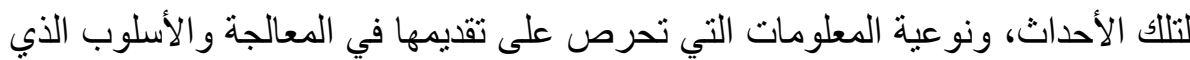
تقدم به الطرف الآخر في تللك الأحداث و الصفات التهات التي تتسبها إلبه.

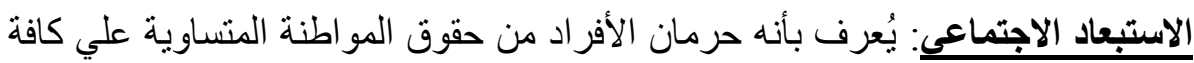

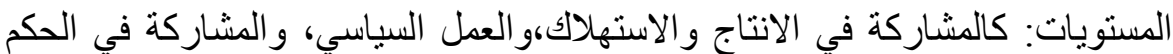

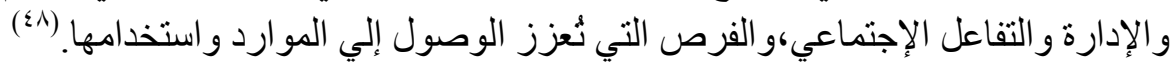

النتائج العامة:

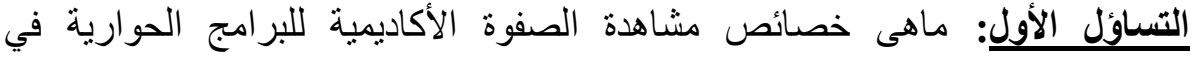
الفضائيات المصرية من حيث (منوسط ساعات المشاهدة- تحديد المحتوى الذئى يتم

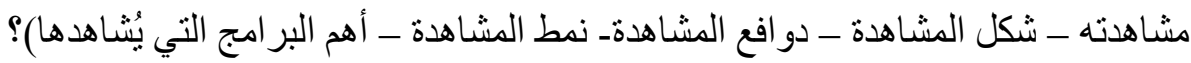

1- متوسط عدد ساعات المشاهدة :

جدول رقم ( ) يوضح متوسط ساعات مشاهدة الصفوة الأكاديمية للبرامج الحوارية عرلمات

الفضائيات المصرية

\begin{tabular}{|c|c|c|}
\hline$\%$ & ك & متوسط ساعات مشاهداتك البرامج الحوارية علي الفضائيات المصرية \\
\hline rq. & rq & أقل من ساعة. \\
\hline rr. & ז & حو الي ساعتين \\
\hline $1 \pi$. & 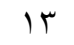 & أكثر من ثلاث ساعات \\
\hline ro. & ro & غير محدد \\
\hline $1 \cdots \cdot$ & $1 \ldots$ & الاجمالى \\
\hline
\end{tabular}

توضح بيانات الجدول رقم (1) أن معدلات مشاهدة الصفوة الأكاديمية للتلفزيون

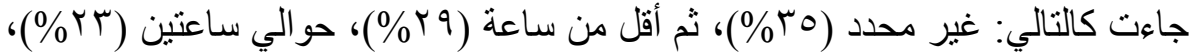

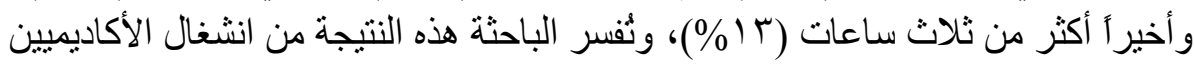

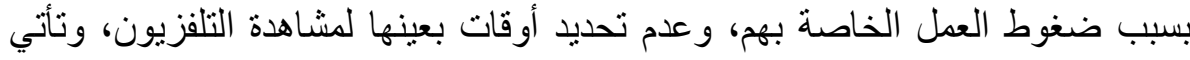




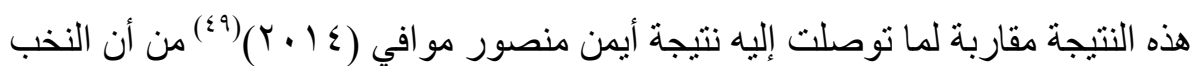

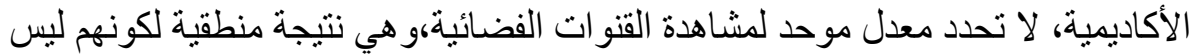

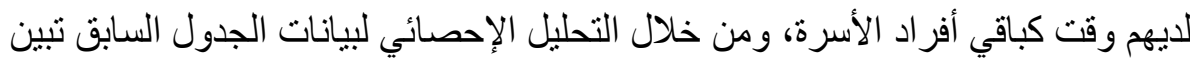

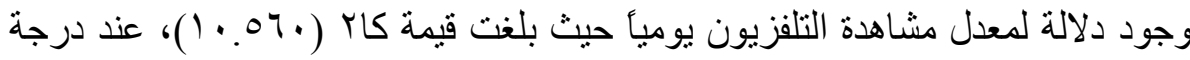

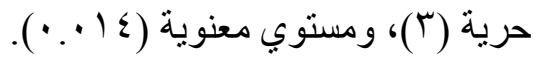

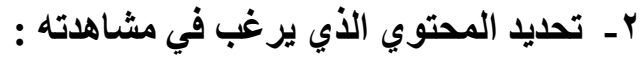

جدول رقم (ץ) يوضح تحديد الصفوة الأكاديمية للمحتوى مسبقاً قبل مشاهدة هذه البرامج؟

\begin{tabular}{|c|c|c|}
\hline$\%$ & ك & هل تحدد المحتوى الذي تريده مسبقًا قبل مشاهدة هذه البرامج \\
\hline$r \cdot$. & $r$. & نعم \\
\hline$\varepsilon V_{.}$ & $\varepsilon V$ & أحيانأ \\
\hline$r r$. & r & $y$ \\
\hline $1 \cdots \cdot$ & $1 \ldots$ & 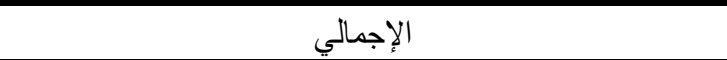 \\
\hline
\end{tabular}

تشير نتائج الجدول رقم (Y) إلي أن الصفوة الأكاديمية عند مشاهدتها للبرامج

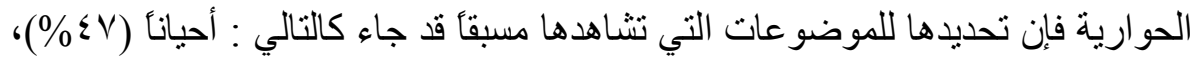

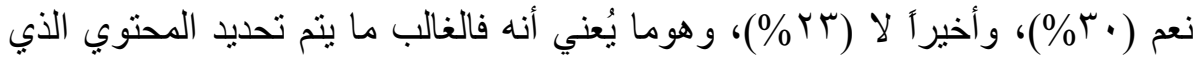

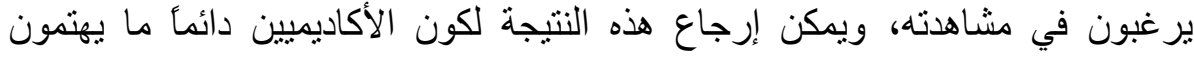

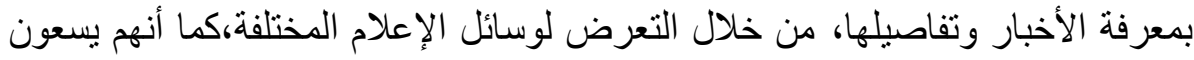

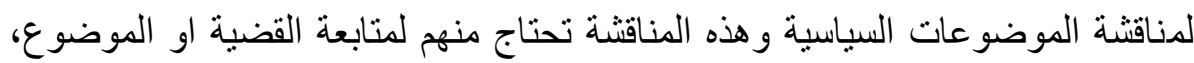

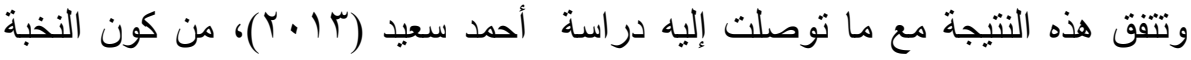

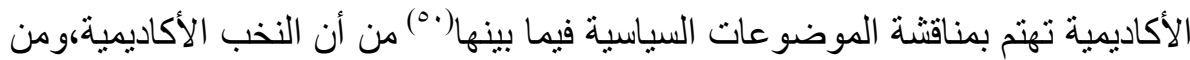

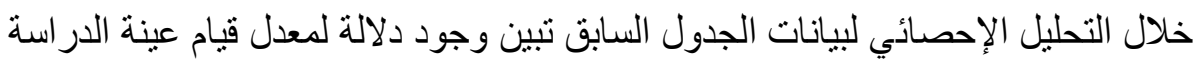

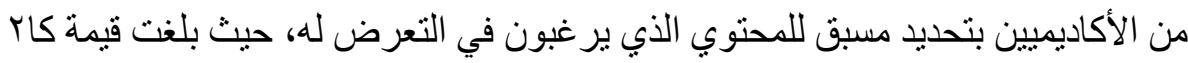

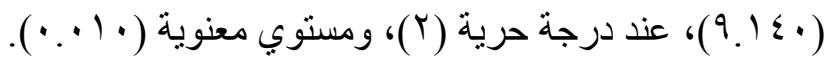

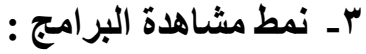

\begin{tabular}{|c|c|c|}
\hline$\%$ & ك & عندما تشاهد هذه البرامج: \\
\hline$\wedge$. & $\wedge$ & تشاهد ها كاملة \\
\hline ^. & $\wedge$ & تشاهد موضو عات معينة فيها \\
\hline$\wedge \varepsilon$. & $\Lambda \varepsilon$ & حسب الظروف \\
\hline $1 \cdots$ & $1 \cdots$ & الإجمالي \\
\hline
\end{tabular}

جدول رقم ("آ) يوضح نمط مشاهدة الصفوة الأكاديمية لبرامج الحوارية من حيث المشاهدة 
تظهر بيانات الجدول رقم (ب) أن نمط مشاهدة الصفوة الأكاديمية للتلفزيون جاءت كالتالي

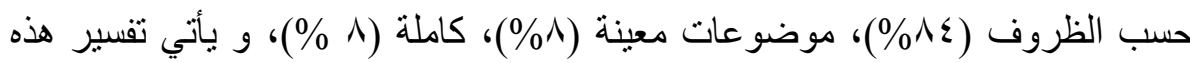

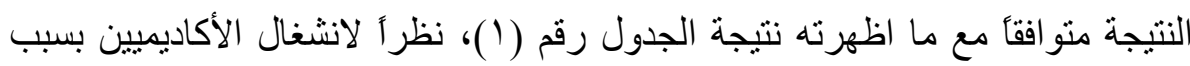

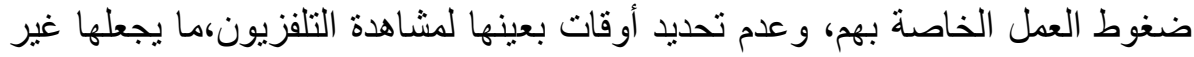

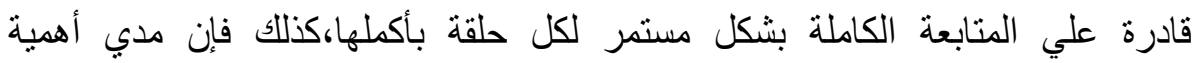
الموضوعات المعروضة قد تكون أحد أسباب منابعة الموضوع علئرة بعينها، ومن خلال التحليل

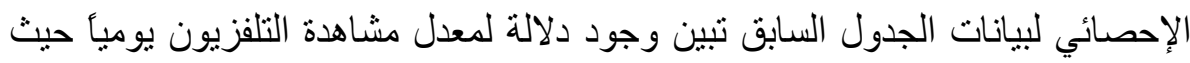

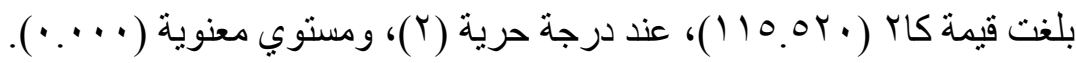
ع- دوافع مشاهدة البرامج الحوارية: (اهن:

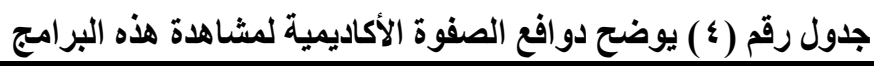

\begin{tabular}{|c|c|c|}
\hline$\%$ & ك & الدافع لمشاهدة هذه البرامج \\
\hline 0 & 0 & الجر أة في تناول الموضو عات \\
\hline ry & rt & الإلمام بخلفية الأحداث \\
\hline 1. & 1. & الإبهار و التشويق في عرض ملابسات الحدث \\
\hline 7 & 7 & التسلية وتقضية وقت فراغ \\
\hline r & r & لايها شبكة مر اسلين و اضحة مما يوفر لها المعلومات السهولة و السر عه \\
\hline 1. & 1. & استضافة ضيوف ذات صلة وثيقة بموضوع القضية \\
\hline$\varepsilon$ & $\varepsilon$ & تهنم بالتقارير و التحليل الإخباري و الصور الحية \\
\hline r & r & فورية في المتابعة \\
\hline $1 \varepsilon$ & $1 \leq$ & تقديم جميع وجهات النظر بموضو عية \\
\hline ry & rч & كل ماسبق \\
\hline \multicolumn{2}{|c|}{$1 \ldots$} & جملة من سئلوا \\
\hline
\end{tabular}

بينت نتائج الجدول رقم (ع) أن دو افع الصفوة الأكاديمية لمشاهدة البر امج الحوارية

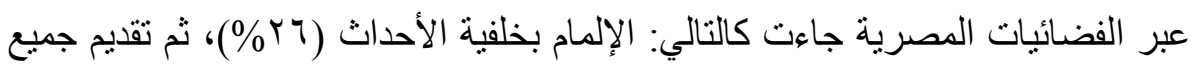

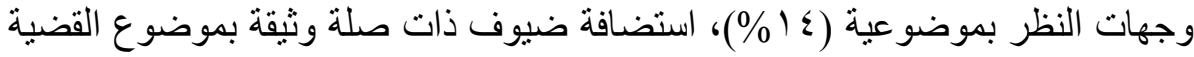

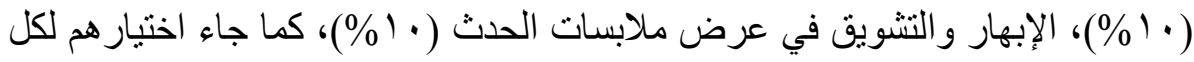

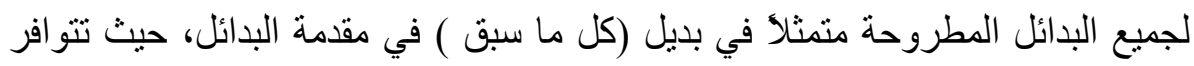

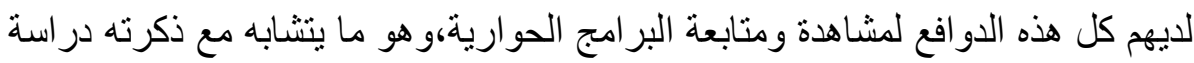

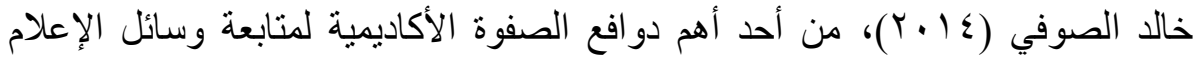

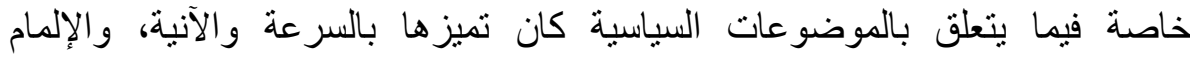

بالأحداث. (01) 


$$
\text { هـ - نوعية القضايا التي تفضل العينة متابعتها عبر البرامج الحوارية }
$$

جدول رقم (•) يوضح دوافع الصفوة الأكاديمية لمشاهدة هذه البرامج

\begin{tabular}{|c|c|c|}
\hline$\%$ & ك & نوعية القضايا التي تتناولها البرامج الحوارية \\
\hline TV & tr & سياسية خارجية \\
\hline r纟 & r६ & صحية \\
\hline 71 & 71 & سياسية داخلية \\
\hline rq & rq & اقتصادية اجتماعية \\
\hline$V \varepsilon$ & $V \varepsilon$ & دينية \\
\hline rt & rt & أمنية \\
\hline r & or & رياضية \\
\hline$\varepsilon$. & $\varepsilon$. & فنية ثقافية \\
\hline - & - & 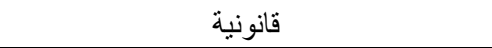 \\
\hline$V \varepsilon$ & $V \leqslant$ & علمية وبحثية \\
\hline r. & r. & تعليمية \\
\hline \multicolumn{2}{|c|}{$1 \ldots$} & جملة من سئلو ا \\
\hline
\end{tabular}

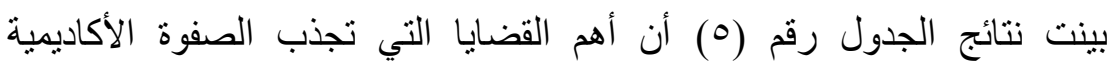
لمشاهدتها عبر البر امج الحوارية عبر الفضائيات المصرية جاءت كالتالي : نوعية القضايا

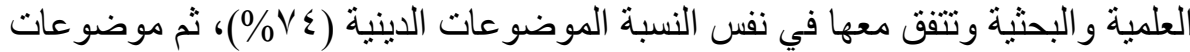

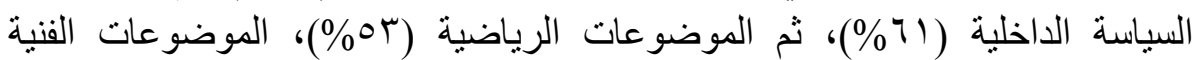

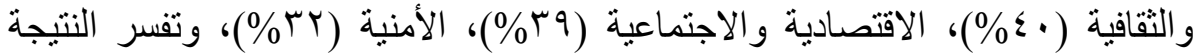

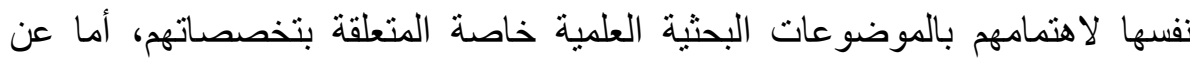

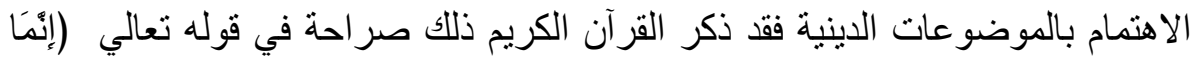

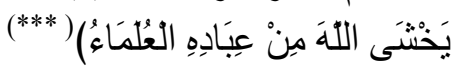

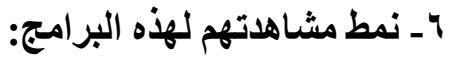

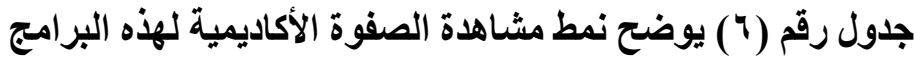

\begin{tabular}{|c|c|c|}
\hline$\%$ & 5 & مع من تثـاهد البرامج الحوارية بالقتوات الفضائية المصرية \\
\hline$\varepsilon$ & $\varepsilon$ & بمفردي \\
\hline ro & ro & 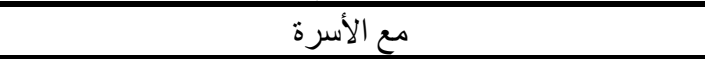 \\
\hline$\cdot$ & $\cdot$ & مع الاصدقاء \\
\hline 71 & 71 & حسب الظروف \\
\hline $1 \ldots$ & $1 \cdots$ & الاجمالي \\
\hline
\end{tabular}

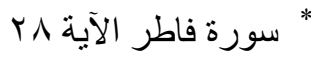


تظهر بيانات الجدول رقم (؟) أن نمط مشاهدة الصفوة الأكاديمية للتلفزيون جاءت

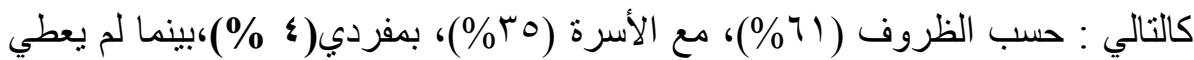

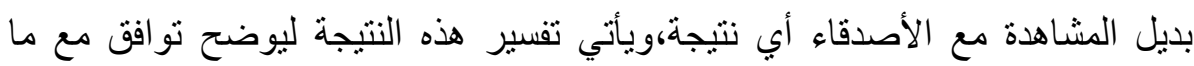

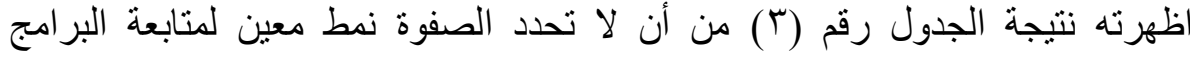
الحوارية، إلا أنها فالغالب ما تكون غير محددة، ومن خلال التهان التحليل الإحصائي لبيانات

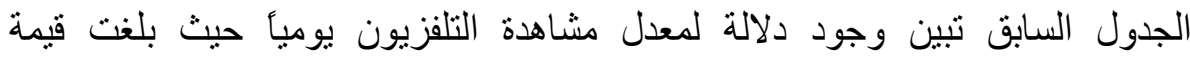

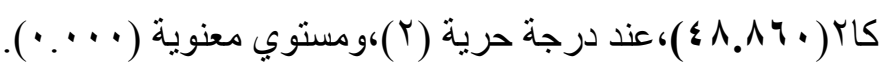

Vـ كانت أهم البر امج التي يفضل الصفوة الأكاديمية متابعتها خلال فترة الدر اسة كل يوم

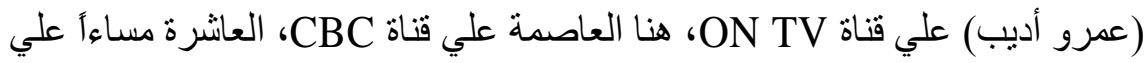

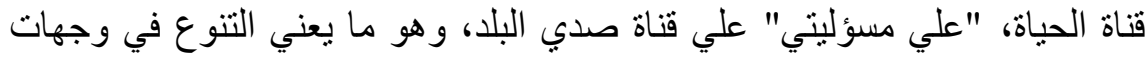

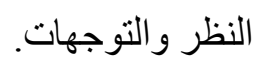

التساؤل الثانى: ما هي أوجه القصور في البرامج الحوارية عبر الفضائيات المصرية كما

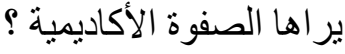

جدول رقم (V) يوضح أوجه القصور في البرامج الحوارية

\begin{tabular}{|c|c|c|}
\hline$\%$ & ك & أوجه القصور في البرامج الحوارية المعروضة على القتوات الفضائية المصرية من \\
\hline$\wedge$ & $\wedge$ & مناقثة بعض الموضو عات الحساسة بطريقة خادشه للحياء العام \\
\hline$\wedge$ & $\wedge$ & غياب حرية الر أي و الصر احة في مناقتشة بعض القضايا \\
\hline o & 0 & عدم الاستعانة باللقطات الحية و التقارير التي توضح موضوع النقاش في بعض البرامج \\
\hline rt & r & الحدة في الحوار والصر اخ و الانفعال بين الاطر اف المتحاورة في البرنامج \\
\hline$\varepsilon$. & $\varepsilon$. & كثرة المناقثات دون التوصل إلى نتائج أو حلول مفيدة \\
\hline 1 & $\wedge$ & الاستعانة بضيوف غير متخصصين في النقاش \\
\hline r) & r) & كثرة الفواصل الاعلانية التي تتخلل البرنامج فتتشت الانتباه \\
\hline ru & ru & إثارة المشكلة و عدم الاهتمام بمتابعة حلها مما بسبب حالة احباط للى المشاهدين \\
\hline 7 & 1 & كل ما سبق \\
\hline \multicolumn{2}{|c|}{$1 \ldots$} & حملة من سئله | \\
\hline
\end{tabular}

تشير نتائج الجدول رقم (V) إلي أن الصفوة الأكاديمية تحدد بعض جو انب القصور

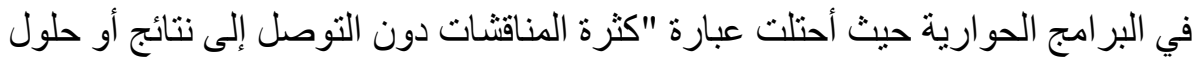

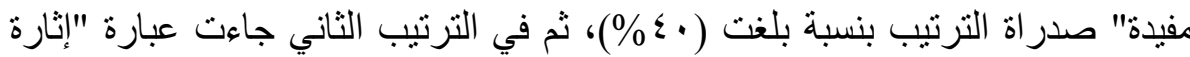

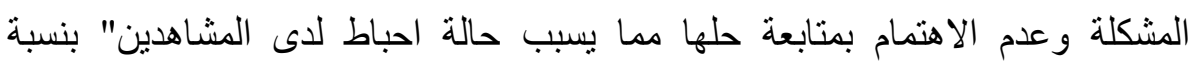




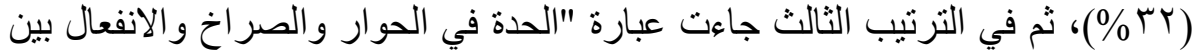

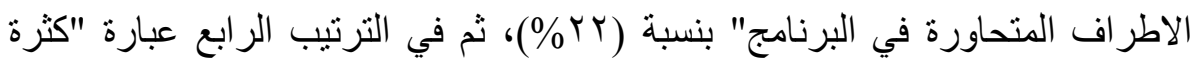

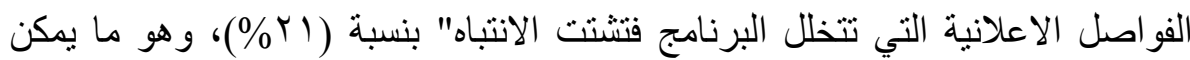
تبريره بوجود ثقافة مختلفة لدي أفراد العينة تجعلهم يبحثون عن حلول للموضوعات

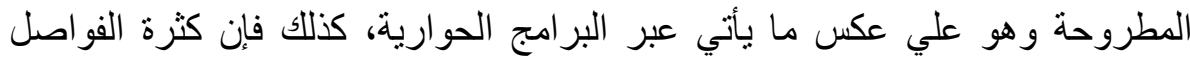

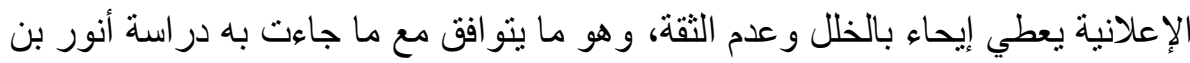

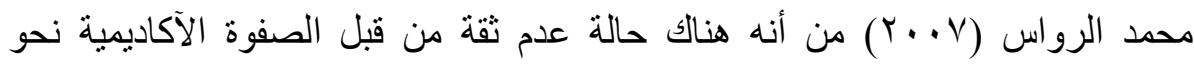
الموضوعات المقدمة عبر بر امج الر أي و الحوار ناتجة عن اعتمادهم علي رسائل إعلامية موجهة لفتر ات طويلة. (or)

التساؤل الثالث ما مفهوم الاستقطاب السياسي من وجهة نظر الصفوة الأكاديمية؟ عند سؤال المبحوثين من الأكاديميين عن مفهوم الاستقطاب السياسي من وجهة

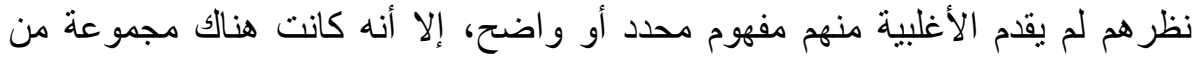

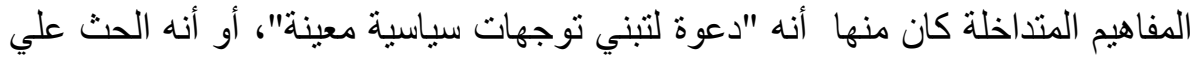

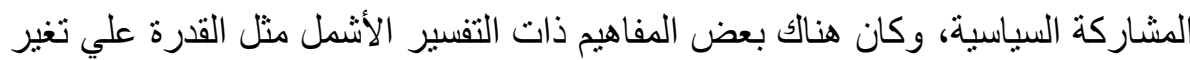

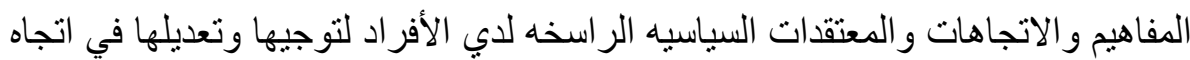

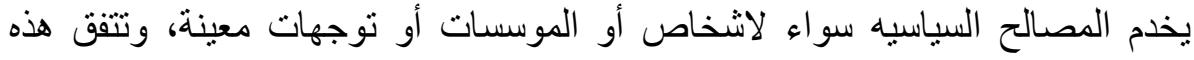

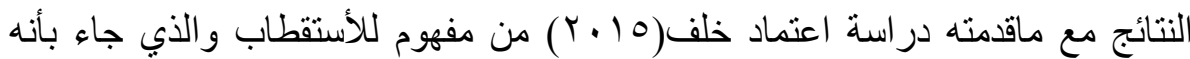

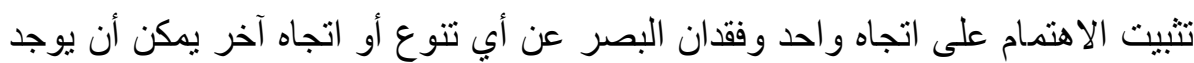
في سباق الأحداث وذللك بهدف تحقيق أهداف محدده سلفاً. (or)

التساؤل الر ابع: ما مفهوم الاستبعاد الاجتماعي من وجهة نظر الصفوة الأكاديمية؟ جدول رقم (^) يوضح مفهوم الاستبعاد الاجتماعي من وجهة نظر الصفاعة الصفوة الأكاديمية

\begin{tabular}{|c|c|c|}
\hline$\%$ & ك & مفهوم الاستبعاد الاجتماعي \\
\hline$\leqslant V$ & $\leqslant V$ & و الاجتماعية والسياسية لبعضئ المجتمع و عدم القدرة علي المشاركة بفاعلية في الحياة الاقتصادية \\
\hline 9 & 9 & مجمو عة من العوامل التي تحول الفرد دون المشاركة في الحياة المجتمعية \\
\hline r^ & r^ & والحرمان أو الاقصاء من المشاركة أوتهميش دور فئة مجتمعية في الحراك السياسي \\
\hline rT & r & هو مجمو عة من المشكلات و المعوقات التي تتر اكم وتفرز شخصأ غير مندمج في مجتمعه \\
\hline$\varepsilon$ & $\varepsilon$ & السعي نحو عزل الاقليات التي لا يفضلها الذي يقوم بذللك \\
\hline \multicolumn{2}{|c|}{$1 \ldots$} & جملة من سئلو ا \\
\hline
\end{tabular}


وفقً لبيانات الجدول رقم (^) نجد أنه جاء تعريف الصفوة الأكاديمية لمفهوم

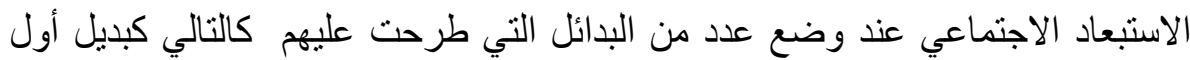

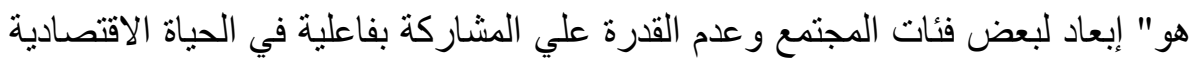

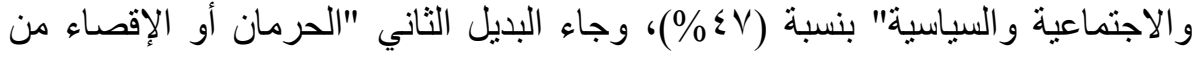

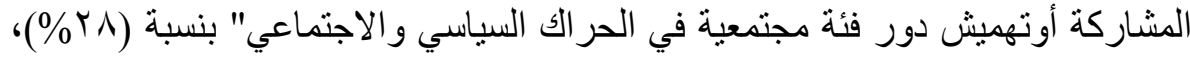

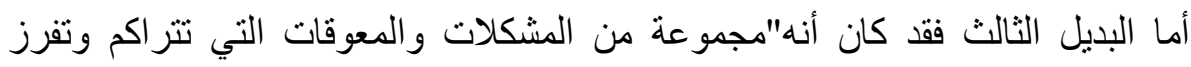

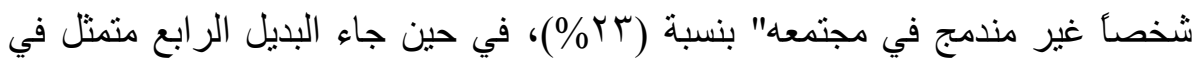
كونه"مجموعة من العوامل التي تحول الفرد دون المشاركة في الحياة المجتمعية" وذلك الك الكي بنسبة (9\%)، ويتفق ذللك مع ما قدمه محمد الجوهري في ترجمته لكتاب جون هيلز

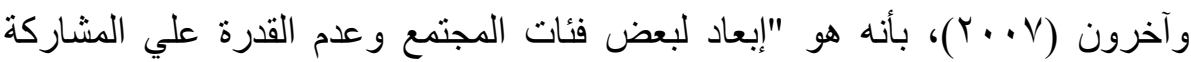

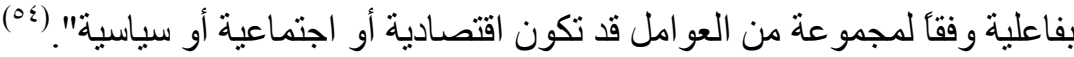
التساؤل الخامس: ما أهم أنكال الاستبعاد الاجتماعي التي ربما يعاني منها بعض الأفراد

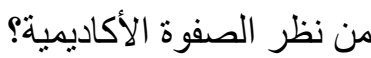

جدول رقم (9) يوضح أثكال الاستبعاد الاجتماعي من وجهة نظر الصفوة الأكاديمية

\begin{tabular}{|c|c|c|}
\hline$\%$ & ك & أشكال الاستبعاد الاجتماعي \\
\hline TV & TV & التهميش الإجتماعي \\
\hline 19 & 19 & الحرمان المادي \\
\hline r & r & الأستبعاد علي أساس العرق أو الجنس \\
\hline$\varepsilon$. & $\varepsilon$. & الاستبعاد من الأسرة والمجتمع \\
\hline rV & TV & الاستبعاد من المشاركة السياسية \\
\hline $1 \varepsilon$ & $1 \varepsilon$ & الاستبعاد الإر ادي \\
\hline IV & IV & الاستبعاد اللاار ادي \\
\hline ro & ro & الاستبعاد من سوق العمل و الحياة الأقتصادية \\
\hline \multicolumn{2}{|c|}{$1 \ldots$} & جملة من سئلو \\
\hline
\end{tabular}

عند النظر لبيانات الجدول رقم (9) نجد أن الصفوة الأكاديمية قد حددت مجموعة من الأشكال للاستبعاد الاجتماعي من وجهة نظرهم جاءت مرتبة في المرتبة الأولي

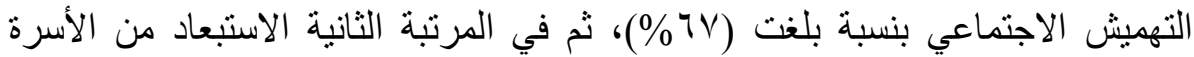

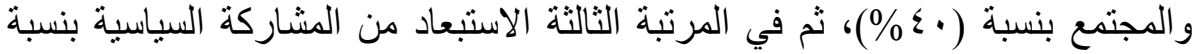

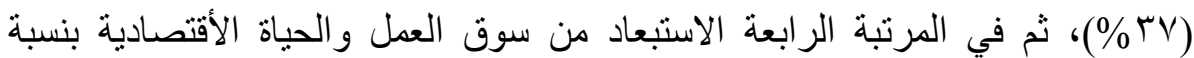

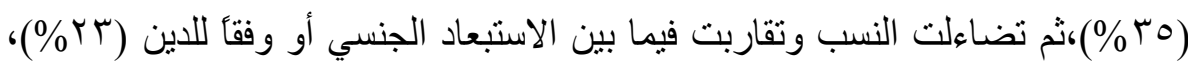
الحرمان المادي (9 (\%)، و الاستبعاد اللار ادي، وتنسب الباحثة هذه النتيجة إلي المرجعية ولنية 
الثقافية التي يعتمد عليها الصفوة الأكاديمية في نظرتهم للموضوعات خاصة الإجتماعية

التساؤل السادس: هل تقوم البرامج الحوارية فى الفضائيات المصرية بعملية الاستقطاب

السياسي للمستبعدين اجنماعياً من وجهة نظر الاكاديميين؟

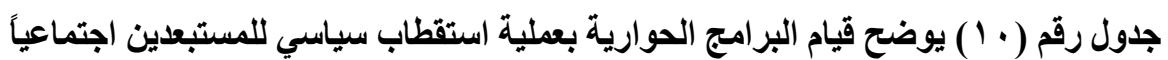

\begin{tabular}{|c|c|c|}
\hline$\%$ & ك & 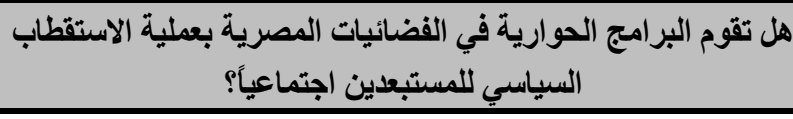 \\
\hline r. & r. & نعم \\
\hline 0. & 0. & أحيانأ \\
\hline r. & $r$. & $y$ \\
\hline $1 \ldots$ & $1 \ldots$ & الإجمالي \\
\hline
\end{tabular}

تظهر بيانات الجدول رقم (• (1) أن رأي عينة الدراسة من الأكاديميين عن عملية

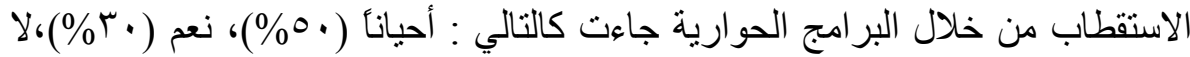

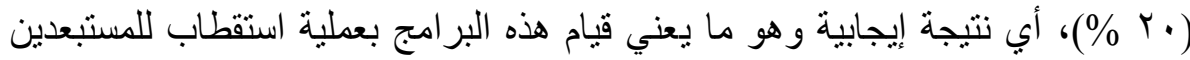

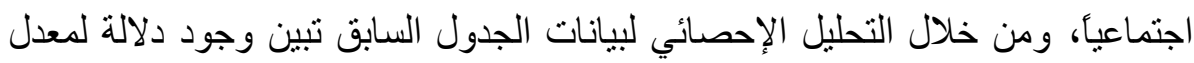

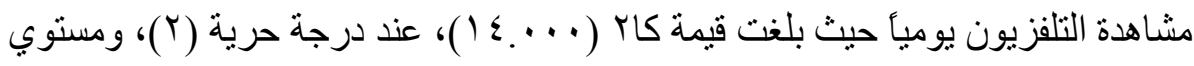

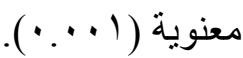

جدول رقم (1 1 ) يوضح طبيعة الدور الأي تقوم به البرامج الحوارية في الاستقطاب السياسي للمستبعدين اجتماعياً

\begin{tabular}{|c|c|c|}
\hline$\%$ & ك & طبيعة الدور الذي تقوم به البرامج الحوارية في الاستقطاب السياسي للمستبعدين اجتماعياً \\
\hline 01 & 01 & قوي \\
\hline$\mu$. & $r$. & متوسط \\
\hline 19 & 19 & ضعيف \\
\hline $1 \ldots$ & $1 \ldots$ & 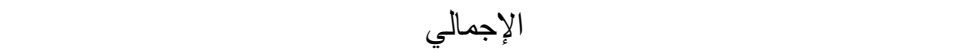 \\
\hline
\end{tabular}

وقد كان هذا الدور قوي حيث جاء (قوي) في المقدمة بنسبة (1\%)، (1\%)، تلاه منوسط بنسبة (•r\%)، ثم ضعيف بنسبة (9 (\%)، وهي علاقة دالة، حيث بلغت قيمة كاب

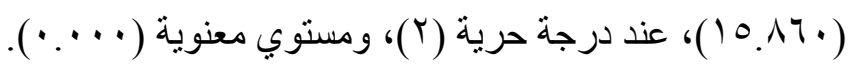

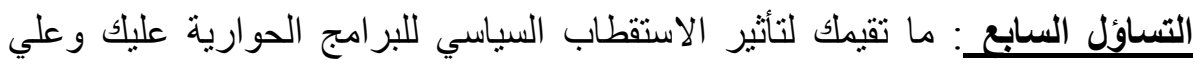

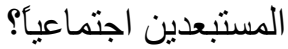




\begin{tabular}{|c|c|c|}
\hline \multicolumn{3}{|c|}{ جدول رقم (Y I) يوضح تأثثير الاستقطاب السياسي للبرامج الحوارية } \\
\hline$\%$ & كs & الاستقطاب العياسي للبرامج الحوارية \\
\hline 19 & 19 & اكثر تأثير أ أعلي من تأثثبر ها علي المستبعدين اجتماعياً \\
\hline or & or & أكثر تأثثير ها علي المستبعدين اجتماعيأ من تأثثيرها علية \\
\hline rA & rᄉ & يتساوي تأثثير ها علي المستبعدين اجتماعياً \\
\hline $1 \ldots$ & $1 \ldots$ & الإجمالى \\
\hline
\end{tabular}

تثنير نتائج الجدول رقم (Y I ) إلي أن رؤية المبحوثين من عينة الدراسة لتأثيرات

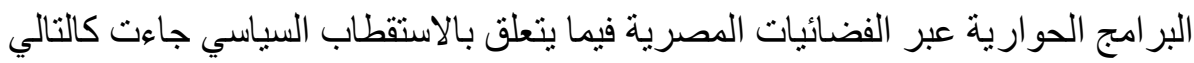
جاء بديل التأثير الأكثر علي المستبعدين في المرتبة الأولي بنسبة (به\%)، ثم تساوي

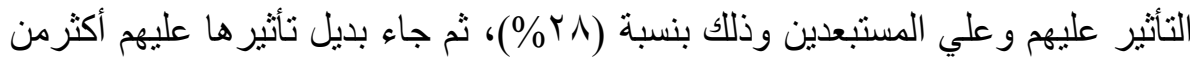

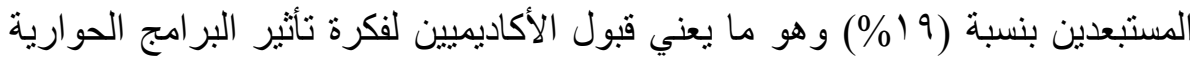

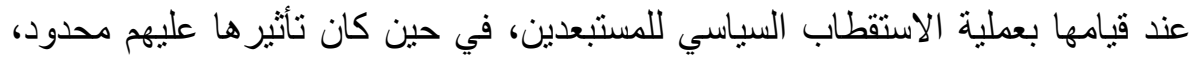

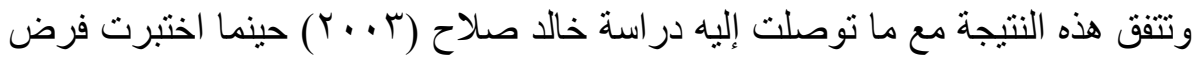

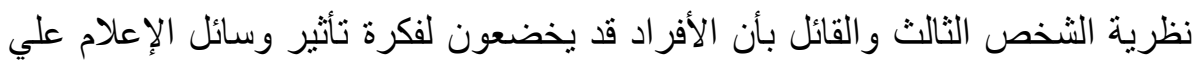

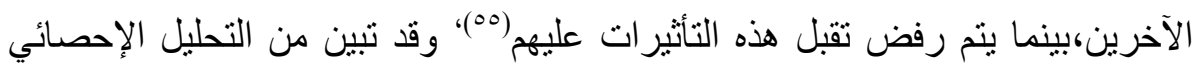

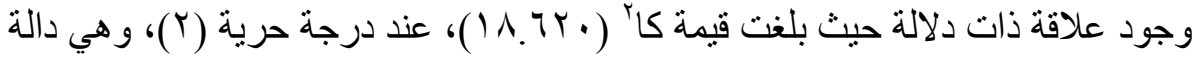

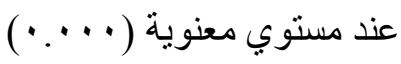

التساؤل الثامن :ما هي أهم استراتيجيات الاستقطاب السياسي التي تستخدمها برامج

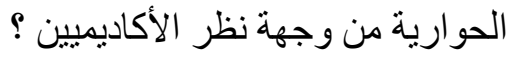

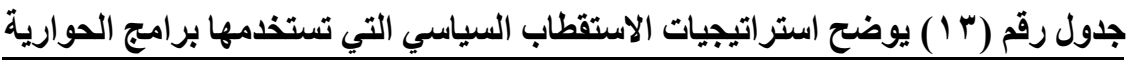

\begin{tabular}{|c|c|c|}
\hline$\%$ & ك & أهم استراتيجيات الاستقطاب السياسي التي تستخدمها برامج الحوارية من وجهة نظر \\
\hline זr & Tr & التخويف و التزرهيب \\
\hline rq & rT & عرض الحقائق \\
\hline Tr & Tr & عرض وجهات النظر \\
\hline 19 & 19 & التهريد \\
\hline$T \varepsilon$ & $T \varepsilon$ & التعبئة و الحشد \\
\hline 11 & 11 & الخوف من الآخر \\
\hline Y & ץ & تتاول قضايا الفقراء \\
\hline$r \varepsilon$ & $r \varepsilon$ & التضخيم \\
\hline ro & ro & التهويل \\
\hline \multicolumn{2}{|c|}{1.} & جملة من سئلوا \\
\hline
\end{tabular}


وفقاً لبيانات الجدول (r ا) نجد أن أبرز استر اتيجيات الاستقطاب السياسي التي تم

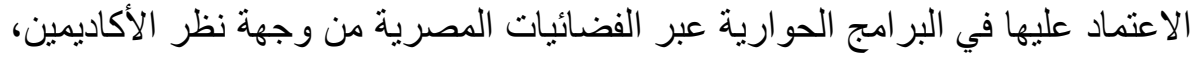

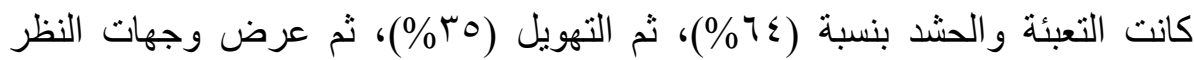
و التخويف و الترهيب (rr\%)، ثم تناول قضايا الفقراء وعرض الحقائق (דr\%)؛ ثم

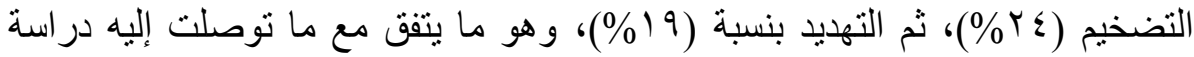

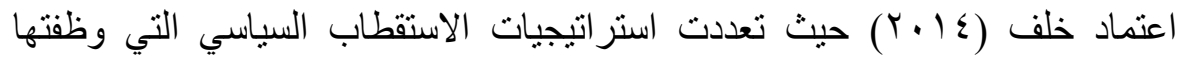

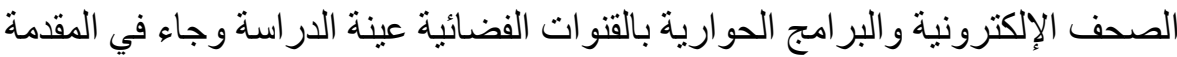

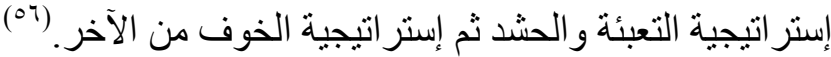
التساؤل التاسع:من فضلك أعطي تقيمك لما يأتي: تأثير الاستقطاب السياسي للبرامجة جدول رقم ( 1 ) يوضح تأثير الاستقطاب السياسي للبرامج الحوارية

\begin{tabular}{|c|c|c|c|c|c|c|c|c|c|c|c|c|c|}
\hline \multirow{2}{*}{ النسبي } & \multirow{2}{*}{ المعياري } & \multirow[t]{2}{*}{ المتوسط } & \multicolumn{2}{|c|}{ سلبي جدا } & \multicolumn{2}{|c|}{ سلبي } & \multicolumn{2}{|c|}{ لا تأثير } & \multicolumn{2}{|c|}{ ايجابي } & \multicolumn{2}{|c|}{ ايجابي } & \multirow[t]{2}{*}{ العبارات } \\
\hline & & & $\%$ & ك & $\%$ & ك & $\%$ & ك & $\%$ & ك & $\%$ & ك & \\
\hline$\leqslant \leqslant . \wedge$ & 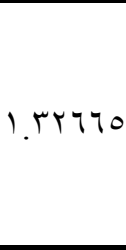 & $r . r \leqslant \ldots$ & $\varepsilon v$ & $\sum V$ & 1. & 1. & 11 & 11 & Yr & rr & r & $r$ & تأثنير الاستقطاب \\
\hline$q \Psi . V$ & $\cdot \vee \wedge \wedge \leqslant \neg$ & r.A $\ldots$ & r & r & צד & M & \& & $\varepsilon 1$ & r) & r) & . & · & تأثير الاستقطاب السباسي \\
\hline א.ד"ו & $1.1 \cdot 11 \varepsilon$ & $\varepsilon .9 .$. & . & . & IT & IT & $r$. & r. & 10 & 10 & or & Or & التأثير الاستقطاب اللباسي \\
\hline
\end{tabular}

تظهر نتائج جدول رقم (ع ا) أنه عند قياس تأثنبر الاستقطاب السياسي للبرامج

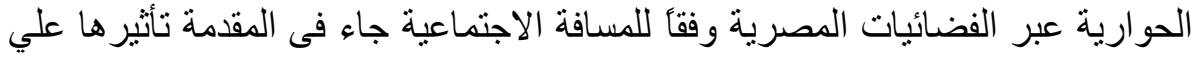

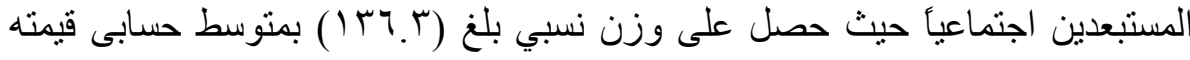

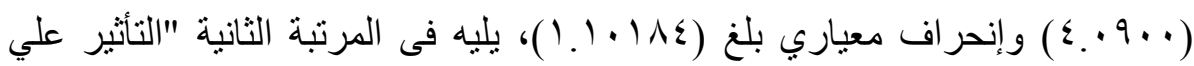

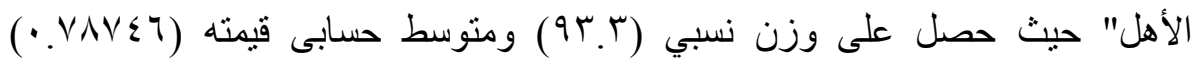




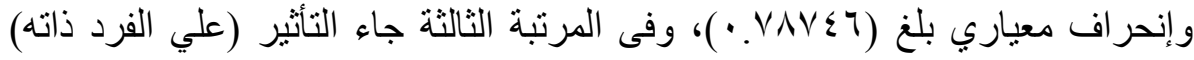

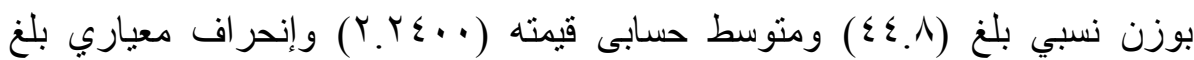

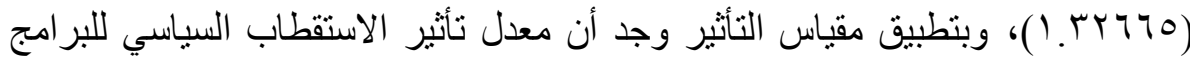

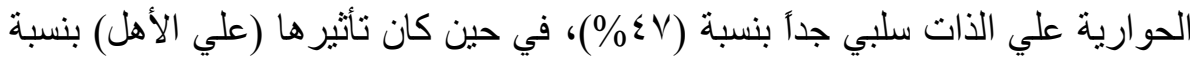
(1\%)؛ بينما كان تأثثرها علي المستبعدين اجتماعياً ايجابي جداً بنسبة بلغت

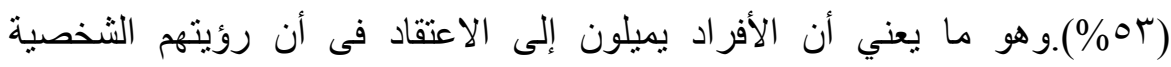

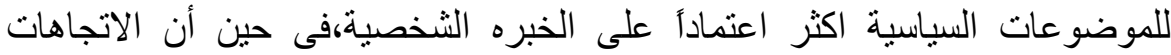

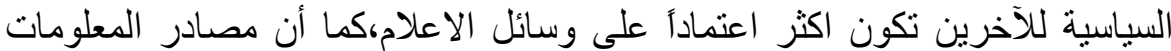

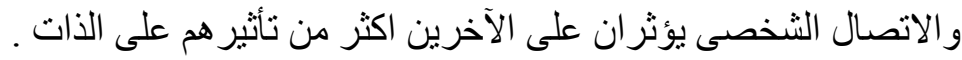
وفي ضوء ذلك جاء المقياس (جدول رقم 10 ) ليوضح مدي هذا التأثير و الذي ظهر بشكل فوق المتوسط حيث بلغت نسبة متوسط (1^\%)، ثم عالي بنسبة (10\%)، ثم منخفض بنسبة (ع\%)، ويأتي ذللك في ظل موجود عو امل استقطاب اخري قد نكون أكثر

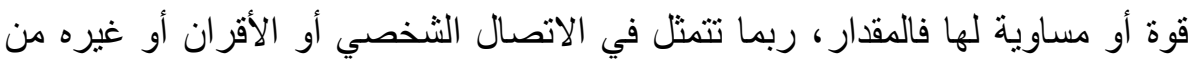

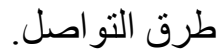
جدول رقم (0 1 ) يوضح مقياس تأثير الاستقطاب السياسي التي تستخدمها برامج الحوارية

\begin{tabular}{|c|c|c|}
\hline$\%$ & ك & مقياس تأثير الاستقطاب السياسي للبرامج الحوارية \\
\hline$\varepsilon$ & $\varepsilon$ & منخفض \\
\hline 1) & 1) & منوسط \\
\hline 10 & 10 & عالى \\
\hline $1 \ldots$ & $1 \ldots$ & الإجمالى \\
\hline
\end{tabular}

التساؤل العاشر ما اتجاهات الأكاديميين نحو الاستقطاب السياسي من خلال البرامج

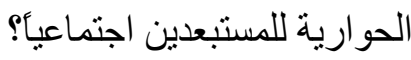

جدول رقم (7 1 ) يوضح استراتيجيات الاستقطاب السياسي التي تستخدمها برامج الحوارية

\begin{tabular}{|c|c|c|}
\hline$\%$ & ك5 & اتجاهات الأكاديميين نحو الاستقطاب السياسي من خلال البرامج الحوارية للمستبعدين \\
\hline$r \varepsilon$ & $r \varepsilon$ & ايجابية \\
\hline 07 & 07 & محايدة \\
\hline r. & $r$. & سلبية \\
\hline $1 \ldots$ & $1 \ldots$ & الإجمالي \\
\hline
\end{tabular}


توضح نتائج الجدول (7 (1) أن اتجاهات الأكاديمين نحو الاستقطاب السياسي من

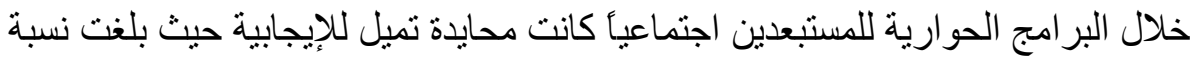

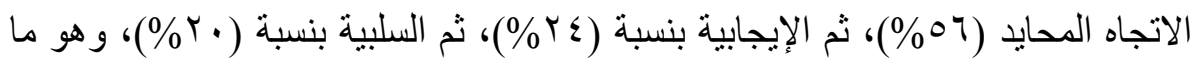

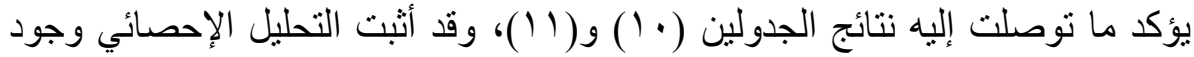

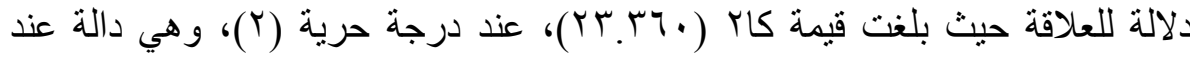

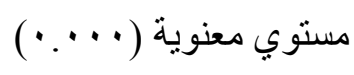
نتائج اختبار الفروض: الفرض الأول : توجد علاقة ارتباطية ذات دلالة إحصائية بين اختبار الصفوة الأكاديمية

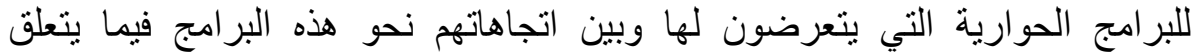
بالاستقطاب السياسي

\begin{tabular}{|c|c|c|c|}
\hline \multicolumn{3}{|c|}{ اختيار الصفوة الأكاديمية للبرامج الحوارية التي } & \multirow{2}{*}{ الاتجاه نحو هذه البرامج } \\
\hline الدلالة & المغتوية & معامل ارتباط & \\
\hline 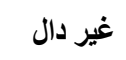 & . & $\because$ lor- & لاتجاه نحو هذه البرامج \\
\hline \multicolumn{3}{|c|}{$1 \ldots$} & ن = العينة \\
\hline
\end{tabular}

توضح بيانات الجدول رقم (IV) أن التحليل الإحصائي قد أنثبت عدم وجـود التها

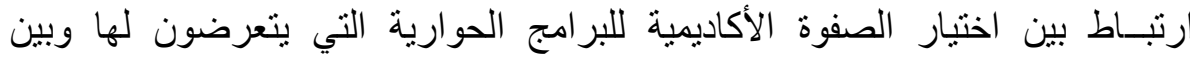

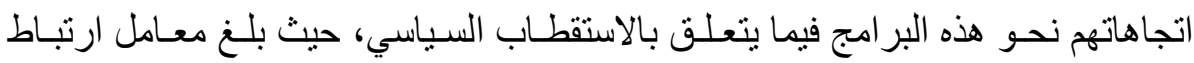

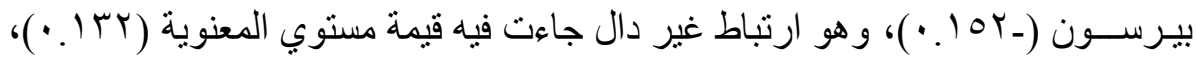

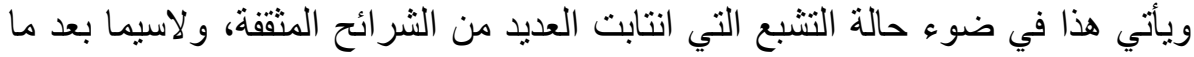

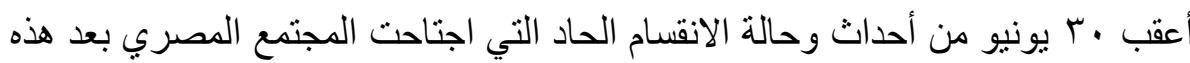

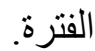

\section{وعليه فقد ثبت عدم صحة الفرض الأول}

الفرض الثانى : توجد علاقة ارتباطبة ذات دلالة إحصائية بين دوافع مشاهدة الصفوة

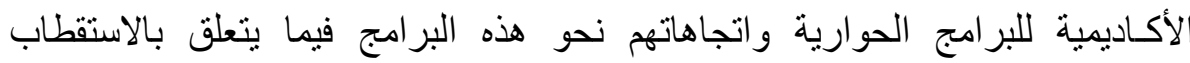
السياسي. 


\section{جدول رقم (1 ا ) يوضح العلاقة بين دوافع مشاهدة الأكاديميين للبرامج الحوارية} و اتجاهاتهم نحوها فيما يتعلق بالاستقطاب السياسي

\begin{tabular}{|c|c|c|c|}
\hline \multicolumn{3}{|c|}{ اتجاهات الاكاديميين نحو هذه البرامج فيما } & \multirow{2}{*}{ دوافع مشاهدة الصفوة الأكاديمية للبرامج الحوارية يتعلق بالاستقطاب السياسي هذه البرامج فيما } \\
\hline الالالة الد & 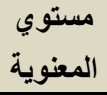 & معامل ارتباط & \\
\hline غير دال & $.0 \wedge \varepsilon$ & $\because .00$ & الجر أة في تناول الموضو عات \\
\hline 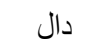 & $\because \cdots 7$ &.$Y V \varepsilon_{-}$ & الإلمام بخلفية الأحداث \\
\hline 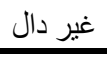 & .870 & $\because \cdot r \cdot-$ & الإبهار و التشويق في عرض ملابسات الحدث \\
\hline 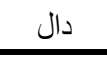 & $\because \cdot \varepsilon \cdot$ & $* . r \cdot T$ & التسلية وتقضية وقت فراغ \\
\hline 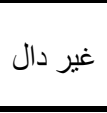 & .917 & $\because 11$ & و للديها شبكة مر اسلين و اضحة مما يوفر لها المعلومات السهولة \\
\hline 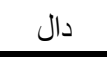 & $\because \cdots 1$ & $* . r V Y$ & استضافة ضيوف ذات صلة وثيقة بموضو ع القضية \\
\hline 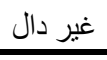 & $\cdot .9 \cdot r$ & $\because \cdot 1 r$ & تهتم بالتقارير و التحليل الإخباري والصور الحية \\
\hline 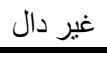 & .917 & $\because 11$ & فورية في المتابعة \\
\hline 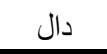 & $\because \cdots \varepsilon$ & $* .$, YᄉT & تقديم جميع وجهات النظر بموضو عية \\
\hline
\end{tabular}

توضح بيانات الجدول رقم (1/) أنه عند قياس العلاقة بين دوافع مشاهدة

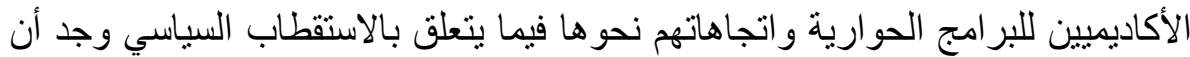

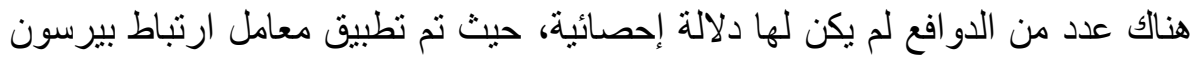

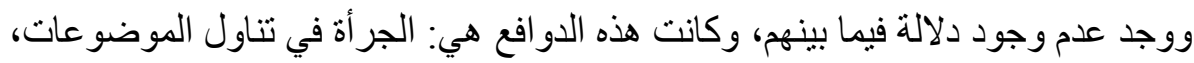

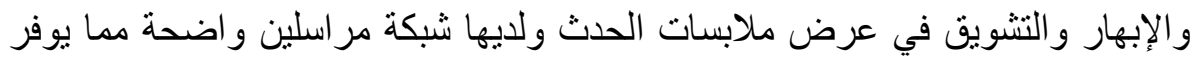
لها المعلومات السهولة والسرعة،و الاهتمام بالتقارير و التحليل الإخباري و الصور الحية،

$$
\text { وفورية في المتابعة. }
$$

في حين أن التحليل الإحصائي قد أثبت وجود ارتباط بين فيما بين عدد من الدوافع

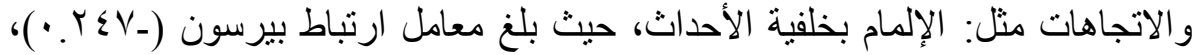

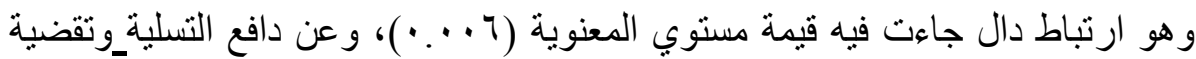

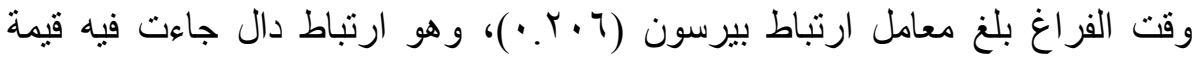

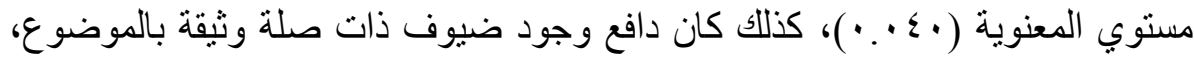

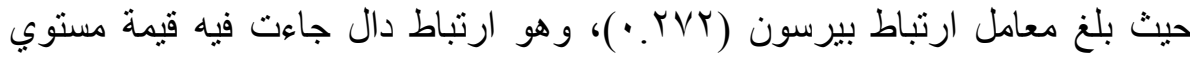

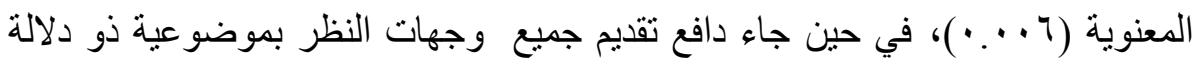

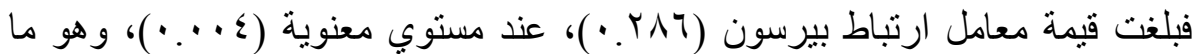

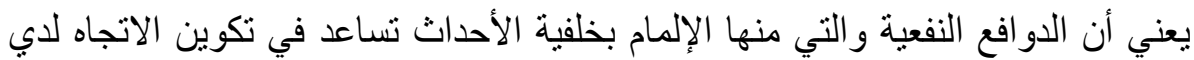




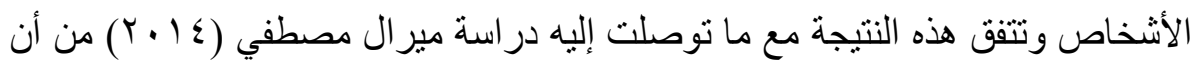

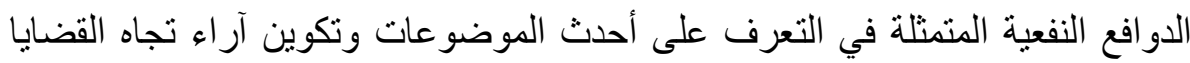
المختلفة في مقدمة الدو افع الرئيسبة لمشاهدة بر امج الر أبي التلفزيونية.

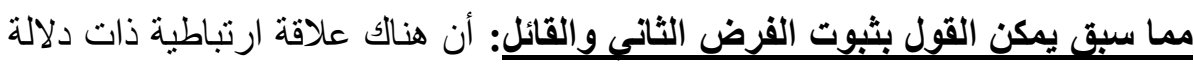

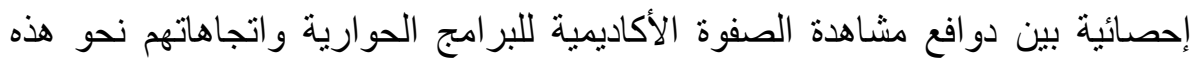

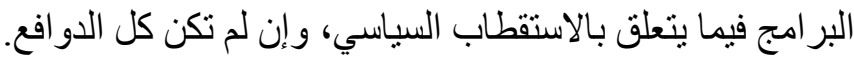
الفرض الثالث :توجد فروق ذات دلالة إحصائية بين مستوي ادراك الصفوة الأكاديمية

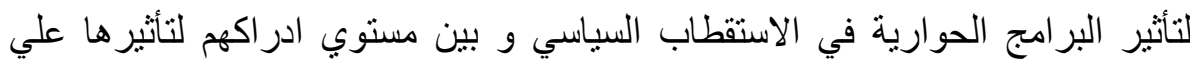
المستبعدين اجتماعياً. جدول رقم (9 1 ) يوضح الفرق بين مستوي ادراك الصفوة الأكاديمية لتأثير البرامج الحوارية في الاستقطاب السياسي و بين مستوي ادراكهم لتأثير ها علي المستبعدين اجتماعياً.

\begin{tabular}{|c|c|c|c|c|c|c|}
\hline \multicolumn{3}{|c|}{ مؤشر ات إحصائية } & \multirow{2}{*}{ الانحراف } & \multirow[b]{2}{*}{ المتوسط } & \multirow[b]{2}{*}{ العدد } & \multirow{2}{*}{ مستوي ادراك الصفوة الأكاديمية لتأثير } \\
\hline مسنوى المعنوية & الحرجة & الإختبار & & & & \\
\hline \multirow{3}{*}{ احصائيا } & \multirow{3}{*}{$\begin{array}{l}\text { Y } \\
q V\end{array}$} & \multirow{3}{*}{ rq.199=ف } & $1 . r \leq \Lambda$ & 1.97 & 01 & قوي \\
\hline & & & .940 & $r . \varepsilon r$ & r. & متوسط \\
\hline & & & I.KKA & $\left\{. Y_{1}\right.$ & 19 & ضعيف \\
\hline & & & $1 . \leqslant r_{0}$ & r.or & $1 \ldots$ & الإجمالي \\
\hline
\end{tabular}

تثير نتائج الجدول رقم (9 1) أن دلالة الفروق للمبحوثين بين مستوي ادراك

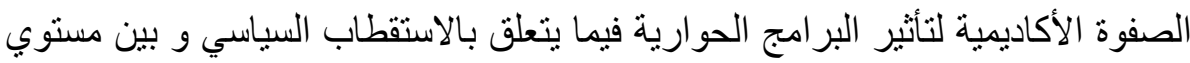
ادراكه لتأثيرها علي المستبعدين اجتماعياً كانت كالتالى :جاءت قيمة الفرق بين الآنين

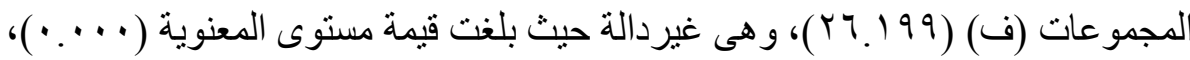

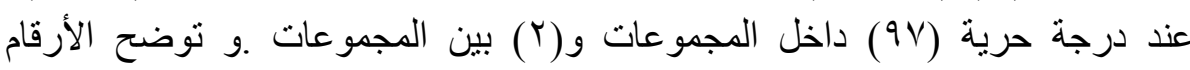

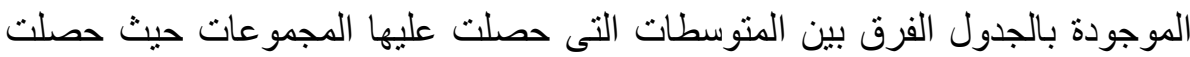

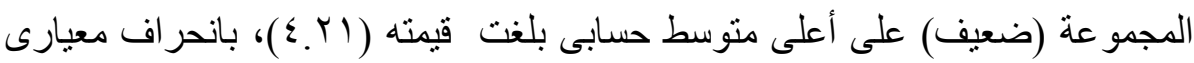

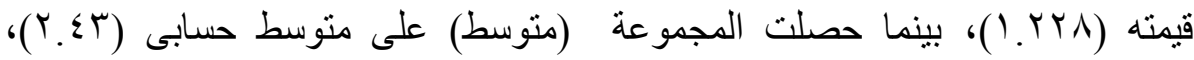

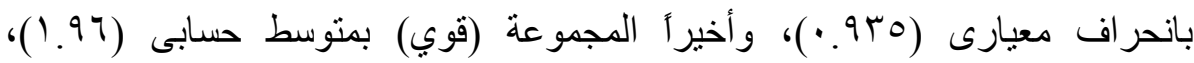

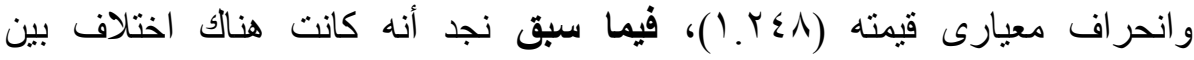

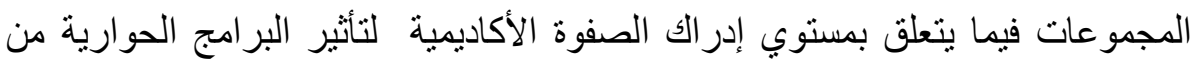


خلال عملية الاستقطاب السياسي وبين إدر اكهم لقيمة هذا التأثير علي المستبعدين اجتماعياً

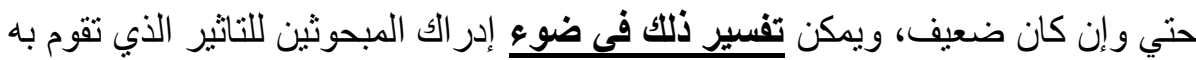

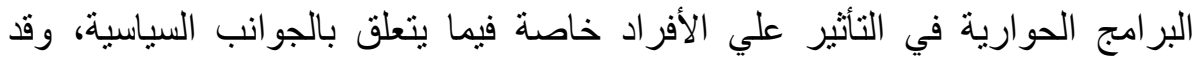

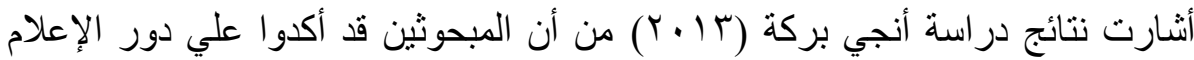

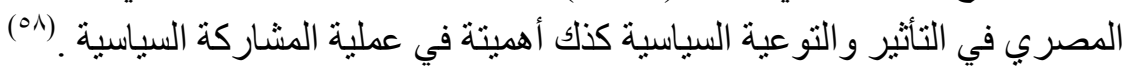

\section{وعليه يمكن قبول صحة الفرض الثالث كلية}

الفرض الرابع: توجد فروق ذات دلالة احصائية بين مستوي ادراك الصفوة الأكاديمية

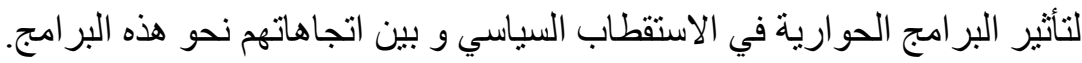

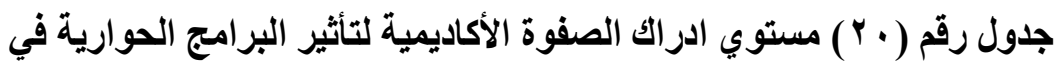

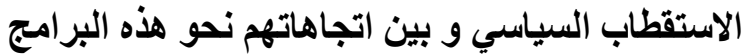

\begin{tabular}{|c|c|c|c|c|c|c|}
\hline \multicolumn{3}{|c|}{ مؤشرات إحصائية } & \multirow{2}{*}{ المعياري } & \multirow[b]{2}{*}{ المتوسط } & \multirow[b]{2}{*}{ العدد } & \multirow{2}{*}{ مستوي ادراك الصفوة الأكاديمية } \\
\hline المعنوية & الحرجة & إلاختباري & & & & \\
\hline \multirow{3}{*}{ احصائياً } & \multirow{3}{*}{$\begin{array}{c}r \\
q V\end{array}$} & \multirow{3}{*}{ ف= 11.919} & $\cdot v \cdot 1$ & 1.11 & 01 & قوي \\
\hline & & & ס & r. $\cdot V$ & r. & متوسط \\
\hline & & & .Tा & T. $\leqslant V$ & 19 & ضعيف \\
\hline & & & .770 & 1.97 & $1 \ldots$ & الإجمالي \\
\hline
\end{tabular}

تشير نتائج الجدول رقم (†) أن دلالة الفروق بين مستوي ادراك الصفوة الأكاديمية لتأثير البرامج الحوارية في الاستقطاب السياسي و بين اتجاهاتهم نحو هذه دانه

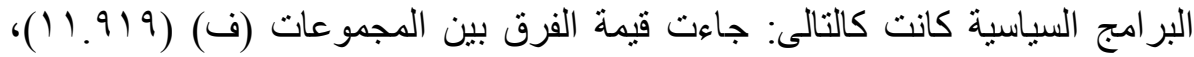

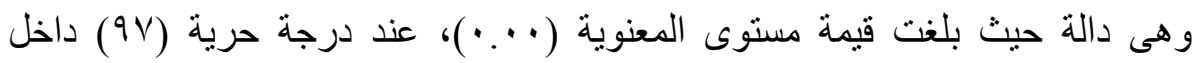

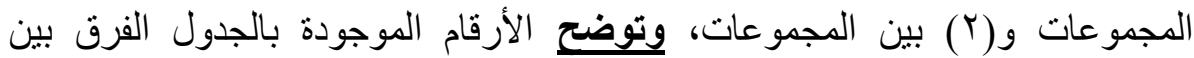

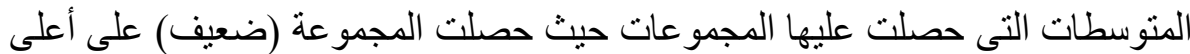

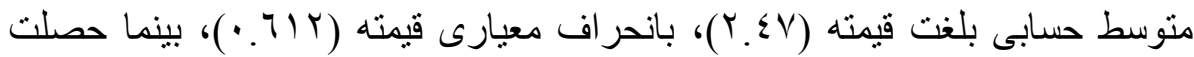

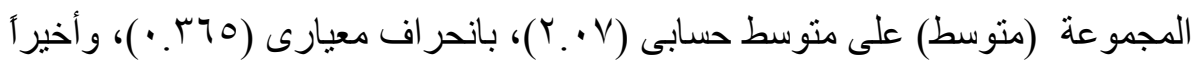

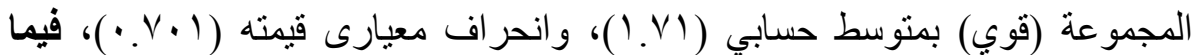

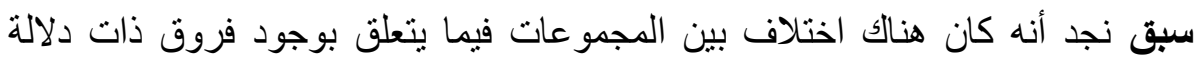

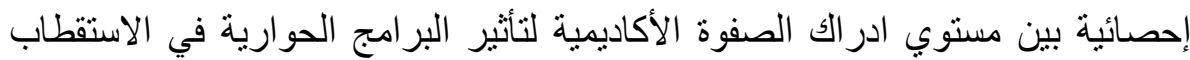
السياسي و بين اتجاهاتهم نحو هذه البرامج وهو ما يمكن تفسيره بأن اتجاهات الأكاديمين

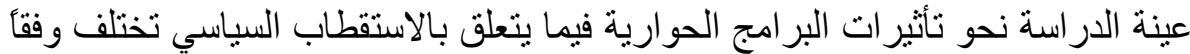

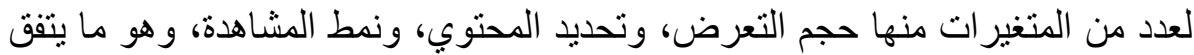




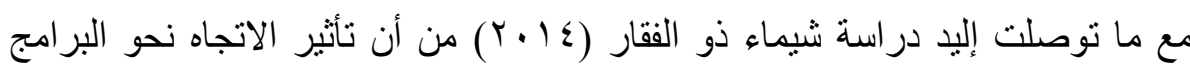

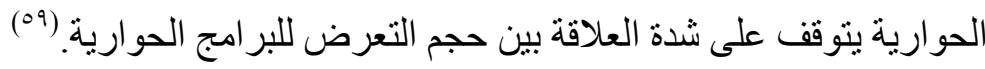

\section{و وعليه يمكن قبول صحة الفرض الر ابع كلية}

الفرض الخامس : توجد فروق ذات دلالة احصائية بين أفر اد عينة الدر اسة من الأكاديمبين

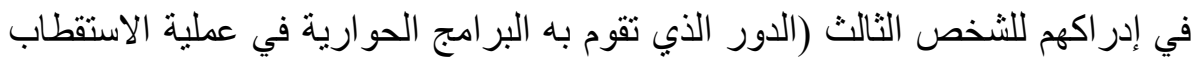
السياسي) باختلاف خصائصهم الديموجر افية (السن - النوع - الجامعة ـ الاهن الهنمام العام بالسياسة).

جدول رقم ( Y ) يوضح العلاقة بين المتغيرات الديموغرافية للمبحوثين وبين إدراكهم لتأثير البرامج الحوارية التية

\begin{tabular}{|c|c|c|c|c|c|c|c|}
\hline \multicolumn{3}{|c|}{ مؤشرات إحصائية } & \multirow{2}{*}{ الانحر افـ } & \multirow[b]{2}{*}{ المتوسط } & \multirow[b]{2}{*}{ العدد } & \multirow{2}{*}{\multicolumn{2}{|c|}{ المتغيرات الايموغرافية }} \\
\hline المسنوية & الحرجية & إلاختباري & & & & & \\
\hline \multirow{2}{*}{ 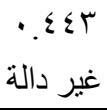 } & \multirow{2}{*}{$9 \wedge$} & \multirow{2}{*}{$\begin{array}{l}=ت \\
\ddots V \vee 1-\end{array}$} & $\cdot \Lambda \cdot r$ & Y.YY & 0. & ذكور & \multirow{2}{*}{ النوع } \\
\hline & & & . vor & r. & 0. & اناث & \\
\hline \multirow{4}{*}{ ع الة . } & \multirow{4}{*}{$\begin{array}{c}r \\
q 7\end{array}$} & \multirow{4}{*}{$\begin{array}{c}={ }^{=} \\
Y Y Y Y\end{array}$} & $\cdot \wedge \cdot 1$ & T. TV & 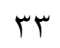 & اقل من • س سنـ & \multirow{4}{*}{ 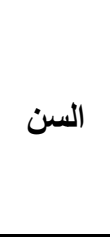 } \\
\hline & & & $\cdot \wedge 1 \leq$ & Y. $1 \varepsilon$ & $\varepsilon r$ & من اس سنه الي •؛ سنه & \\
\hline & & & .779 & T. $\varepsilon r$ & IT & من إ سنه الي .0 سنة & \\
\hline & & &.$Y V V$ & r.qr & $1 T$ & اكثر من •0 سنة & \\
\hline \multirow{2}{*}{ غير دالة ـ } & \multirow{2}{*}{$9 \wedge$} & \multirow{2}{*}{$\begin{array}{c}=ت \\
\ddots V \vee V\end{array}$} & r.YT & †.ґ & 0. & حكومية & \multirow{2}{*}{ الجامعة } \\
\hline & & & $\cdot \Lambda \cdot r$ & . vor & 0. & خاصة & \\
\hline \multirow{3}{*}{ غ • ع ؛ } & \multirow{3}{*}{$\begin{array}{c}r \\
q V\end{array}$} & \multirow{3}{*}{$\begin{array}{l}=\dot{ } \\
\ddots 911\end{array}$} &.$\wedge 0$. & r.rv & r. & مهتم & \multirow{3}{*}{ الالاهتمام } \\
\hline & & & $\because$ Vo. & T.YA & 71 & مهتم الي حد ما & \\
\hline & & & $\because \cdots$ & $r .$. & r & غير مهتم & \\
\hline
\end{tabular}

تثنير نتائج الجدول رقم (YY) أن الفروق الديموجر افية بين المبحوثين من الصفوة

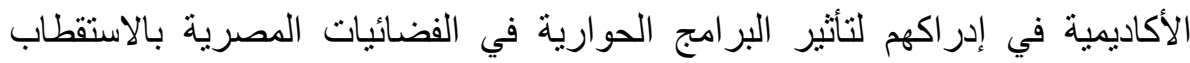

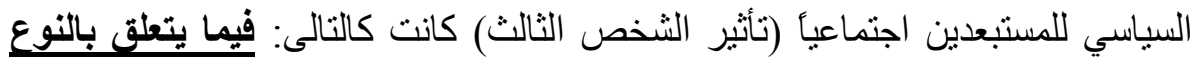

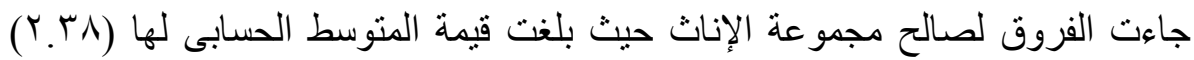

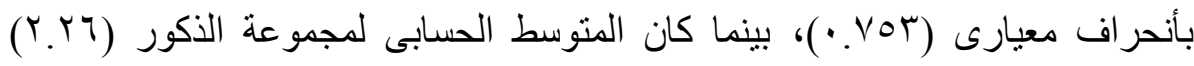

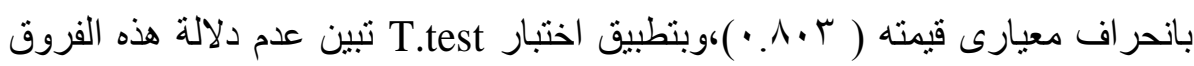

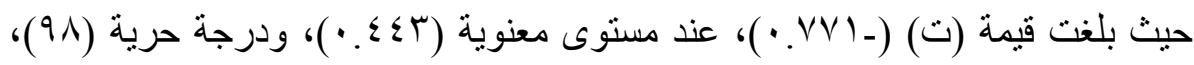


و هو ما يؤكد ما توصلت إلبه عزة عبدالعظيم (ع · . Y)، من أن متغير النوع غير دال في

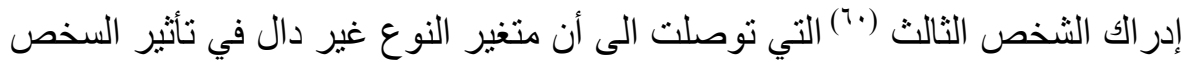

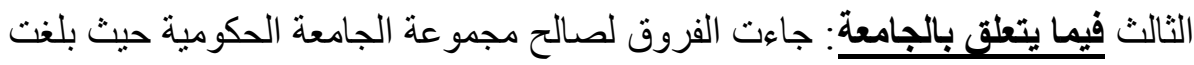

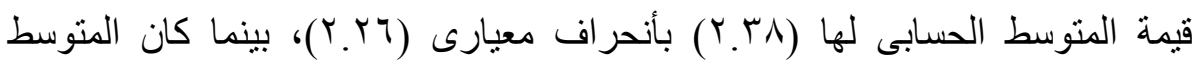

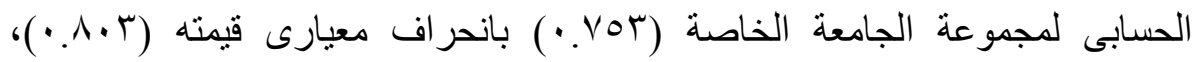

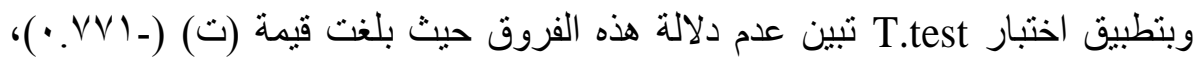

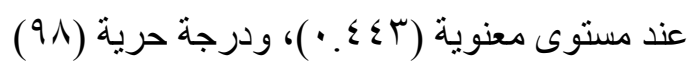
وفيما يتعلق بالاهتمام السياسي كتغير ديموجرافي جاءت قيمة الفرق بين

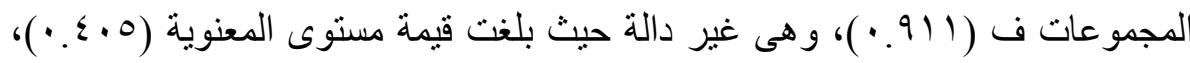

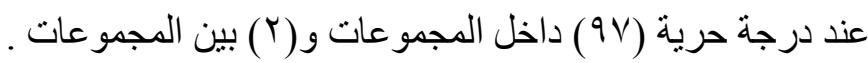

بينما جاء متغير السن كمتغير ديموجر افي ليثبت وجود بعض الفروق حيث جاءت

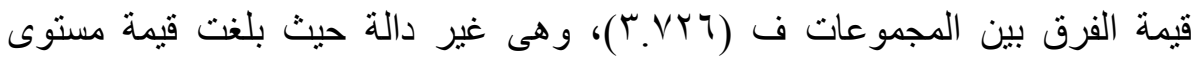

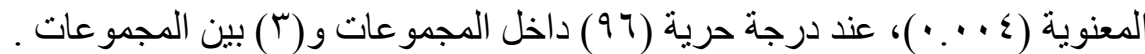
و هو ما يؤكد أنه لا توجد فروق بين الصفوة الأكاديمية فيما يتعلق بالنوع، و الجامعة

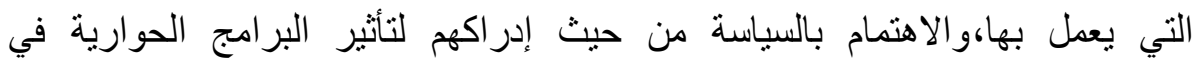

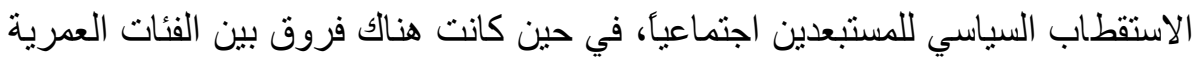

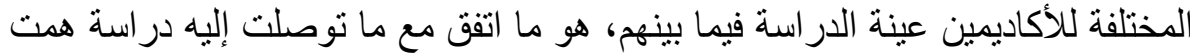

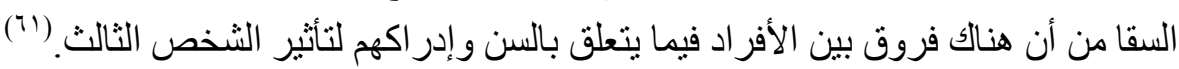
وعليه يمكن القول بأنه لم تثبت صحة الفرض الخامس بأكمله باستنتاء الجزء الخاص بالسن الفرض السادس: تختلف درجة تأثثر الثخص الثالث (عملية الاستقطاب السياسي من قبل البر امج الحوارية علي الفضائيات المصرية) باختلاف المسافة الاجتماعية . وفي هذه الدر اسة تبدأ المسافة الإجتماعية بالذات، ثم الأهل،ثم و المستبعدين اجتماعياً.

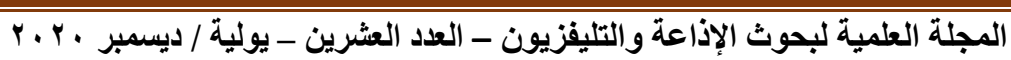


جلول رقم (Y Y ) يوضح الفروق للمبحوثين وفقاً لإدراكهم لتأثير الثخص الثالث باختلاف المسافة الإجتماعية

\begin{tabular}{|c|c|c|c|c|c|c|}
\hline \multicolumn{3}{|c|}{ مؤشرات إحصائية } & \multirow{2}{*}{ الانعراف المعياري } & \multirow[b]{2}{*}{ المتوسط } & \multirow[b]{2}{*}{ العدد العد } & \multirow[b]{2}{*}{ تأثير الاستقطاب السياسي } \\
\hline المعنوية & الدرية & إحصائي & & & & \\
\hline \multirow{3}{*}{ 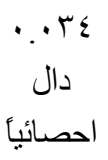 } & \multirow{3}{*}{$\begin{array}{l}r \\
q V\end{array}$} & \multirow{3}{*}{ ف= } & $.0 \ldots$ & $1.10 \ldots$ & $\varepsilon$ & عليك \\
\hline & & & $.9 \vee 09$. & 1.7778 & 10 & علي الاسرة \\
\hline & & & .7 .190 & $1.9 \wedge \vee V$ & (1) & علي المستبعدين اجتماعيا \\
\hline & & & •. & $1.91 \ldots$ & $1 \ldots$ & الإجمالي \\
\hline
\end{tabular}

تتثير نتائج الجدول رقم (Yr) أن دلالة الفروق للمبحوثين وفقاً لإدر اكهم لتأثير

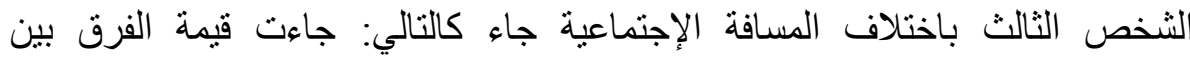

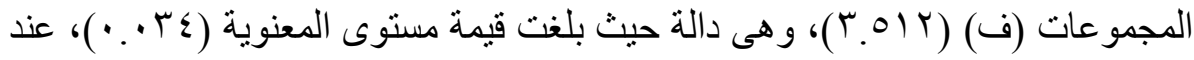

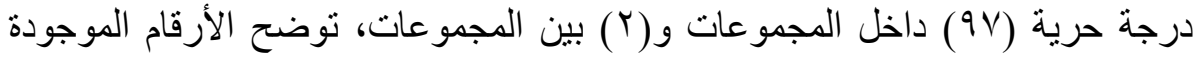

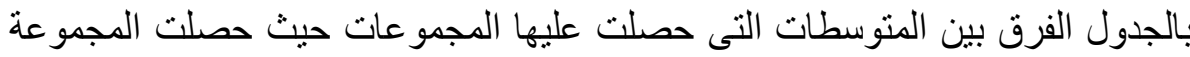

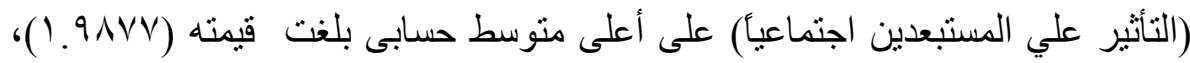

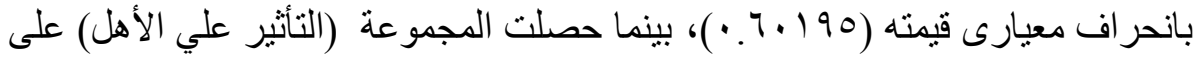

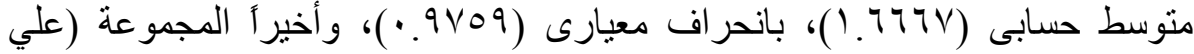

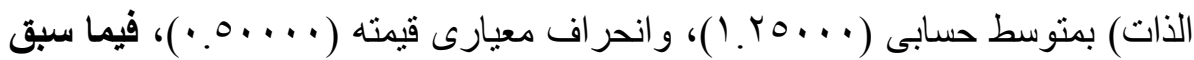
نجد أنه كانت هنالك اختلاف بين المجمو عات فيما يتعلق بمستوي إدر الك الصفوة الأكاديمية لتأثير البرامج الحوارية من خلال عملية الاستقطاب السياسي وبين إدراكهم لقيمة هذا

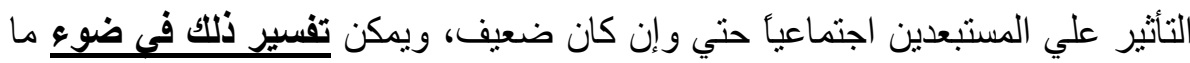

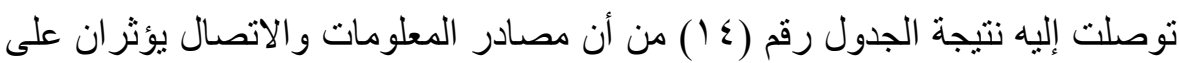

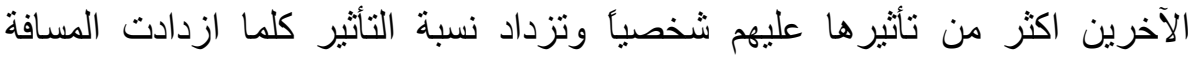

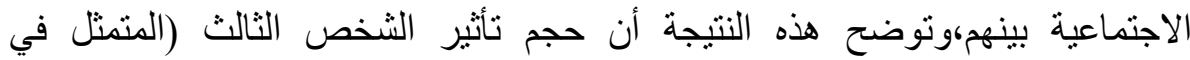

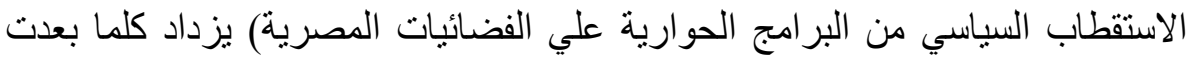

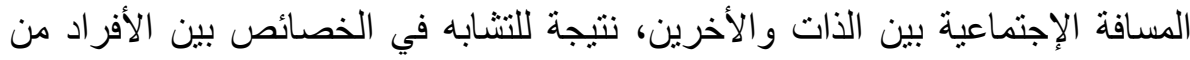

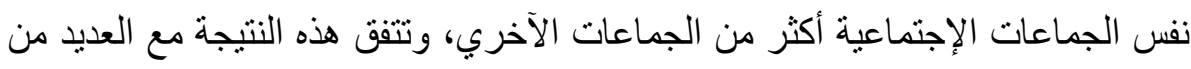
الار اسات التي تناولت نظرية اشخص الثنالث. 
• معدلات مشاهدة الصفوة الأكاديمية للبرامج الحوارية علي الفضائيات المصرية غير

$$
\text { محددة بعدد ساعات يومي. }
$$

• تحدد الصفوة الأكاديمية المحتوي الذي تر غب في متابعته مسبقاً .

تشاهد الصفوة الأكاديمية البرامج الحوارية علي الفضائيات العربية حسب الظروف

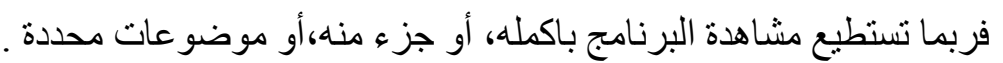

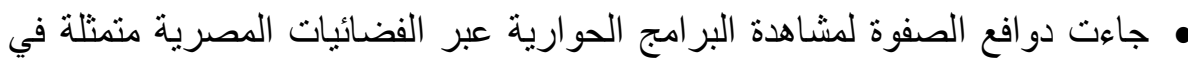
(الإلمام بخلفية الحداث ـ استضافة ضيوف ذات صلة وثنقة بموضوع القضية).

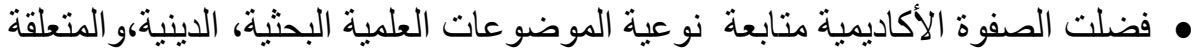

بالسياسة الداخلية، و الأمنية و الصحية.

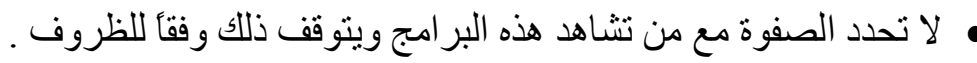

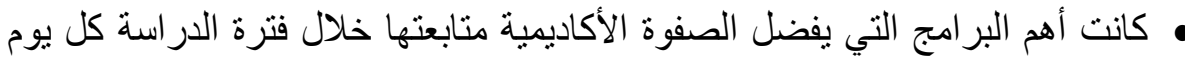

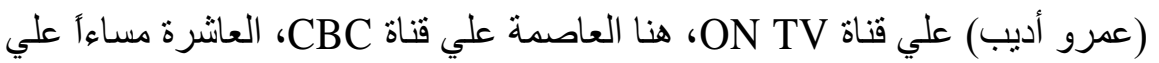
قناة الحياة، "علي مسؤليتي" علي قناة صدي البل فيلد.

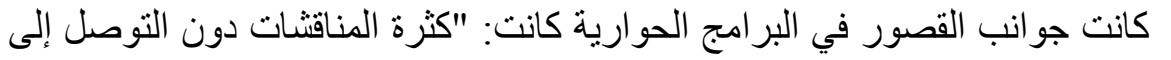

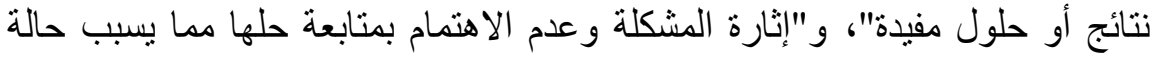

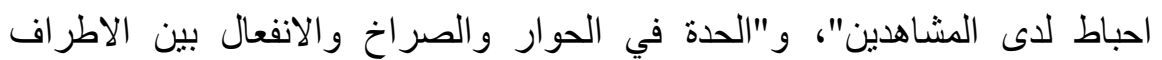

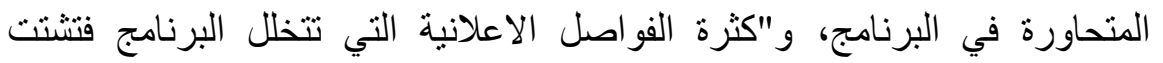
الانتباه" قدمت الصفوة الأكاديمية تعريفاً عن الاستقطاب السياسي تمثل في أنه "القدرة علي تغير

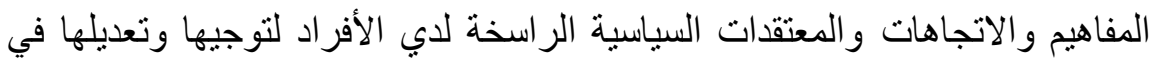
اتجاه يخدم المصالح السياسيه سواء لاشخاص أو الموسسات أو توجهات معينة.

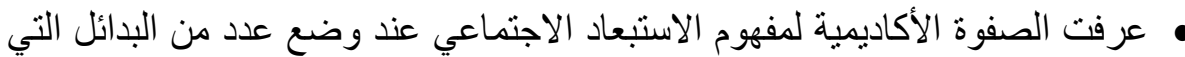

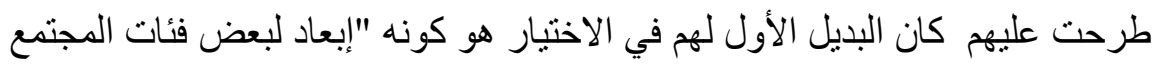

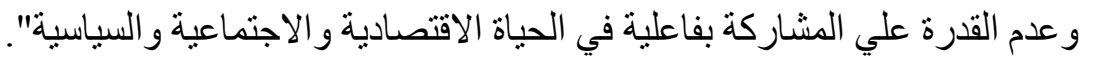

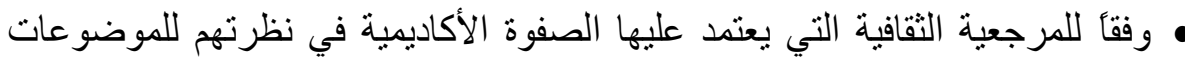

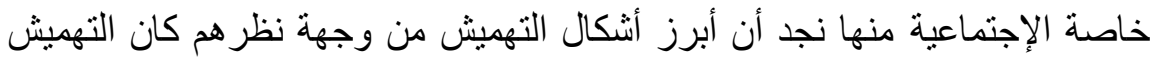

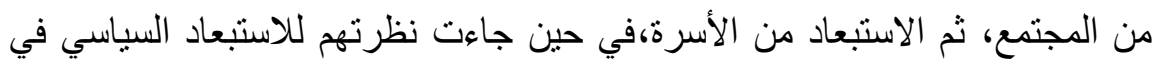

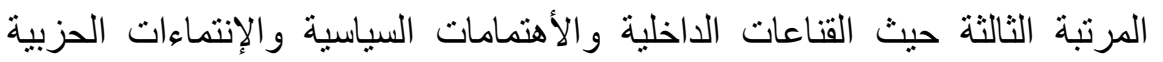

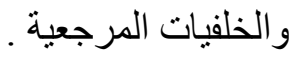


• تقوم البر امج الحوارية عبر الفضائيات المصرية بعملية استقطاب سياسي للمستبعدين

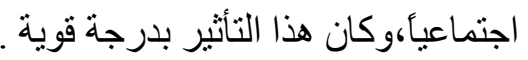

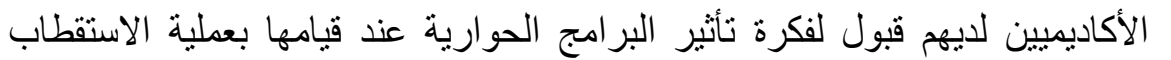
السياسي للمستبعدين، في حين كان تأثثير ها عليهم محدود.

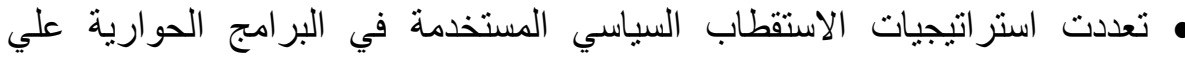

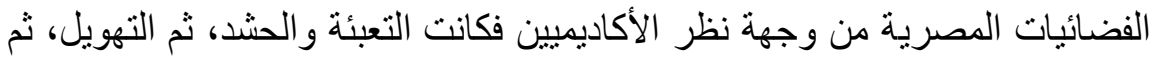

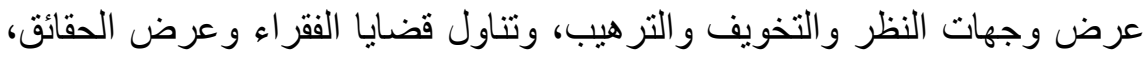

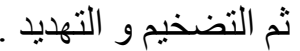

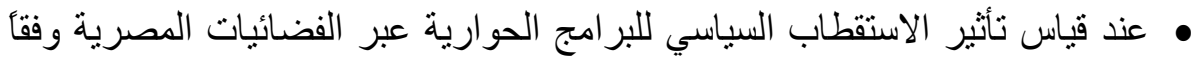

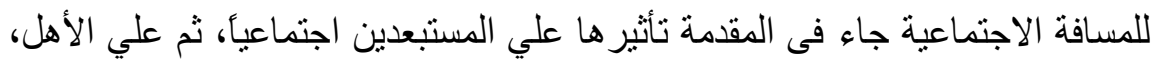

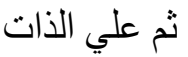
• اتجاهات الأكاديمين نحو الاستقطاب السياسي من خلال البرامج الحوارية للمستبعدين اجتماعياً كانت محايدة تميل للإيجابية. • ثبت عدم صحة الفرض القائل بأنه توجد علابة التة ارتباطية ذات دلالة إحصائية بين

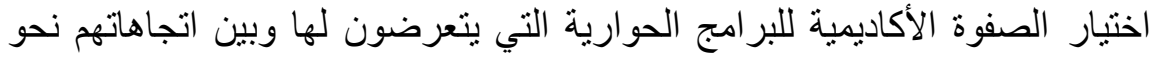
هذه البر امج فيما يتعلق بالاستقطاب السياسي الني

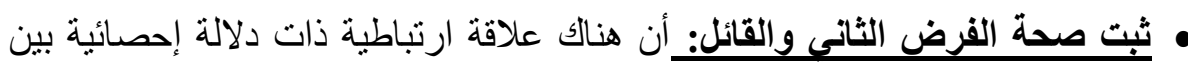

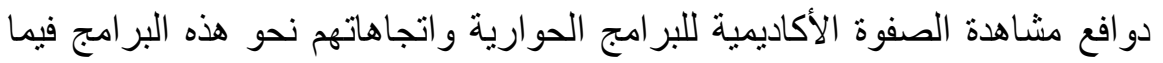

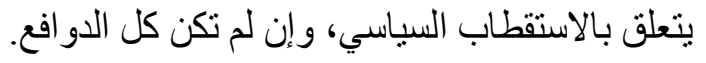

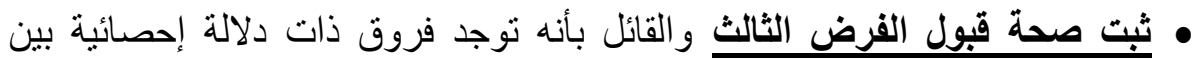

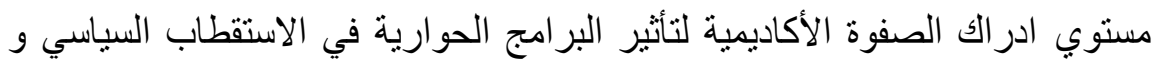
بين مستوي ادر اكهم لتأثير ها علي المستبعدين اجتماعياً.

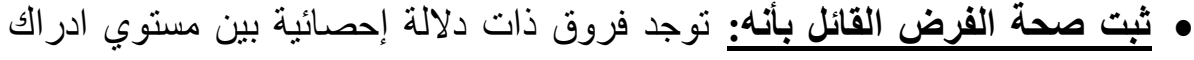

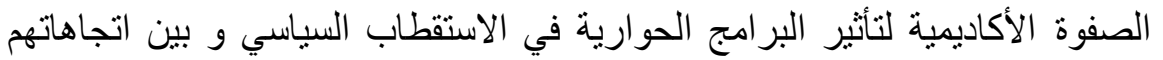

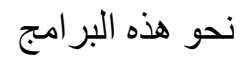
• لم تثبت صحة الفرض الخامس بأكمله باستثناء الجزء الخاص بالسن

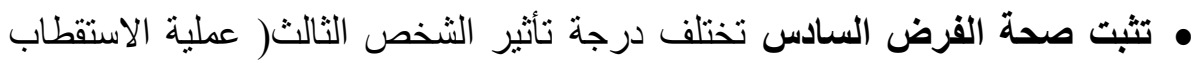

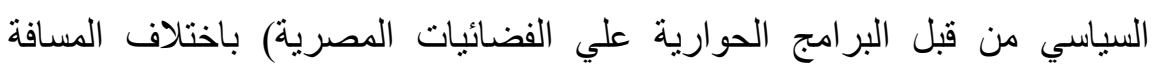
الاجنماعية . 


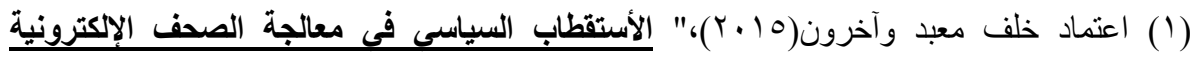

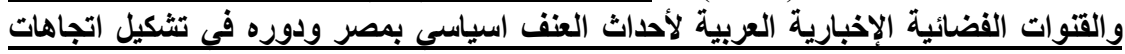

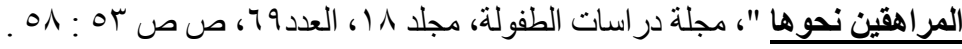

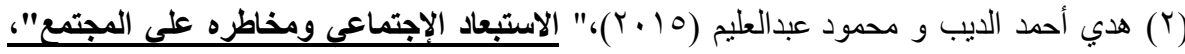

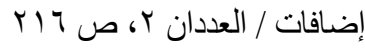

(3) Scutella, Rosanna, Roger Wilkins and Weiping Kostenko (2009), Estimates of Poverty and Social Exclusion in Australia: A Multidimensional

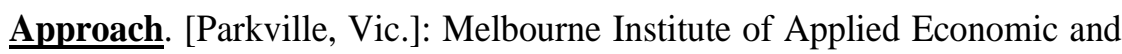
Social Research, University of Melbourne. (Melbourne Institute Working Paper; no. 26/09)

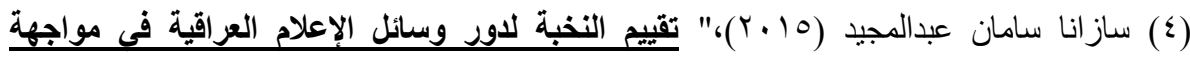
الطائفية"، رسالة ماجستير غير منشورة، (الأردن: جامعة البتر ا- كلية الإعلام).

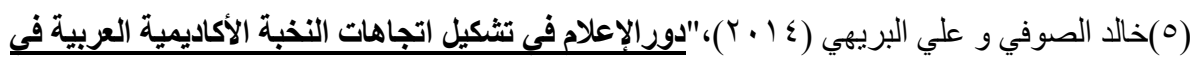

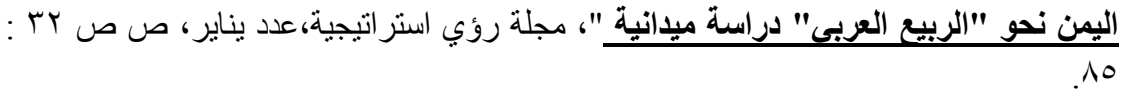

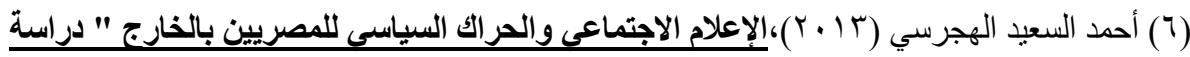

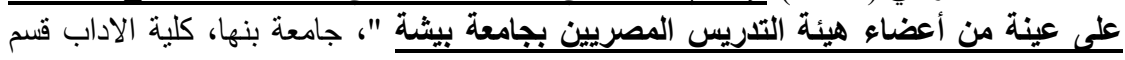

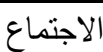

www.bu.edu.eg/.../sociology /.../Ahmed

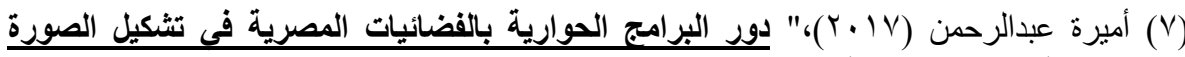

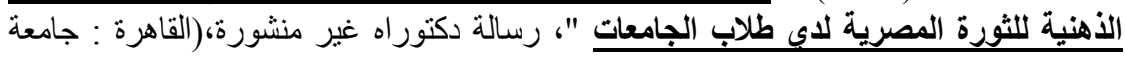
عين شمس - معهز الطفولة).

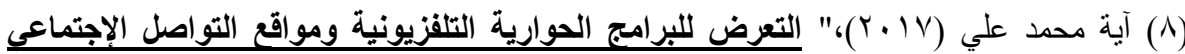

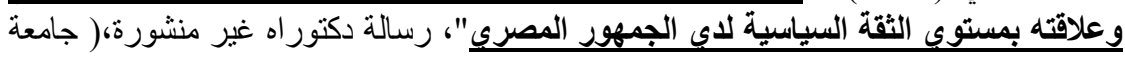
القاهرة،كلية الإعلام).

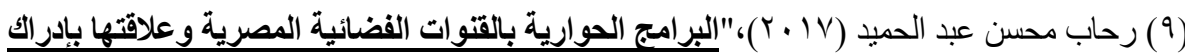

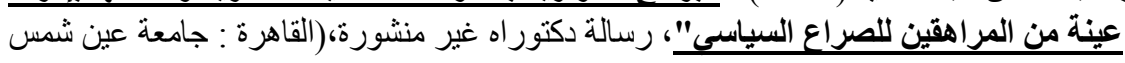

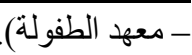

(10) Emily Vraga \& Others ،" The Correspondent ‘The Comic and The Combatant : The Consequences of Host Style in Political Talk Shows " ، Journalism \& Mass Communication Quarterly ،Vol.89 ‘No.1 ‘2012 ‘PP 522. Available at :

http://journals.sagepub.com/doi/pdf/10.1177/1077699011428575

Accessed on 18/12/2017 
اتجاهات الصفوة الأكاديمية نحو البرامج الحوارية في الفضائيات المصرية ودورها في الاستقطاب السياسي للمستبعدين اجتماعياً

(11) Naomi Sakr (2012) ،" Social media, Television talk shows and political change in Egypt" ،Television \& New Media ‘Vol.14 ‘No.4،2012 ‘P322337, Available at: http://www.academia.edu/5291141/Social_Media_Television_Talk_Sho ws_and_Political_Change_in_Egypt Accessed on 18/12/2017.

(12) Juliana Abdul Wahab, "Television Talk Shows and The Public Sphere" ، Journal Komunikasi Malaysian Journal of Communication ‘Vol. 27 ‘No. 2 ، 2011, PP 29-45. Available at: http://www.ukm.my/jkom/journal/pdf files/2011/V27 2 2.pdf Accessed on 18/12/2017.

(13) Marie Jackson, " The Late - Night Presidential Strategy : A Historical Review of The First 40 Years of Presidential Campaign Use Of late Night Talk Show Appearances ", PHD, ( U.S.A : The University of Utah, 2010 ). Available at :

https://search.proquest.com/openview/315dc00041ed657c30cba910073d3874 Accessed on 20/12/2015/1 ?pq-origsite=gscholar\&cbl=18750\&diss $=\mathbf{y}$

(14) Seham Mohamed Abd Alkhalek (2016), The Battle of Framing on you Tube : Exploring How Citizen Journalists Covered The Dispersal of Muslim Brotherhood Sit-ins in Egypt

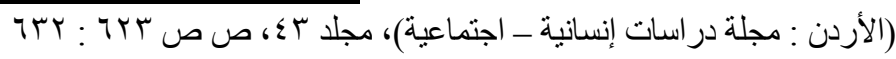

Available at : https// search.mandumadh.com/record/749123

(15) Sounman Hong Sun HyoungKim(2016), Political polarization on twitter: Implications for the use of social media in digital governments, Government Information Quarterly Volume 33, Issue 4, October, Pages 777-782 Available at : www.sciencedirect.com/science/article/pii/S0740624X16300375

(16) Elizabeth Suhay, Allyson Blackwell, Cameron Roche, anil Lucien Bruggeman(2015), "Forging Bonds and Burning Bridges:Polarization and Incivility in Blog Discussions About Occupy Wall Street", American Politics Research, (VOL. 43 NO. 4,)p p 643: 679.

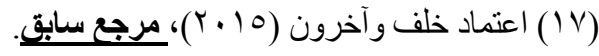

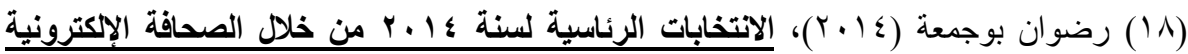

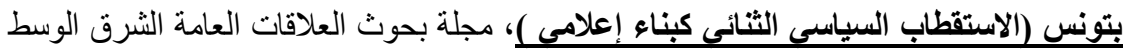

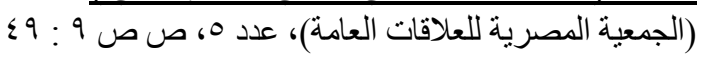

(19) Anatoliy Gruzd and Jeffrey Roy (2014), "Investigating Political Polarization on Twitter: A Canadian Perspective", M. A Dissertation,(Policy Studies Organization, USA,). 
(20) H. Hannah Nam and John T. Jost (2014), "Which American way?System justification and ideological polarization concerning the Ground Zero Mosque", Group Processes\& Intergroup Relations, (Vol. 17, NOj.4).

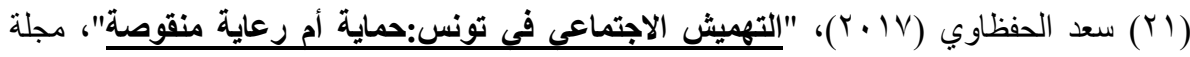

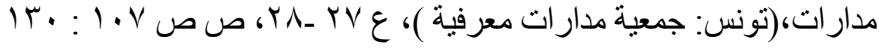

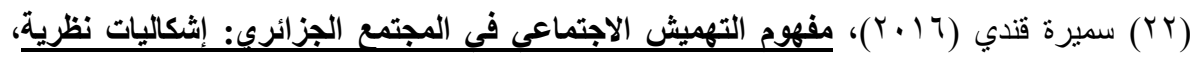

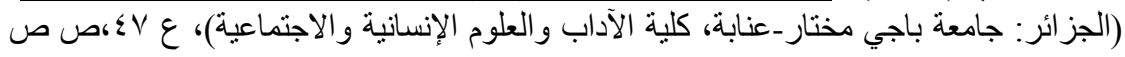

$$
\begin{aligned}
& \text { 19V: IVV }
\end{aligned}
$$

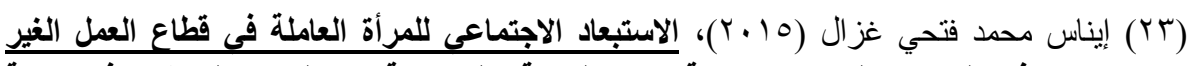

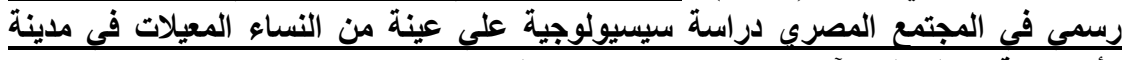

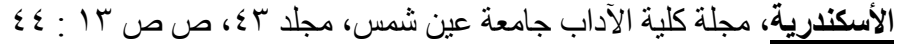

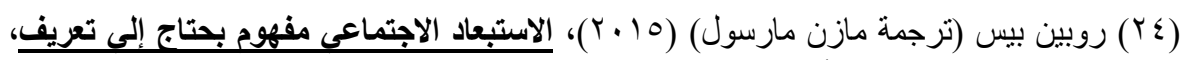

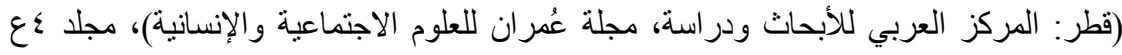

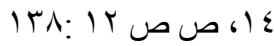

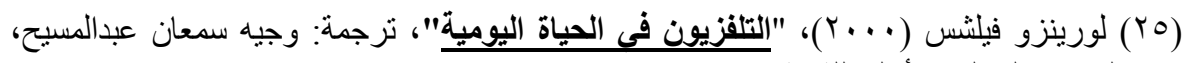

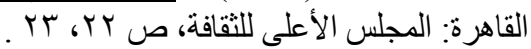

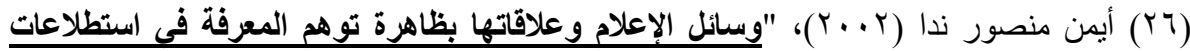

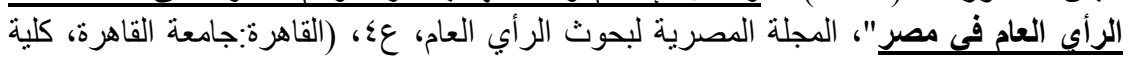

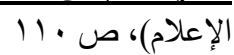

(27) Mark R. Jostym (2003). The Lewinsky Affair: Third Person Judgments lay Scandal Frame, Political Psychology, 24(4), P.829-835

(28) ReaceyJ. Elder, KatenM.Douglas and Robbie M.sultton (2006). Perceptions of Social Influence When Messages Favour Us versus Them: A Closer Look at the Social Distance Effect, European Journal of Social Psychology, 36, P.1-22.

(29) Perloff,R.M (1996).Perceptions and Conceptions of Political, Media Impact: Third Person Effect and Beyond" In: A.N Crigler (Ed) the Psychology of Political Communication. Ann Arbor: The University of Michigan Press.Pp.177-197.

(30) Atwood Erwin L. (1994). Illusions of Media Power: The Third Person Effects, Journalism Quarterly, 71(2), P.269-281.

(31) Cohen J.and Davis R.(1991).Third Person Effects and Differential Effect in Negative Political Advertising, Journalism Quarterly,68,P.680-688.

(32) David Permell (2006).Third Person Perception of General and Immoral Message, available at:http// mtsu32.mtsu.edu:1297/2006/dave-critique2 
(33) Salween M.B. (1998). Perception of Media Influence and Support of Censorship, the Person Effect in the 1996 Presidential Elections, Communication Research, 25, P.261

(34) Rucinski, D. and Salmon, C. T. (1990).The Other as the Vulnerable Voter: A Study of the Third Person Effect in the 1988 U.S. Presidential Campaign, International Journal of Public opinion Research,2,P.345-368

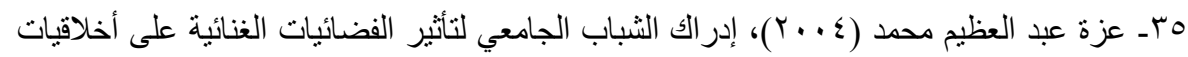

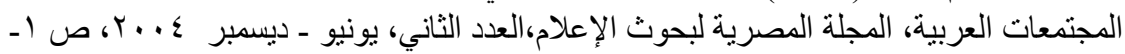

(36) Philips Davison, P.W. (1983). TheThird Person Effect in Communication, Public Opinion Quarterly, Op.Cit. P.6

(37) Rojas,h.,Shah,d.v. and Faber,R.J.(1996).For the Good of Otters: Censorship and the Third Person, International Journal of Public OpinionResearch,8,P.163-186

(38) Cunther,C.Albert (1995).Overrating the X-rating the Third Person Effect Perception and Support for Censorship of Pornography, Journal of communication, 45,P.27-28

(39) Davison, W. P. (1983) the third-person effect in communication, Public Opinion Quarterly, 47, P. 1-15

(40) Meirick, P. C (2004) .Topic-relevant reference groups and dimensions of distance: Political advertising and first-and third-person effects, Communication Research., 31, P. 234-255.

(41) Salwen, M. B. (1999). Perceptions of media influence and support for censorship: The third-person effect in the 1996 presidential election, Communication Research, October; 26, (5), P. 523-549

(42) Cohen J.and Davis R. (1991). Third Person Effects and Differential Effect in Negative Political Advertising, Op.Cit. P.683

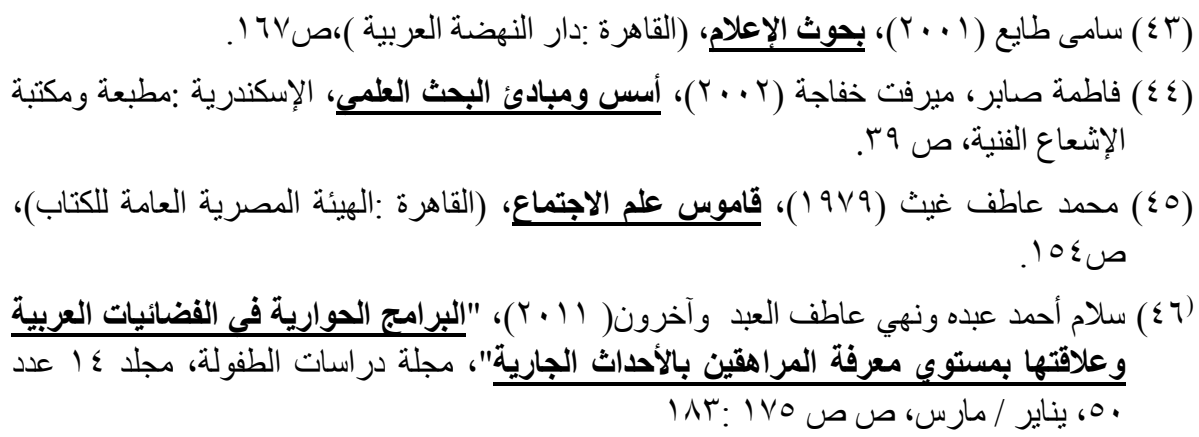


(47)McCluskey, Michael and Mie Kim, Young. "Moderatism or Polarization? Representation of Advocacy Groups' Ideology in Newspapers", Joumalism\& Mass Communication Quarterly, (VOL. 89, NO. |4, 2012

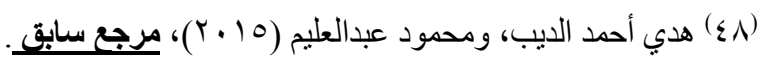

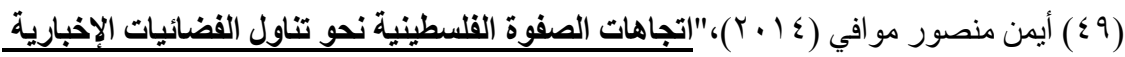

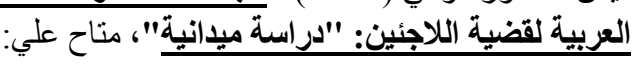

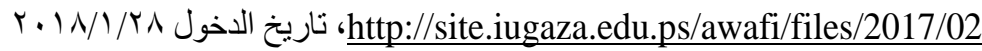

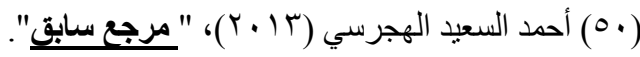

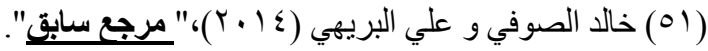

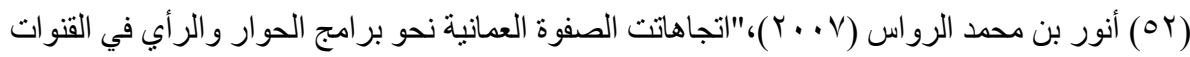

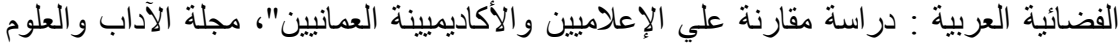

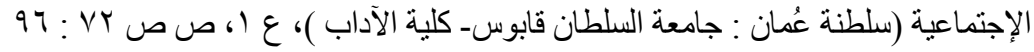

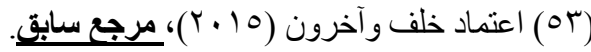

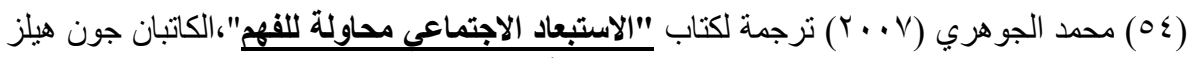

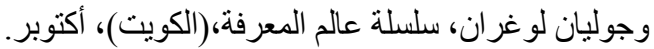

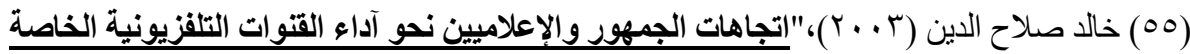

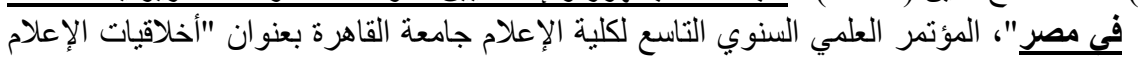

$$
\text { بين النظرية و النطبيق". }
$$

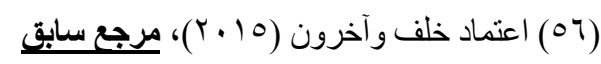

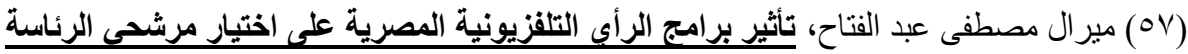

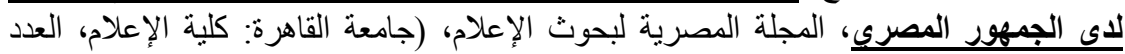

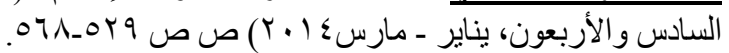

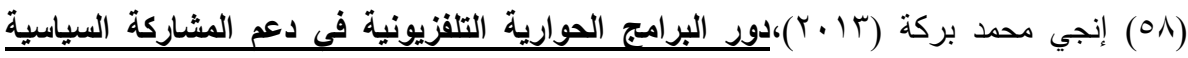

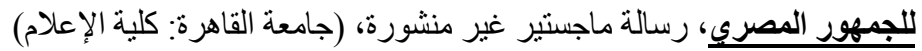

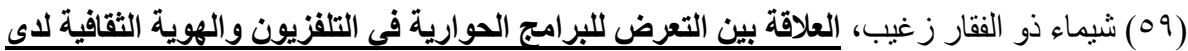

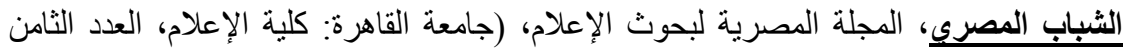

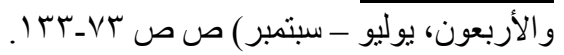

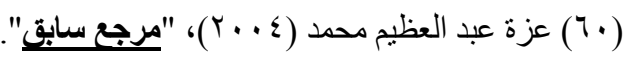

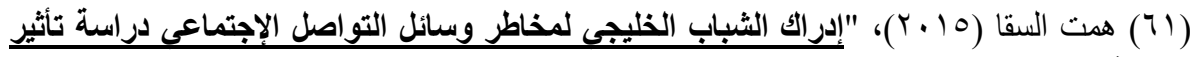

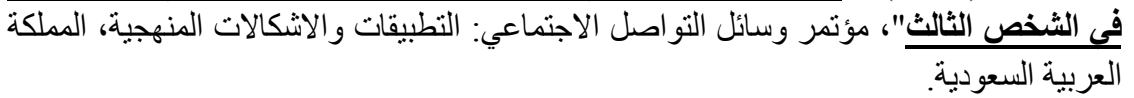

